UC-15

Reporting Date: Septtmber 1975

Issued: February 1976

\title{
NOTICE
}

PORTIONS OF THIS REPORT ARE IIIEGIBLE. It has been reproduced from the best avallable copy to permit the broadest possib eb111ty.

\section{Automated Spectrophotometer for \\ Plutonium and Uranium Determination}

by

D. D. Jackson

D. J. Hodgkins

R. M. Hollen

J. E. Rein 
This work was sponsored by the Division of Sideguards and Stcurity of the Energy Research and Development Administration.

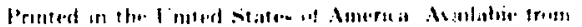

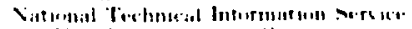

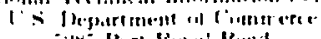

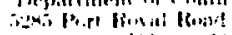

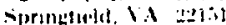

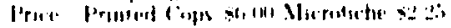

Thin repopt weo pregared ac an arcuunt of enph nposeured

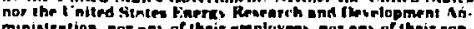

minisiration, nor ens of their employmen. nar ans of their ran.

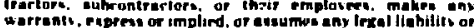

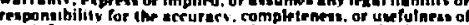

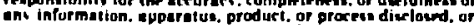

regrewente that is use would nat infrinte privetels ouned

riehto. 


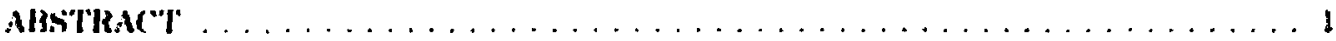

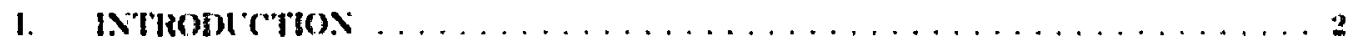

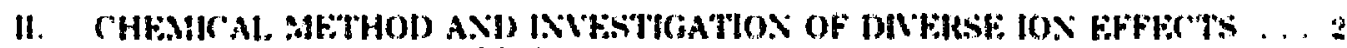

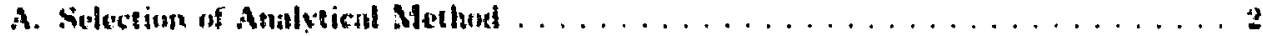

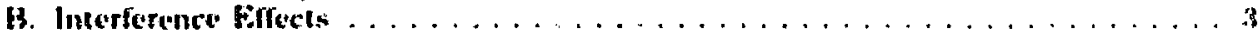

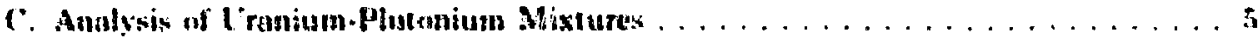

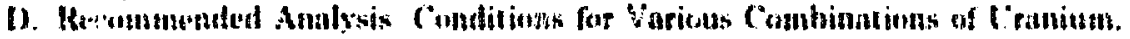

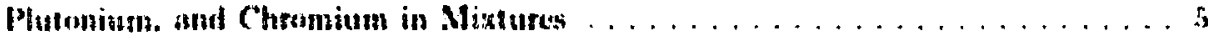

E. Aridity Bffert $\ldots \ldots \ldots \ldots \ldots \ldots \ldots \ldots \ldots \ldots \ldots \ldots \ldots$

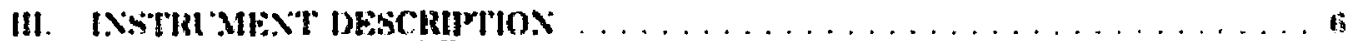

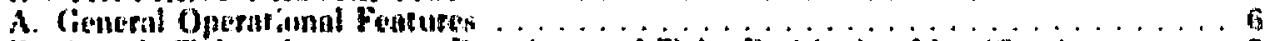

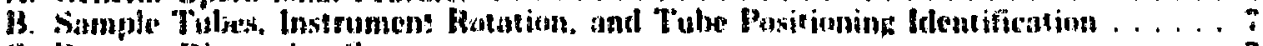

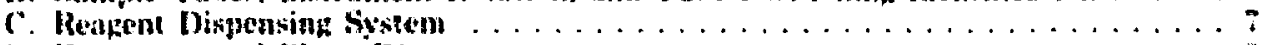

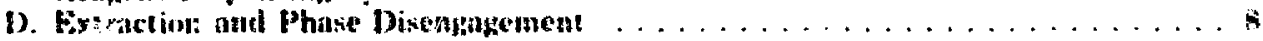

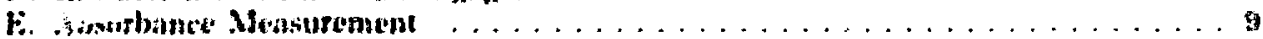

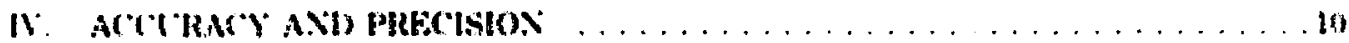

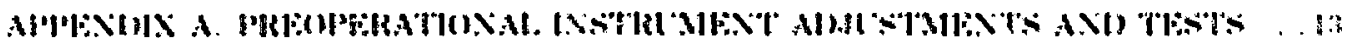

Alगf:

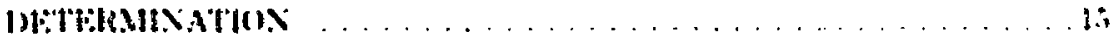

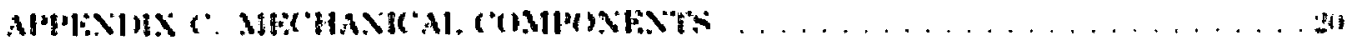

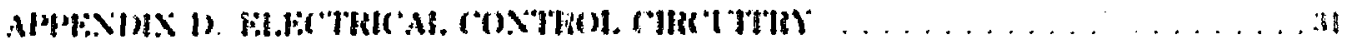

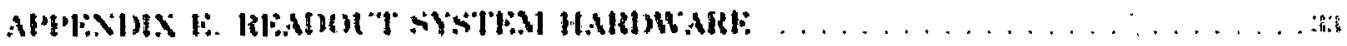

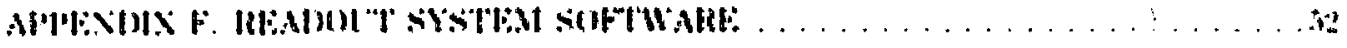

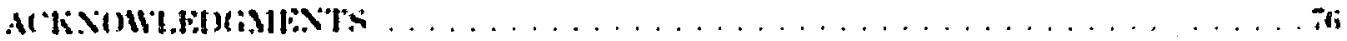

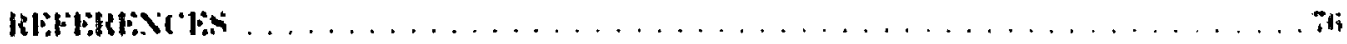

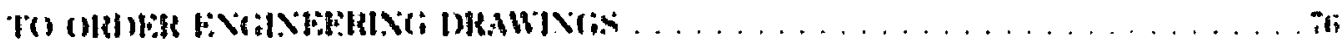

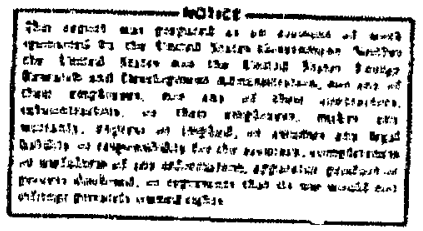




\section{FItatuss}

f.:

E. :

E.

E...

Fit.

E.

F...

5. 6.

\&111

fi:

l. Is.

政.

1.19.

B.

E. illi.

\$. 15

\$* 1 .

$\$$

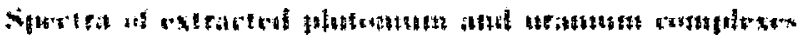

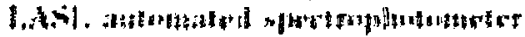

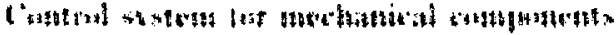

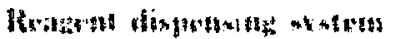

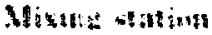

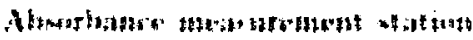

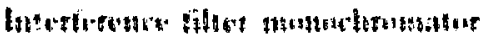

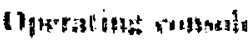

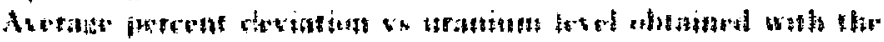

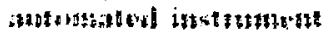

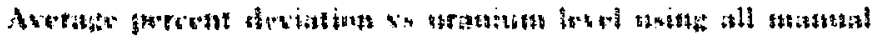
antorationts: ...

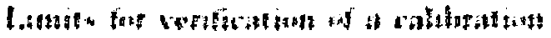

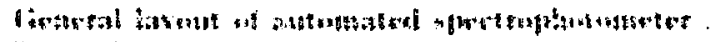

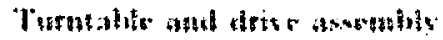

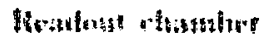

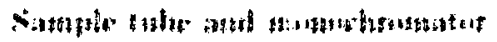

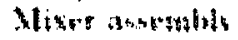

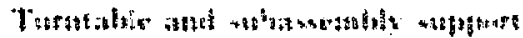

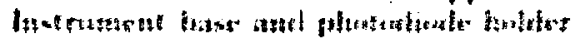

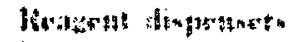

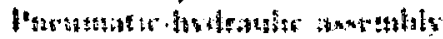

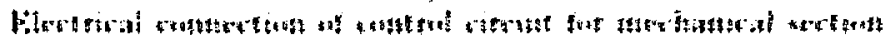

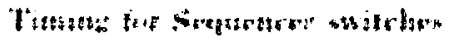

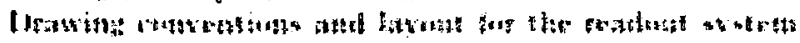

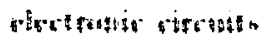

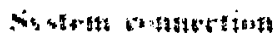

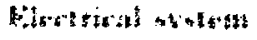

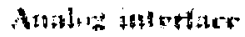

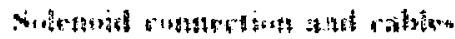

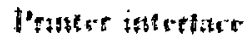

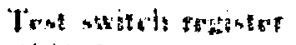

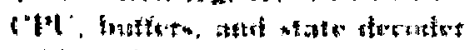

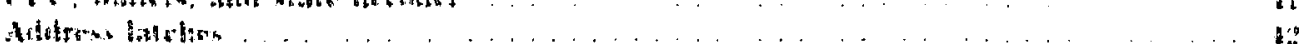

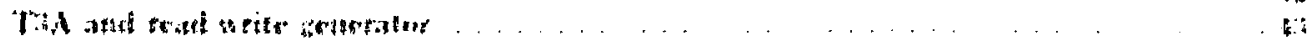

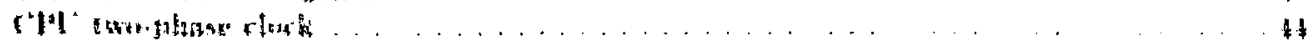

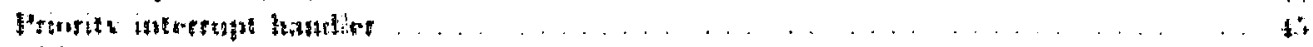

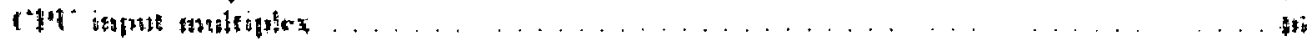

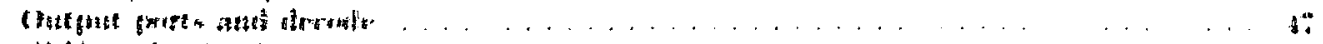

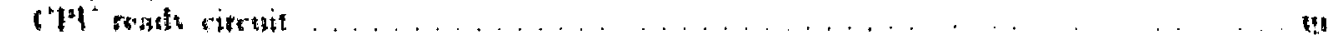

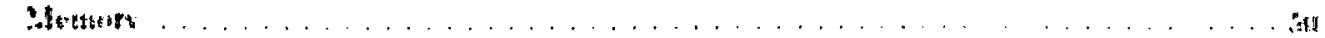

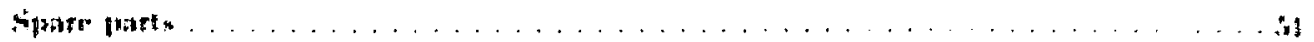

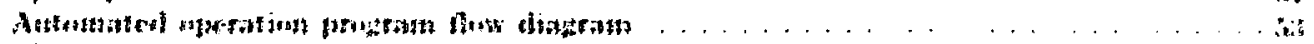

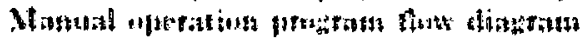

. int 


\section{TABLFS}

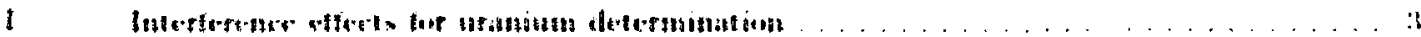

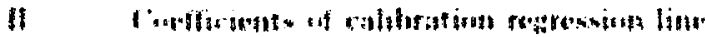

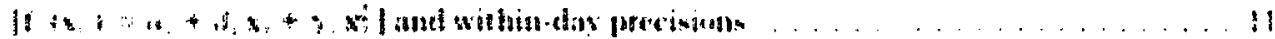

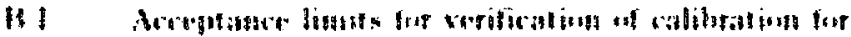

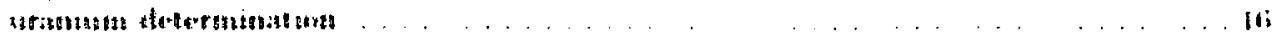

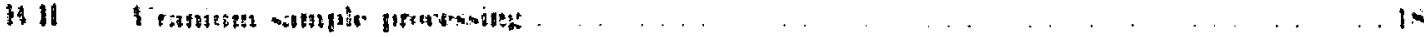

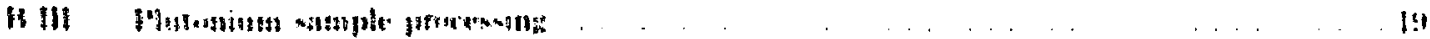

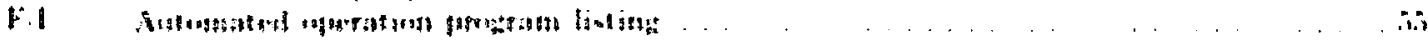

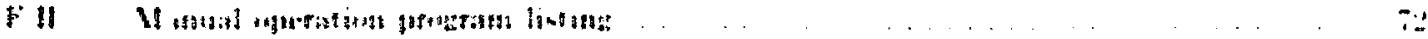




\title{
AUTOMATED SPECTROPHOTOMETER FOR PLLTONIUM AND URANIUM DETERMINATION
}

by

D. D. Jackson, D. J. Hodgkins,

R. M. Hollen, and J. E. Kein

\begin{abstract}
The automaled spectrophotometer presented in this report is the first in a planned series of automated instruments for determining plstonium and uranium in nuclear fucl cycle materials. It has a throughput rate of $\mathbf{5}$ min per sample and uses a highly specific method of anaiysis for these elements. The range of plutonium and uranjum measured is 0.5 to $14 \mathrm{mg}$ and 1 to $14 \mathrm{mg}$, respectively. in 0.5 $m$ ' or less of solution with an option to pre-evaporate larger volumes. The precision of the measurements is about $0.112 \mathrm{mg}$ standard deviation over the range corresponding to about 2 rel\% at the I-mg level and 0.2 rel\% at the 10-mg levei.

The method of analysis involves the extraction of tetrapropylammonium plutonyl and uranyl trinitrate complexes into 2nitropropane and the measurement of the optical absorbances in the otganic phagm at unique peak wavelengths. Various aspects of the chemistry associated with the method, including tolerances for metal and nonmetal impurities, are presented.

The automated spectrophotometer features a turntable that rotates as many as 24 samples in tubes (made from precision-bore tubins) to a series of stations for the sequentisl chernical operations of reagent addition and phase mixing to effect extraction, and then in a station for the absorbance measurement. With this system, the complications of sample transfers and now-through cells are avoided. The absorbance measurement system features highly stable interference filters and a microcomputer that controls the timing sequence and operation of the system components. Output is a paper tape printout of three numbers: a four-digit number proportional to the quantity of plutonium or uranium, two-digit number that designates the position of the tube in the turntable, and a one-digit number that designates whether plutonium or uranium was determined.

Details of the mechanical and electrical components of the instrument and of the hardware and software aspects of the computerized control system are provided. Also detailed are instrument preoperational adjustments and tests und chemical procedures for instrument calibration and sample aizalysis.
\end{abstract}




\section{INTRODLCTION}

Development of the automated spectrophotometer for plutonis:un anc uranium determibation was spon. sored by the Division of Safeguards and Security of the Fnergy Research and Devesponent Administration. The spectrophotometer. the lirst in a planned series of automated instruments, features high specificity and a moderate precision capability of about $0.5 '$, relative standard deviation. Intended use is: primarily the analysis of s(rap-lype materials often charact srized by heterogeneily and high levels of diverse impurity elements. Sibbseguent in. struments are to continue the high specificity leature with higher levels of procision for use on product - and sctap-type materials.

This report provides a description of the automated spectroptotometer including the chemistry of the analytical procedure and informa. tion relative to impurity effects. a discussion of the major mechanitol and electrical components and their operation. and test dat a showing accuracy and precision capability. The appendixes provide detail. ed descriptions of (a) preoperational tests and adjustments, (b) procedures for the netarmination of uranium and plutonium. (c) mechanieal com. ponents, including construction drawings. (d) elec. irical components. including circuit diagrams. (e) readout system hardware, and (i) readout system software.

\section{CHEMICAI. METHOD AND INVESTIGATION OF DIVERSE ION EFFECTS}

\section{A. Selection of Analytical Method}

To ixpedite development of the first automated instrument, we reviewed the literature with the intent of using an established method. Major criteria were (a) a capability to detcrmine plutonium and, preferably. uranium as well. (b) sensit vity in the low milligram range. (c) minimum operations, (d) high specificity. and (e) a measurement precision of about $1^{\prime \prime}$ relativi standard deviation. The selected method ${ }^{1.2}$ was a spectrophotometric one in which an ion assoriation complex of tet rapropylammonium plutonyl (or uranyl) trinitrate, $\left.\left\{\mathrm{Propy}_{4} \mathrm{~N}\right\}^{+} \mid \mathrm{PuO}_{2}\left(\mathrm{NO}_{3}\right)_{3}\right]^{-}$, is extracted from an aluminum nitrate-salted aqueous phase into an orgaric solvent, 4-methyl-2-pentanone imethylisobutylketone (MIBK)), to give characteristic spectra (Fig. 1). Intensities at peak wayelengths, directly measurable in the organic

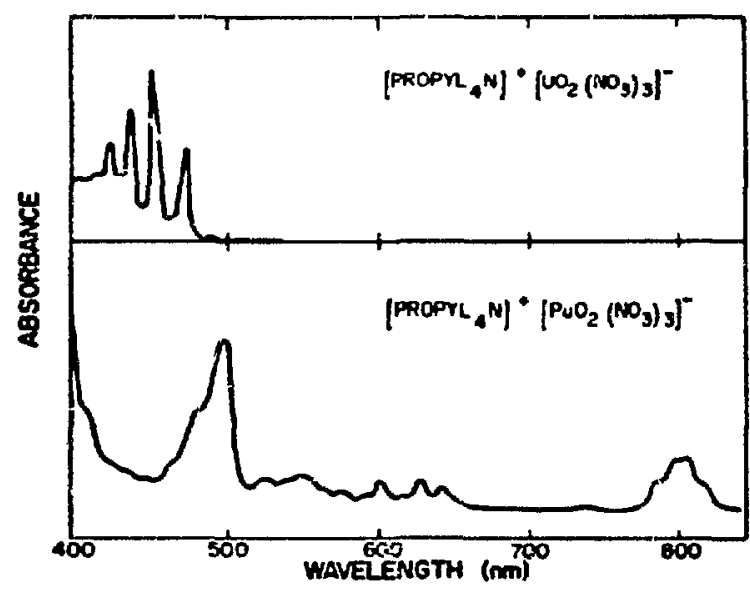

Fig. $l$.

Spectra of extracted plutomium and uranium complexes.

phase, are proportional to plutunium and uranium concentrations. The ranfes of plutonium and uranium determined. under the recoummended conn. ditions of the methokls, were $0.51015 \mathrm{mg}$ and 0.5 (1) 12 mg. respectively.

Operational simplicity is shown by the following sequence fis manual determinat ion of uranium.'

(a) To a sample aliquat of $50.5 \mathrm{~m} /$ in a test tahe. ndd $4 \mathrm{~m} /$ of a sulting-complexing solusion. $0.0125, M$ tetrapropylammonium nitrate-2.8M Al(No, $1,-2 \mathrm{M}$ $\mathrm{NH}_{4} \mathrm{OH}$.

(b) Add $2 \mathrm{~m} /$ of MIBK. stopper. and extract for 3 min.

(c) Centrifuge to facilitate phase disengagement.

(d) Transfer the organic phase in a $1 . \mathrm{rm}$ cell and mecsure ahsorbance at inajor peak wavelength of $452 \mathrm{~nm}$.

Fot the determination of plutonium, an oxidation to $\mathrm{Pu}^{6+}$ is necessary before starting the above sequence. This is accrimplished either with $\mathrm{AkO}$ or $\mathrm{KMnO}_{4}$, the former preferred exeept for chloridecontaining samples. A larger volume of $4 \mathrm{~m} /$ of MIBK is used for the plutonium determination since the molar absorptivity of the plutonium complex at its major peak of $\mathrm{502} \mathrm{nm}$ is ahout twice that of the uranium complex at its major peak.

This method provided several major advantages relative to the design of an automated spec. trophotometer. The complete chemical operational sequence could be done by adding rengents to a tube. thereby avoiding pump-metered transfers of reacting solutions. Further, this tube could serve as the cell for the absorbance measurement, avoiding the 
use of a tlow-through rell and its attendant memory difficulties.

\section{B. Interference Efrects}

For a diverse ion to interfere. it inust both extract and oftically absorb at the wavelen $n_{\dot{k}}$ as used for the plutunium and uranium measurements. $A$ detailed investigation' ${ }^{3}$ of the extraction of 49 cations and the effects of 30 anions on the extraction of uranium had preceded the development of the uranium spec. trophotometric methud. As part of the development of the spertrophotometric uranium method.' the affects of 27 metal ions and 1.3 anions were reported as given in Table I. Only thorium and $\mathrm{Ce}^{-1+}$ interfered by combining with the tetrapropylammonium ion fo form a nonabsurbing thorium com. plex and a slightly absorbing cerium complex.

Interference information obtained for the method fo: isanium determinaton applies to plutonium determination with the exception that the $A g()$ or $\mathrm{KMnO}$, pretreatment to produce $\mathrm{Pu}^{\mathrm{it}+}$ can oxidize a diserse ion to a species that interferes. Of the elements previously investigated for the uranium determination. chromium. cerium. and chloride were considered to merit further study. Chloride formed a precipitate on the surface of the $\mathrm{AgO}$ which prevented complete oxidation of the plutonium. To analyze samples containing chloride, either a double fuming with $\mathrm{HNO}_{3}$ preceding the $\mathrm{AgO}$ oxidation or the use of $\mathrm{KMnO}_{4}$ with no fuming was satisfactory. The $\mathrm{Ce}^{4+}$ complex does not optically absorb above $480 \mathrm{~nm}$ and, hence, does not affect the plutonium determination. Chromium, oxidized to $\mathrm{Cr}^{6+}$. extracts and has an absorbance continuum that adversely affects plutonium determination at the major absorbance peak of $502 \mathrm{~nm}$. Deterritination of plutonium may be made using the less sensitive 806. $\mathrm{nm}$ peak with not effect of chromium up to $0.1 \mathrm{i}$ nmol.

Construction of a prototype of the automated spect rophotometer facilitated further investigation of int erference effects snd factors affecting the determination of plutonium and uranium in the presence of each other. Interference effects investigated were thorium, $\mathrm{Cr}^{6+}$, sulfate, fluoride, and acidity. The two metals were virtually the only ones reported to interfere at low ratios relative to plutonium and uranium. Reported data were considered insufficient!y definitive for the common anions, sulfate and fluoride, and for acidity.

TABLE I

\section{INTERFERENCE EFFECTS FOR URANIUM DETERMINATION}

\begin{tabular}{|c|c|}
\hline Metal Ion & $\begin{array}{c}\text { Highest } \\
\text { Level } \\
\text { Studied } \\
\text { Causing } \\
\text { No Efrect } \\
\text { mmol }\end{array}$ \\
\hline Barium(II) & 0.025 \\
\hline Bervillium(II) & 1.0 \\
\hline Bismuth(III) & 0.5 \\
\hline Cadmium(,I) & 0.5 \\
\hline Calcium(II) & 0.75 \\
\hline Cerium(III) & 0.5 \\
\hline Cerium(IV) & 0.008 \\
\hline Chromium(III) & 1.5 \\
\hline Cobalt(II) & 1.2 \\
\hline Copper(II) & 1.0 \\
\hline Iron(111) & 0.5 \\
\hline Lanthanum(III) & 0.5 \\
\hline lead(II). & 0.25 \\
\hline Magnesium(II) & 0.75 \\
\hline
\end{tabular}

\begin{tabular}{c}
$\begin{array}{c}\text { Highest } \\
\text { Level } \\
\text { Studied } \\
\text { Causing } \\
\text { No Effect, } \\
\text { mmol }\end{array}$ \\
\hline \\
0.5 \\
0.5 \\
0.5 \\
0.025 \\
1.0 \\
0.5 \\
1.2 \\
1.2 \\
0.5 \\
0.008 \\
0.012 \\
1.0 \\
0.25
\end{tabular}

\begin{tabular}{c}
$\begin{array}{c}\text { Hizhest } \\
\text { Level } \\
\text { Studied } \\
\text { Causing } \\
\text { No Effect. } \\
\text { mmol }\end{array}$ \\
\hline \\
\\
1.2 \\
0.025 \\
0.50 \\
0.25 \\
0.25 \\
0.25 \\
1.2 \\
0.25 \\
0.050 \\
0.25 \\
0.25 \\
0.25 \\
0.25
\end{tabular}

al level $=0.042 \mathrm{inmol}$. 
Thorium. sike uranium and plutonium. forms a tetrapropylamnonium nitrate complex but, unlike uranium and plutonium, does r.st spticaliy absrorb in the wavelength region of iuterest. The thorium complex does interfere. however. by cr.mp.oling fur the complexing agent of tetrapropylar monium nit rate to cause low bias when the uranium plus thorium, or plutonium plus thurium level. exceds the complexing agent capacity. Also. when using MIHK as the organic extractant, the thorium complex extracts as an insoluble stospension into the organir phase. In the original. manual operation method. the phases are cent rifuged after ext raction. resulting in a clean separation from the organir phase with mo interference. Centrifugation. because of mochanical complexity. is not used in the autumated spectrophotometer.

Two pis sible wiays of overcoming the thorium difficulty were invest igated: (a) use of a masking agent and (b) substitution of an urganic solvent in which the thorium complex is soluble. Of a wide variety of organic complexants tested as masking agents. none prevented formation of the thorium tet rapropylam. monium suspension without also complexing taranium and probably plutonium as well.

Of variuus organic solvents tested, 2-nit ropropane. in which the thorium complex was soluble. prosed an excellent subst it ûe for M!BK. It was imniscible with the aquenus phase, gave $39.93^{\prime}$, ext raction of the uranium and plutonium complexes, and produced no significant changes relative to interterenco effects. Furthermore. the uraniutn and plutonium complexes had the same absorption spectra in 2 . nitropropane as they had in MIBK. A minor dirference was a $3^{\prime \prime}$, lower intensity of the peak ahsorbance for the urani:um complex with 2 . nit ropropane than with MIBK. Ising the conditions established for the automated instrument $14 \mathrm{~m} /$ of $0.025 M$ tetrapropylammonium nitrate-2.8M All $\mathrm{NO}_{1},{ }_{1} \cdot 2 \mathrm{M} \mathrm{NH}_{4} \mathrm{OH}$ salting-complexing solution and $3 \mathrm{~m} /$ of 2 -nitropropanel. the tolerance for thorium was t:stablished. This tolerance is expressed best in terms of the number of millimoles af thorium plus uranium and is considered to apply on a summ. ed millinole basis for thorium-plutonium and thorium-uranium-plutonium mixtures. At the lower uranium limit of $0.004 \mathrm{mmol}$ (about $1 \mathrm{mg}$ ). low hias starts at $0.05 \mathrm{mmol}$ of thorium plus uranium. At a higher level oi $0.05 \mathrm{mmol}$ of uranium (abrut $12 \mathrm{mg}$ ). low bias sets in at $0.07 \mathrm{mmol}$ of thorium plus uranium. The tolerance to thorium can be increassed by increasing the concentration of tetrupropylammonium nitrate in the salting-romplexing solution at the disadvantage of extracting extranesus ions.
Chromium extracts, in the + fioxidat jon slate. and the spect rum of the ext racted species is a broad prak at fis) $\mathrm{nm}$ followed by a decreasing absorbintere in alsout $580 \mathrm{~nm}$. For chromiun-uranium mixtures in which the chromitum and uraninm buth are present in ihe ti oxidation stalle. chromium does not in.

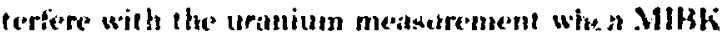
is the oryanic exiractast. It dene incerfere. howeser. by caltsing a positive bias when 2-nit ropropsane is the organic extractant. This intertisenese is remosed ly redsteing the chromium lo Itonitutertering ip before adding the salting-cumplexing solusiem ator in the case of the automatesl speet ruphenometer. hefore placings the tube un the instrument). Various redus.-

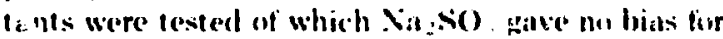

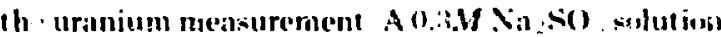
is . dded drepwise (o the sample until the color chy nge from orange (" $\mathrm{r}^{\text {tit }}$ to blue ( $\mathrm{r}^{3+}$ is complete. Other reducits agents insestipated lformic acid.

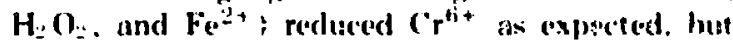
caused a negative bias for uramium.

The effect of chromium upon the measurement of plutonium is nowre serinus. The abourlsance of the ex. tracted c $^{\text {tit }}$ comples is sicater all the matur pletonium peak wavelength al aot 1 nut e precisely measured: see sece. III.F. than it is at the valley wavelength position of $518.11 \mathrm{~nm}$ for both the MHBK as $d$ 2-nit ropropane ext ractants thereby coussing a pesitive bias in the plutomium mensurement. As: discussed in Sec. III.E. a peak-minus-valdey absur. bance is ased as the meastire of plutoniun and uranium-- concent rat ion. I Hecause a st rongr oxirlant. usually $A_{f} O$. is addent lo produce Putis any chromium present will be oxidixed to ( $\mathrm{r}^{\mathrm{fit}}$. It is mol feasible to reduce $\mathrm{Cr}^{\text {it }}$ without also reducine $\mathrm{Pu}^{\mathrm{it}+}$. Thus, the less sensitive peak at $8017.0 \mathrm{~mm}$ is used for the treasurement of plutonium in plutmium. ch:omium mixtures. The sutomated spec. trophotometer is equipped with filiers for the 8070 . nm measurement.

The tolerances of the automated spec. trophotometer method for sullate and fluoricle were determined and found to he essentially equal for the MIBK and 2-nitropropane extractants. Adverse effects occur onls at combinations of high lesels of sulfite er fluoride and high levels of uranium (or plutonium ). Up io $1.8 \mathrm{mmol}$ of sullate has no effect at uraniam levels of $8 \mathrm{mg}$ or less. At the 11 - my uranium level, up to $0.9 \mathrm{mmol}$ of sulfate has no effect, and $1.8 \mathrm{mmol}$ causes $T^{\prime}$; low hias. Up to 1.5 mmol of thoride has no effect at uranium teveis of $8 \mathrm{mg}$ and less. A gelatinous precipitate forms with $3 \mathrm{mmol}$ of lluoride and $8 \mathrm{mg}$ of uranium which 
susplends in the urganic phase, therely causing in. errference. The colerance for husride al the 11 -mg uranium level is ils mmol.

Simple that contain high levels of sulfate and muoride ean be evaporated to near druness as a presteatment. In the case of the autumated spece trephutometer. this esaporarion can be made aller the sample is delivered inis the able. In our latheraters: a healted aluminum block is lised which has cicepl holges is which the tuhex are immersed com.

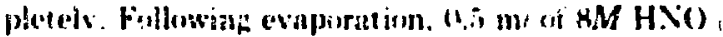

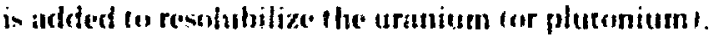

\section{Analysis of I'ranium-Plutonium Mixtures}

The measurement of aranium and plutenium in mixtures of these two elements and in mixtures with rhromium was investignted. For both . MllBk and 2. nit ropropante extractants. the cextracted upanium complex durs not absorts at eigher the penk lioll.t

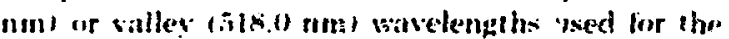
plutunium measurement. For 2-pitrupropane as the extractatu. plutonium denes not interfere with the aranium measurement. It does cause a pusitive plutuitum bias when the extractant is MIBli. The

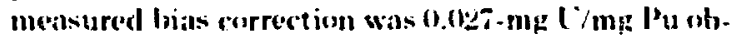
bained on an instrument prototype. This correction shuld bo determined for ench instrument.

In the determination of uranitum, wo investigated the eflere of ondting the oxidation using ApC when annivaing mixtures of araniam and plutonium. linder these conditions. plutonium can be present primarily as the +1 oxidation stiste. Measurements midte on mixtures of plutonium and uranium omit. tiang the oxidation step gave low values for plutsmiuns, as expected, and hip? bias for uranium. Thus. the ApO oxidation is necessiary for uranium determinations ats well as for plutonium deter. minit ions in samples containing plutonium.

\section{1). Hecommended Analysis Conditions for Various Combinations of Uranium. Plutonium, and Chromium in Mixtures}

Based on :he information presented in the two previous subsections, the following analysis conditions are recommended for various combinations of' uranium, pluronium, and chromium in mixtures.

For uranium-plutonium mixtures free of chromium, use $\mathrm{AgO}$ as the oxidant, 2-nitropropane as the extractant, and measure the plutonium at the more sensitive 501.4- $\mathrm{nm}$ peak position. There is no effect of $\epsilon$ ither element upon the other. For uranium.
(' $\mathrm{r}^{\text {fit }}$ mixtures. use MIBK as the extractan:. except whon thorium also is present. Fer uranium $-\mathrm{Cr}^{6+}$. thorium mixtures, use 2-nitropropane as the extrarlant and a preseduction with $\mathrm{Xa}_{2} \mathrm{SO}_{3}$. For chronium-plutonium mixtures. the less sensitive 807,(1)-nin peak position must be used for the plutronium measurement eit her with 2-nit ropropane or MLHK as the extractant. For uranium-plutoniumchromium nixtures. use $\mathrm{AgO}$ as the oxidant. MIbK as the extractant, and measure the plutonium at $80: .0 \mathrm{~nm}$. ('orrect the uranium result for plutonium interference using a factor determined for each instrument. The factor for the instrument prototype was $0.027 \mathrm{mgr} \mathbf{l} / \mathrm{mg} \mathbf{P u}$.

\section{E. Acidity Effect}

Inorganic acids. such as $\mathrm{HNO}_{3}$, extract into the orpanic phase of MIBK or 2 -nitropropane. The salting-complexing solution is made basic with $\mathrm{NH}_{4} \mathrm{OH}$. thereby increasing the tolerance of the method to acid. The $\mathrm{HNO}_{3}$ content of the Ali $\mathrm{OO}_{3}, \mathrm{H}_{1} \cdot 9 \mathrm{H}_{2} \mathrm{O}$ reagent varies among lots and the st rengt h of $\mathrm{XH}_{4} \mathrm{OH}$ depends on its storage integrity. Also, during the preparation of the saiting. complexing solution. $\mathrm{NH}$. may volatilize. Thus, the tolerance to acid varies among salting-complexing solutions.

The acidity of a salting-complexing solution was determined b: an oxalate complexing-pH titrimet ric method: the salting solution then was used to in. vestifate the effect of acid on the determination of uranium. The salting-complexing solution was prepared as $0.025 M$ tetrapropylammonium hudroxide-2.8M Al(NO):-2M $\mathrm{NH}, \mathrm{OH}$. The determined base concentration was $12 N$. The acid effect was measured at iwo uranium levels of 2.5 and il mg. using $4 \mathrm{~m}$ / of the salting-complexing solution and $0.5-\mathrm{m} /$ samples with $\mathrm{HNO}_{3}$ levels ranging from 6 to $15.8 M$ (3 to $7.9 \mathrm{mmol}$ ). The absorbance was constant for both uranium levels up to $5 \mathrm{mmol}$ of $\mathrm{HNO}_{3}$. then it decreased continuously with increasing acidi. ty. At the $10-\mathrm{mg}$, uranium level, the negative bias was $0 . c^{\prime \prime}$; for $6.1 \mathrm{~m}$ : $u$ ol $\mathrm{HNO}_{3}, 1.5$; ; for $6.6 \mathrm{mmol}$. and $2.5^{\circ}$ for $7.0 \mathrm{mmol}$. The effect was greater at the

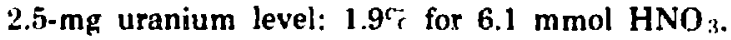
$2.3^{\circ}$; for $6.6 \mathrm{mmol}, 3.4^{\circ}$; for $7.0 \mathrm{mmol}$, and $5.8^{\circ}$; for $7.9 \mathrm{mmol}$. The effect appears to become significant when the acidity content of the sample exceeds the base content of the salting solution. For this reason, each salting-complexing solution that is prepared should $i s$ analyzed for its base concentration and then adj. 'sted to $2 \mathrm{~N}$ base by the addition of $\mathrm{NH}_{4} \mathrm{OH}$. 


\section{INSTRUMFNT DESCRIPTION}

\section{A. General Operational Features}

The automated spectrophotometer, shown $1:$ Fig. 2 , features a turntable, holding up to 24 tubes, that rotates to stations for a series of sequential operations. Four of the tube positions, under stations, are inaccessible for initial loading. An analyst can replace tubes of analyzed sarnples with tubes of new samples, thereby attaining continuous operation. The throughput rate is $5 \mathrm{~min}$ per sample. Before placing tubes in the turntable, the analyst delivers the sample aliquots and, for plutonium determination, addis a pellet of $\mathrm{AgO}$ to produce $\mathrm{Pu}^{6+}$

The tubes are made from precision-bore tubing (discussed in Sec. III.B) such that all operations on the instrument, including the absorbance measurement, are done with no transfer of the sample. The holes into which the tubes fit in the turntable are lined with Teflon to prevent tube scratching. At the stations, the following automated operations are performed on a timed sequence: (a) addition of the salting-comniexing solution, (b) addition of the ordanic extractant, (c) mixing to achieve extraction of the uranium and plutonium complexes, (d) addition of a saturated $\mathrm{Al}\left(\mathrm{NO}_{3}\right)_{3}$ solution to raise the level of the organic phase in the tube, and (e) measurement of the absorbance. Three stations are used. The first three operations are done at the first station. At the second station, after a dwell period for phise disengagement, the level of the organic phase is raised. Abosrbance is measured at the third station.

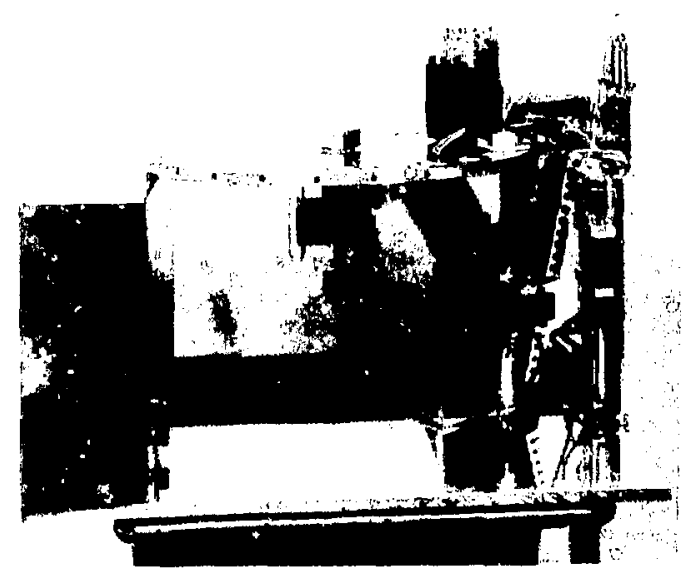

Fig. 2.

LASL automated spectrophotometer.
The abiorbance measurement system is controlled by a microcomputer. Output is a printed lape of a four-digit value that is proportional to the absorbance value. Also printed are the turntable tube positions designated 0 through 23 and a number 1,2 . or 3 designating which peak-valley pair was used and, therefore, whether uranium or plutonium was determined.

Although the phases disengage extremely well after mixing, droplets of the aqueous phase adhere to the tube wall in the region of the organic phase. The organic phase is raised. therefore, to a clean area of the tube to obtain an unbiascd absorbance measurement.

The throughput rate of 5 min per sample " essen. tially set by the time required for extraction. "Le extraction of the complexes is greater than $99.9^{\prime \prime}$ i in about $3 \mathrm{~min}$ but is continued for a totai of $4 \mathrm{~min}$ to guarantee this level of extraction for all samples.

The automated spectrophotometer is equipped with sensors and interlocks to minimize malfunctions and damage. At each station, sensors actuated by the presence of a tube permit the operation at that station to proceed. Thus, operations such as reagent deliveries do not occur unless a tube is present. Interlocks stop operation in case of failure of (a) the turntable unlatching mechanism. (b) the turntable rotation to the geometrically correct position relative to the station, and (c) the air supply to the instrument. Operation ceases following analysis of the last sample.

The instrument is designed to fit in a Los Alamos Scientific Laboratory (LASL) type, sloping front glovebox that is $0.91 \mathrm{~m}$ wide, $0.79 \mathrm{~m}$ deep, and 0.84 $\mathrm{m}$ high. The two gloveports have a $0.21-\mathrm{m}$ diam with centerline locations $0.46 \mathrm{~m}$ apart and $0.61 \mathrm{~m}$ above the glovebox floor. Spectrophotometer construction provides for easy removal of a failed component and its replacement rather than for in-box repair. The control unit, microcomputer, and printer are located outside the glovebox.

The instrument has two independent contro! systems. The mechanical control system was constructed before the microcomputer system was available. Cam-actuated switches driven by a common motor-driven shaft control the sequence of operations required for moving the turntable, deliver'y of reagents, stirring, and raising of the sample tube into the readout chamber. Figure 3 shows some of the components of the control system, in. cluding the cam-actuated switches. relays for interlocks, solenoid valves, and the plumbing associated with the pneumatic-hydraulic system. The second control system is for electronic readout 


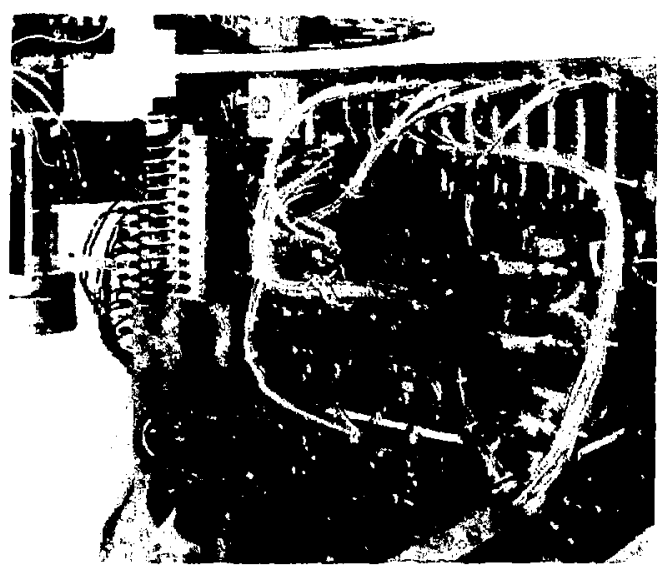

F'ig. 3.

Control system for mechanical components.

and uses a microcomputer and programmable read. only memory (PROM) chips to control the measurement sequence.

\section{B. Sample Tubes, Instrument Rotation, and Tube Positioning Identification}

The tubes are economically made from $1.905 \cdot \mathrm{cm}$ diam. precision bore tubing. This diameter essentially is a compromise based on experiments that investigated efficient phase mixing and disengagement, optical path length, height of the organic phase for the absorbance measurement, and attainment of small error in the effective optical path length caused by positioning perturbation of the tubes in the readout chamber of the absorbance measurement station. As shown in Fig. C-4, tube height is $12.7 \mathrm{~cm}$ and the tube top is flared

The inside diameter of the $1.905-\mathrm{cm}$-diam precision-bore tubing has a stated tolerance of $\pm 0.0005 \mathrm{~cm}$, which is equivalent to $0.026 \%$. However, wall thickness varies, causing a vertical displacement in the absorbance intensity over the entire spectrum. The displacement is equal at the peak and valley wavelengths which are used for absorbance measurements of the uranium and plutonium complexes. The net absorbance difference that serves as the measure of concentration, therefore, is unatiected. Verification of the inside-diameter precision and noneffect of wall thickness was shown by measurement of the net $a b$ sorbance difference of the extracted iranium complex in six randomly selected tubes in a conventional spectrophotometer. The overall precision, which includes tube alignment as well as among-tube difference, was $0.1 \%$ relative standard deviation at a net absorbance level of 0.5 .

The turntable is rotated by a Geneva-drive, intermittent-motion assembly which provides slow acceleration and accurate positioning This positional accuracy is further ensured by a tapered pin driven by a pneumatic cylinder that engages tapered indentations in the rim of the turntable at each of the 24 indexing positions.

The tuve positions are numbered 0 to 23 on the turntable. Five rolle $;$-actuated miniature swirches sense a series of binary-coded holes in the bottom of the turntable and relay the information to the microcomputer where it is converted to a decinnal number from 0 to 23 for output by the printer.

\section{Reagent Dispensing System}

The concentration of the uranium and plutonium extracted into the organic phase is directly proportional to the dispensed volume of organic extractant . Precision of delivery, rather than accuracy, is the important factor. Analysis accuracy is established by processing aliquots of a calibration material through the entire system in a manner identical to sample processing. A dispensing system was developed which consists of a pneumatic-hydraulic cylinder that drives a gas-tight syringe in conjunction with a pneumatic cylinder that operates a threeway valve (Fig. 4). This system is used for all three reagents, the salting-complexing solution, the 2 nitropropane or MIBK extractant, and the organicphase raising solution. The only materials contacting the reagents are glass, Tefion, and Kel-F. Before the development of this system, several commercial units were tested. None gave successful service. Degradation of plastic components by the organic extractants and corrosion of metal surfaces by the acid (less then 1-pH) salting-complexing and organic-phase raising solutions resulted in short service life and poor precision.

The system combines pneumatic and hydraulic pressure transducers to provide a smonth and reproducible motion to the syringes. Delivery volume is set by adjustable stops on the hydraulic cylinder. Delivery rate and size of the syringe tip were established by experimentation to attain the best precision for each of the three reagents. The precision, determined by weighing dispensed volumes, was less than $0.02^{\circ} r$ relative standard deviation for both $3-\mathrm{m} /$ volumes of the organic extractant and $4-\mathrm{m} /$ volumes of the salting-complexing 


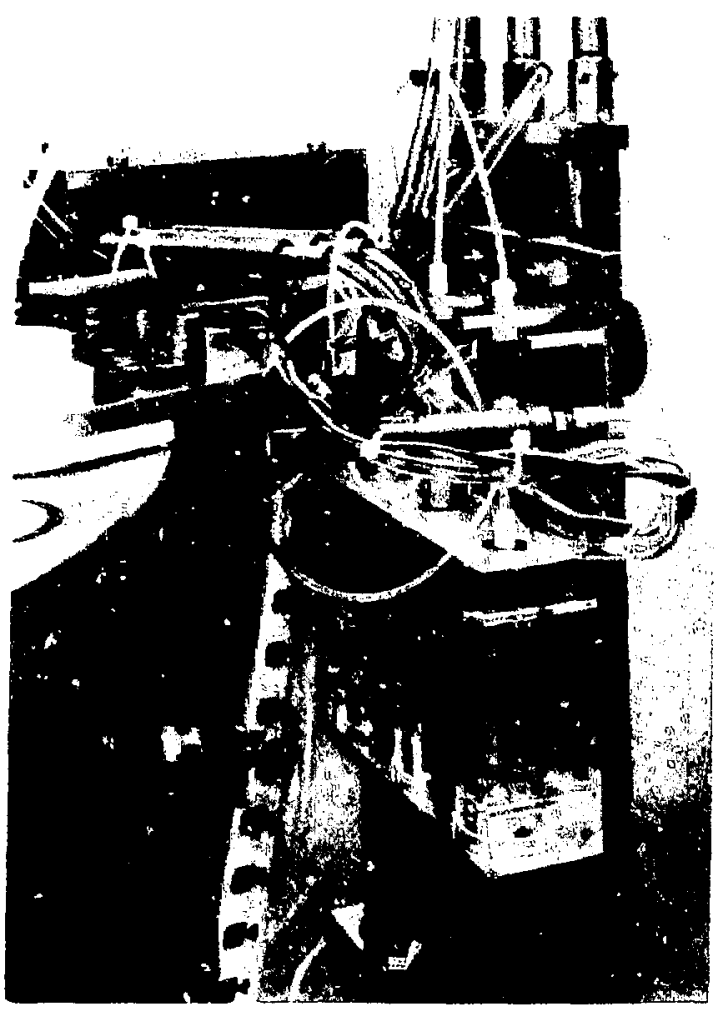

Fig. 4.

Riagent dispensing system.

solution. Appendix C provides construction details of the system; preoperational adjustment is given in Appendix A.

The salting-complexing and organic-phase raising reagents are delivered as fire streams to a position toward the top of the tube that is $90^{\circ}$ radially from the position of the optical path. The organic extractant is delivered as a fine strean just above the acueous mixture of sample and salting-coriplexing solution. 'This minimizes the quantity of the extractant that adheres to the wall to provide a high degree of precision.

\section{Extraction and Phase Disengagement}

In the original method, capped tubes were inverted either manually or on a mechanical extractor followed by centrifugation to effect phase disengagement. These operat ions were considered too complex for automation. The system developed uses a magnetic stirrer followed by a time delay to provide for gravitational phase disengagement. Using a 3 min extraction period and a 5 -min time delay, the extraction efficiency for uranium and plutonium is greater than $99.9{ }^{\prime} \mathrm{r}$, equal to that obtained manually.

An effectively large interphase surface is required to attain extraction from the viscous, saltedcomplexed aqueous phase to the relatively lowdensity, low-viscosity organic phase. This extraction must be attained without emulsion formation and without significart spraying. The magnetic stirrer used in the spectrophotometer (Fig. 5) evolved from a lengthy series of experiments. It provides a long vorte: for efficient extraction without emulsion formation and without spray. The magnet is $2.5 \mathrm{~cm}$ lons and $1 \mathrm{~cm}$ in diameter and is Teflon-covered. A dual magnet rotating at $1200 \mathrm{rpm} 1.2 \mathrm{~cm}$ above the tube bottom provides the required strong coupling.

After the tube reaches the mixing station. the dual magnet raises into position for the mixing period. This is necessary to permit movement of the tubes during their indexing rotation without physical hindrance.

Details of the mechanical system and the electrical control circuitry are given in Appendixes C and $D$.

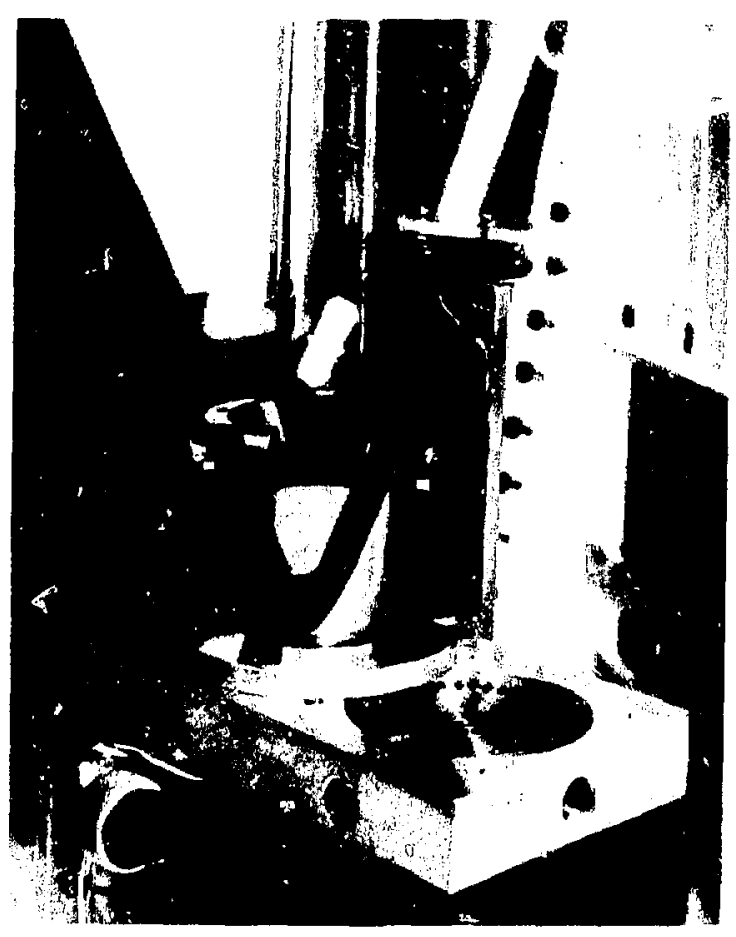

Fig. 5.

Mixing station. 


\section{E. Absorbance Measurement}

In the original methods, a recording spectrophotometer had been used to measure the absorbances of the very sharp peaks of both the extracted uranium and plutonium complexes. Two-and threewavelength measurements had been evaluated in which the first wavelength was the peak, the second wavelength was the valley on one side of the peak, and the third wavelength was the valley on the other side (see Fig. 1). For the automated spectrophotometer, the two-wavelength method was used. The three-wavelength measurement gave significant improvement of precision only toward the sensitivity limit and would have complicated instrument design.

A simple, rugged absorbance measurem ?nt system was constructed in which narrow bandpass interference filters were used. The wavelengths of the peaks and valleys were measured using a highresolution grating spectrograph as 452.5 and 460.0 $\mathrm{nm}$ for uranium, 501.4 and $518.0 \mathrm{~nm}$ for the more sensitive plutonium peak, and 807.0 and $768.0 \mathrm{~nm}$ for the less sensitive plutonium peak. The three pairs of peak-valley interference filters (Corion Instrument Corp., Waltham, MA) were verified to have peak transmittances of about $0.5(50 \%)$. less than 1.4- $\mathrm{nm}$ barifwidths, and less than 0.0001 $\left(0.01^{\prime}\right)$ ) transmittance above and below' he peak bandwidths. The central wavelength value of masimum transmittance was purposely slightly higher than the peak central wavelength to provide for exact matching by slight rotarional adjustment of the filters in the collimated light path (as detailed in Appendix A). No further adjustment to the prototype has been required after $2 \mathrm{yr}$ of use. The final instrument appears to have this same degree of stability.

Figure 6 shows the absorbance measurement station; from left to right, the filter monochromator, the absorbance-measurement chamber, the shutter, and the photodiode detector. The filter monochromator (Fig. 7) consists of a 45 -W quartz-iodine lamp, a simple collimating lens and slit collimator, and three pairs of interference filters. An electronically regulated, dc power supply maintains constant light intensity (and spectrum) output. When starting analysis of a series of samples, the analyst sets a console control that selects the desired peak-valley filter pair. A pneumatic-hydraulic cylinder system, under automated control, sequentially moves the two filters into and out of the optical path.

The chamber for absorbance measurements provides precise positioning of the tubes and is designed to eliminate stray light. The botiom of the

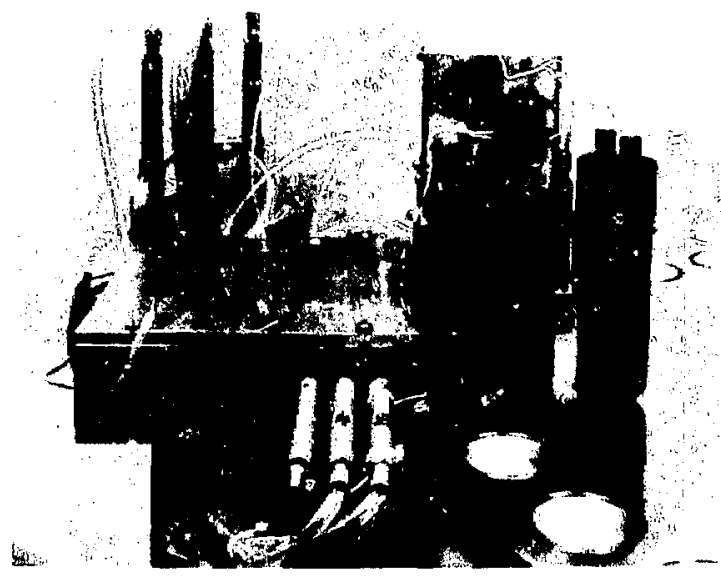

Fig. 6.

Absorbance measurement station.

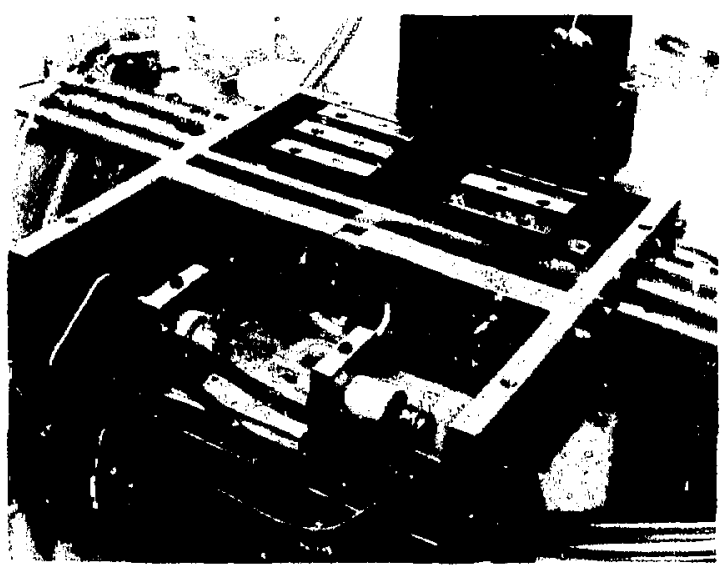

Fig. 7.

Interference filter monochromator.

tube fits into a cone-shaped depression in a lifting mechanism operated by a hydraulic cylinder. When the tube is lifted into the chamber, a spring-loaded. tapered, Kel-F piece partially slides into the top of the tube to reproducibly position it relative to the light path. The use of the inside of the tube for this positioning is necessary because, as discussed in Sec. III.B, the wall thickness of precision-bore tubing is variable. As the tube lifts into place, a spring-loaded shield presses firmly against the bottom of the turntable and a baffle drops into a circumferential gronve on top of the turntable to exclude stray light. To further reduce stray light effects, the inner surfaces of the chamber are anodized or painted black. The 
shutter, normally closed, is cperated by a springextended pneumatic cylinder.

The detector is a 929 photodiode tube connected to a high-gain amplifier. The long-term drift of this system is low compared to a high-gain photomultiplier tube, low-gain amplifier combination because the primary gain is controlled by a feed. back sustem in the amplifier which tends to selfcorrect. Another advantage is the higher level of un. iformity of photodiodes compared to photomultipliers. Operating conditions for the 929 photodiode. including high-voltage setting, maximum current. and light-source intensity. were established experimentally by measuring linearity and reproducibility of the output as a function of these variables over a range of absorbance of the uranium complex. Establishment of these conditions is detailed in Appendix A.

The measurement sequence of the readout system is controlled by a microcomputer and PROMS. Input data to the microcomputer include photodiode detector currents for peak and valley absorbances after analog-to-digital conversion, turnt able position of the tube in the sample absorbance measurement chamber, and identification of the selected filter pair. The microcomputer provides functions to (a) cont rol valves that operate the shutter and select the peak-valley filter pair, (b) initiate measurements of the absorbance at peak and valley. (c) manipulate data, ar.: (d) supply output to a paper-tape digital recorder. Tape printout consists of (a) a four-digit value proportional to the peak-minus-valley absorbance, (b) the tube-turntable position, and (c) a designation of the filter pair used. On the operating console (Fig. 8), the operating status of the shutter and the filters is denoted by lights. As a guide to performance and for aid in troubleshooting. the photodiode output current is continuously displayed on a digital meter.

The combination of the microcomputer and plug. in PROMS with readily changeable software programs provides great flexibility. Sequence and timing of the various operations are accurately controlled and easily altered. Complex data treatment. such as the averaging of many short-duration absorbance measurements to minimize transient effects, is readily attained. A special PROM allows manual control by toggle switches of detector system variables to establish optimum conditions for attaining highly reliable measurements (see Appendix A). Variables that have been evaluated are (a) time delays between (1) shutter closure and dark current rineasurement and (2) positioning of peak and valley filters and absorbance measurements, and (b) interrelationship of time duration of absorbance

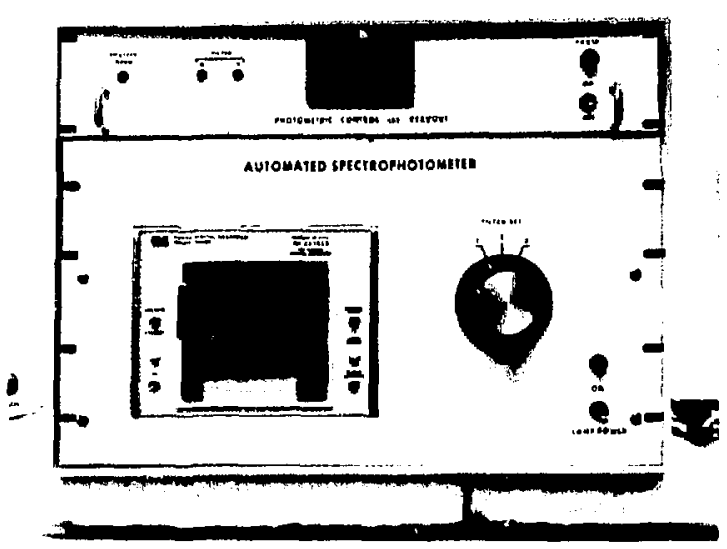

Fig. 8.

Operating console.

measurements with the integrated number of measurements.

The absorbance measurement cycle is initiated when a sample tube rising into position in the measurement chamber actuates a microswitch. An experimentally determined cycle for high reliability is as follows: (a) shutter closed, 10-s delay, measure dark current. store value: (b) move peakwavelength filter into light path. open shutter. 10-s delay, measure four photodiode currents, average the four values. subt ract dark current, store value: (c) replace peak-wavelength filter with valleywavelength filter and repeat sequence b: (d) close shutter: (e) compute $\log _{10}$ of each stored value: (f) subtract $\log _{10}$ values (peak value minus valley value); and (g) printout (1) obtained value as a four-digit number, (2) tube-turntable position. and (3) filter pair designation.

\section{ACCU⿴囗ACY AND PRECISION}

Two series of uranium calıbration solutions, one prepared using the National Bureau of Standards (NBS) Standard Referencs Materia! (SRM) G50 and the other prepared using highly pure, depleted uranium metal from LASL, were processed soon after the instrument became operational. The range of uranium analyzed was 1 to $11 \mathrm{mg}$. The absorbance appeared linear as a function of uranium level. A more accurate calibration was obtained by a least squares fit of a second-order polynomial. Typical precisions, expressed as the relative standard deviation for a single measurement, computed from the 
results for six aliquots processed at each level, were 0.25 ', at the 11 - and $7-\mathrm{mg}$ levels and $2 r$, at the $i-\mathrm{mg}$ level. Stability over a 1 -mont $h$ periond was excellent.

Following this calibration test. which demonstrated satisfactory operation, the inst rument was sent to the New Brunswick Laboratory (NBL). As part of the NBL evaluation, four weight aliquots of a uranium calibration solution at each of eight uranium levels over the range 1 to $12 \mathrm{mg}$ were processed each of 12 days giving a total of 384 measurements. Using a generalized least sq tares program. a second-order polynomial,

$$
f_{i}\left(x_{1}\right)=\alpha_{1}+\beta_{i} x_{j}+\gamma_{1} x_{i}^{2}
$$

Was fitted to the 32 results obtained each day. as well as to all 384 results for the 12 days. The independent variable $x$ is the instrument readout (the four-digit value proportional to the peak-minus-valley absorbances) and the dependent variable $f(x)$ is grams of uranium. Coefficients of the regression lines, calculated for each day's results and for the combined results, are given in Tiable II. The a tor interceptl coefficient has greatest effect at low uranium levels and the $\gamma$ coefficient at high urarium levels.

Comparison tests of the coeflicients $\alpha ., 3$. and $\gamma$ indicated signilicant among-day differences sven when the obviously different 12 th day data weye ex. cluded. Although significant. the among-day differences were very imall from the practical standpoint and were statistsally significant only because the within-day variations were so small. The largest within-day standard deviation was $24 \mu \mathrm{g}$ of uranium (see last column of Table 11 ) and the arithmetic mean of the standard deviation of the 12 days' dat a was $19 \mu \mathrm{g}$ of uranium.

To gain a feeling for inst rument performance over a period of time. the overall regression line was recomputed excluding the 12th day data and the deviation of each of the 352 results was computed relative to this line. The largest of 44 deviations at a uranium level was $4.7^{\prime}$ ', at $1 \mathrm{mg}, 0.78^{\prime}$; at $6 \mathrm{mg}$, and $0.87^{\prime}$ ' at $12 \mathrm{mg}$. Statistically. it can be expected that $95 '$, of the measurements would have deviations less than these values.

Also computed was the algebraic (plus or minus) deviation of the average of the four results at each of the eight different uranium levels for each day

\section{TABIE II}

\section{COEFFICIENTS OF CAIIBHATION \\ RKGRESSION I.INE $\left|f_{i}\left(x_{j}\right)=a_{i}+s_{i} x_{i}+\gamma_{i} x_{i}^{2}\right|$ AND WITHIN-DAY PRECISIONS}

\begin{tabular}{|c|c|c|c|c|}
\hline Dayy & $a$ & $d$ & 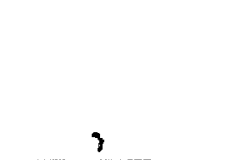 & $\begin{array}{l}\text { Within-Day } \\
\text { Standard } \\
\text { Deviation } \\
\text { (a Uranium) }\end{array}$ \\
\hline 1 & T.1.2461.46F.-11.4 & 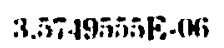 & 5.307865i3t.11 & 1.7.45.8E.-15 \\
\hline 2 & 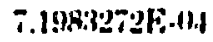 & 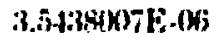 & (6.02793498.-11 & 2.3\%2:36.06 \\
\hline : & 6.982.4.4SKiF-(1). & 3.37.ANMFUP.(K) & $1.8520 ; 025.11$ & 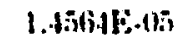 \\
\hline .1 & d.9T.10:BTE-(1) & B.BSII.AF GE.(WF & 3.0T.1316*1: 11 & 2.2 .3018 .05 \\
\hline$i$ & 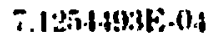 & 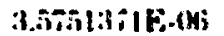 & 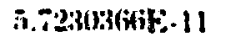 & 1.3415EF,(15) \\
\hline ; & 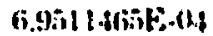 & 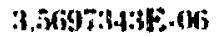 & 4.17616935:-11 & $1.27+15,-45$ \\
\hline$=$ & T.1635.5.36.019 & 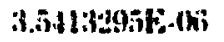 & 15.108,gestif;.11 & 1.7Mallo.di) \\
\hline 8 & 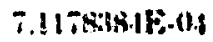 & 3. & 1.7.7xy2-F. 11 & 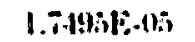 \\
\hline 9 & 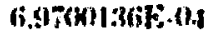 & 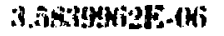 & $1.7216-1005.11$ & 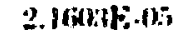 \\
\hline III & 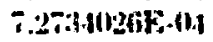 & 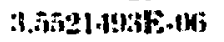 & S.60:4:231E-11 & $2.217,11,-16$ \\
\hline 11 & 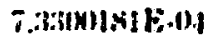 & 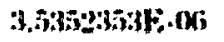 & $6.151 .12-16-11$ & 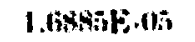 \\
\hline 12 & T.1+11.1.7F.01 & 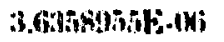 & 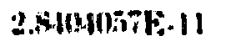 & $2.414 \times 1,0.0 \%$ \\
\hline All" & 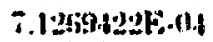 & 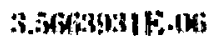 & it.20 & 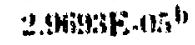 \\
\hline
\end{tabular}

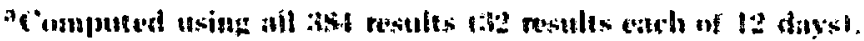

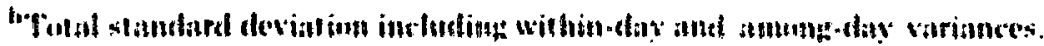


relation to this 11 -day regression line. Pigntre 4 is a phot of the aterage deviations. without reward to sign. is uranium level in which a drawn line connects the average of the average deviations. The average of the average devintions dereasess from 1).9: at the 1-mg uranium level to 0.4 , at the 2-my lesel to about 0.24, for the remainder of the range of :3 to 12 mg of uranium and the largest average deviation for any one day is $2.7^{\prime}$, at $1 \mathrm{mg} .0 .66^{\circ}$, at $6 \mathrm{mg}$. and $0 . \bar{\pi}$, at $12 \mathrm{mg}$.

Based on the above, and as fortilied by experience with the instrument prototype. a calibrution regression line can serve for extended periods. We recommend that a calibration consist of at least If measurements each made at about five different uranium levels and verified on a daily hasis by processing tuplicate aliquots at two different uranium levels, one slightly below the midrange value and the other toward the upper limit. A recommended procedure is given in Appendix $B$. sec. 1.

For purposes of comparison, precision of the analytical method was assessed using all manual operations. The operations were very similar to those described for the original method ${ }^{1}$ with the exception that 2-nitropropane was used as the organic extractant and the volumes of the saltingcomplexing solution and the organic extractant were changed to those volumes used for the automated instrument. An experienced analyst prepared a uranium calibration solution using LASL-produced highly pure uranium metal. Four weight aliquots at three uranium levels of 1,6 , and $10 \mathrm{mg}$ were processed on each of 7 alternate days giving a total of 84 measurements. The absorbance measurements were made using $1-\mathrm{cm}$ cells and a Heath 707 Recording

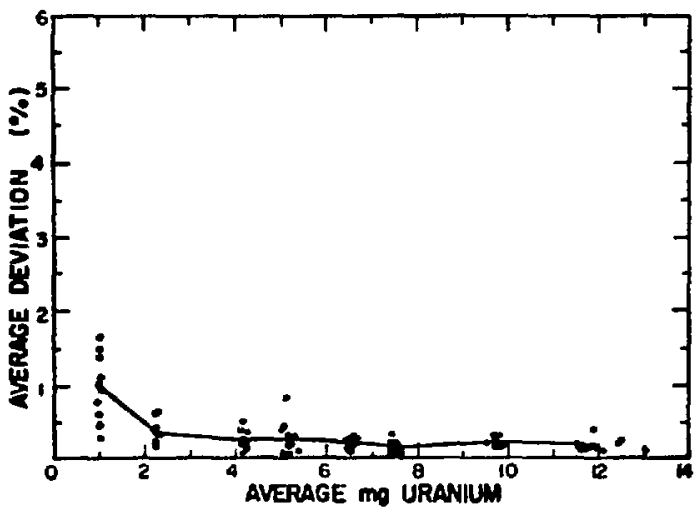

Fig. 9.

Aleragr percent deviation vs uranium level ob. tained with the automated instrument.
Sipuctrophohometer. Rostets wore computed using buth the two-wavelength calculational mole lats used in the automated inst rument ! atod the more precise three-wavelength calculational mode.

In the same masaner as the automated inst rument ditta was handled, second-order polvommials were fitled and regression lines were computed for the 84 values. In similar manmer to Fig. 9 for the data from the automated instrument. Fig. 10 presents the result if for the two calculational modes. The averages of the average deviations are $1.8,0.42$. and 0.50 rell; at the $1-\mathrm{mg}$. $6 \cdot \mathrm{mg}$. and $10-\mathrm{mg}$ levels for the threewavelength calculation. The corresponding values for the two-wavelength calculation are 4.1), (0.48, and $0.50 \mathrm{rel}^{\prime}$. Thus, the precisions of $0.9,0.30$, and 0.27 rel'; (Fig. 9) obtained with the automated instrument, in which the two-wavelength measurement system is used, are superior to those obtained by manual operations by an experienced analyst, espe:ially at the 1-mg uranium level. For the manually obtained data, the among-day difference also was significant at the $6-\mathrm{mg}$ and $10-\mathrm{mg}$ uranium levels.

Because the advanced model of the automated spectrometer was sent to NBL, an instrument prototype. installed in a glovebox. was used to develop the operational procedure for the determination of plutonium that is described in Appendix B. During the course of development, a calibration was obtained using a solution prepared from LASLproduced highly pure plutonium metal. A major difference between the prototype and the instrument supplied. to NBL was the readout system. The prototype had a cruder system compared to the micrcocomputer system of the instrument supplied to NBL. In the prototype, the detector output was converted to a value proportional to absorbance by a

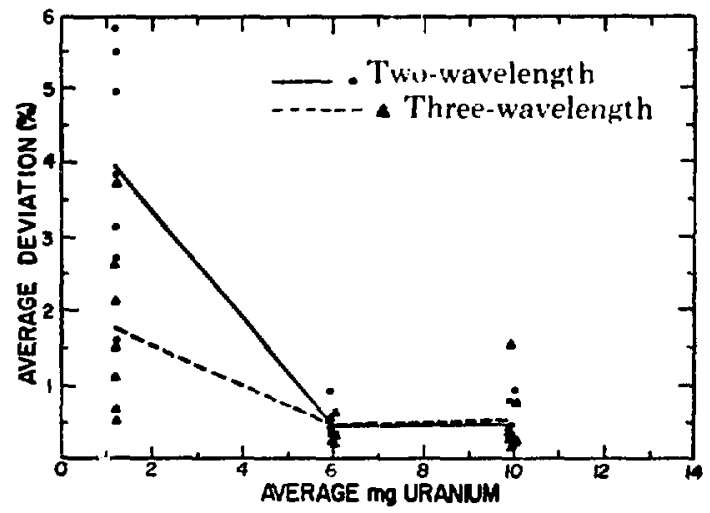

Fig. 10.

Average percent deviation vs uranium level using all manual operations. 
current-to-voltage converter and a diode log converter. the analog signal was made digital with a voltage-to-frequency converter, and the resulting pulse train was counted on a reversible counter. The gate to the counter was controlled by a separate timer. A 10-position adjustable cam switch controlled the readout timing sequence. Although this system performed satisfactorily, it was not as precise as the microcomputer system, primarily because of errors associated with the diode log converter and the gate-control timer. Also, limitations of the amplifier-log converter in the prototype restricted the upper limit of the measurable !evel to $8 \mathrm{mg}$ of plutonium whereas the microcomputer system is predicted to apply to an upper level of $14 \mathrm{mg}$. The lower limit for both instruments was $0.5 \mathrm{mg}$ of plutonium. The relative standard deviations were $2.0 \%, 0.62 \%$, and $0.25 \%$ at the $i-\mathrm{mg}, 3-\mathrm{mg}$. and $i-\mathrm{mg}$ levels. computed from six measurements at each level. As in the case of uranium a second-order polynomial gave an excellent fit.

\section{APPENDIX A}

\section{PREOPERATIONAL INSTRUMENT ADJUSTMENTS AND TESTS}

Preoperational tests, and adjustments if necessary, are required for (a) the reagent delivery system, (b) level of light source inten.ity, (c) orientation of the interference filters, (d) sample tube optical path length reproducibility, and (e) overall operational reliability.

\section{REQUIRED SERVICES}

Electrical power required is $120 \mathrm{~V}, 15 \mathrm{~A}, 60 \mathrm{~Hz}$. A 2.7-atm compressed air or nitrogen supply is required. Ambient air temperature should be maintained constant. The measured absorbance decreases about $1{ }^{\prime} \%$ per $4^{\circ} \mathrm{C}$ temperature rise.

Before plugging into electrical power, all instrument cables must be connected. The HV-OLT connector is at $-200 \mathrm{~V}$ when the instrument is connected to power.

\section{REAGENT DELIVERY SYSTEMS}

The delivery volumes of the three systems used to dispense the salting-complexing solution, the organic extractant, and the organic-phase raising solution are adjusted by stop positions on the hydraulic cylinders. A practical way to establish the delivery volumes is to use a sample tube scribed at :3$\mathrm{m} /$ (organic solvent) and 4-m/ (salting-complexing solution) volumes. (The establishment of the delivery volume for the organic-phase raising solution is described later.) Refer to Appendix $D$ for electrical system diagrams. The delivery systems are manually activated by (a) disconnecting one lead on switch 2 of the Sequencer to inactivate the drive motors. (b) momentarily pressing the START button to activate the enabling relay, and (c) manually activating switch 3 on the Sequencer to deliver the salting-complexing solution or switch 4 to deliver the organic extractant. The needle valve that controls the delivery rate must be adjusted so that the syringe plunger moves smoothly and delivers the reagent in a steady stream with no splashing.

The tip of the salting-complexing solution dispenser is adjusted to deliver the solution at a vertical position near the top of the tube and at a radial position $90^{\circ}$ from the optical path. The tip of the organic extractant dispenser is adjusted so that the delivered strecin strikes the tube wall just above the mixture of salting-complexing solution and sample aliquot. A delivery rate that is too fast wili "ause liquid t" splash from the tube wall resulting in droplets adhering to the wall. A rate that is too slow will cause splashing at the liquid surface as well as a droplet retention at the tip of the dispenser. Both these effects are causes of poor precision.

Delivery precisions are best estahlished by mul. tiplicate deliveries into tared tubes which are stoppered and weighed. We have attained a relative st andard deviation for a single delivery of less than $0.02^{\prime} ;$ for both reagents brised on at least 19 measurements.

The tip of the dispenser that delivers the oryanicphase raising solution is adjusted to deliver a stream with no splashing at a vertical position near the top of the tuhe and at a radial position $90^{\circ}$ from the op. tical path. Volume delivered is adjusted to raise the 
center of the organic phase to a position $6.75 \mathrm{~cm}$ above the bottom of the tube. Manual delivery for this test is attained by activating the tube-sensing switch at thisstation followed by switch 5 on the Sequencer.

\section{II: LIGHT SOURCE INTENSITY LEVEL AND POSITIONING OF FILTERS}

The light source intensity level and positioning of filters are interrelated and their adjustments must be done interchangeably. To make these adjustments, filter and shutter positioning must be controlled manually. Plug a PROM loaded with the Manual Control Program (see Appendix F) into socket 21-31 (see Fig. E.1 for its location) after turning off the Photometric Control and Readout Unit. All readout operations are manually controlled with the eight toggle switches that are mounted inside the front panel of the Readout Control Unit. Turn on the power to the Photometric Control and Readout Unit and to the light source and allow them to warm up for at least $1 \mathrm{~h}$ before making any adjustments.

Set the selector switch on the front panel to position 1 for the measurement of uranium. Set toggle switch 0 to $O N$ to move the filter for the uranium peak measurement into the optical light path. Set a potential of $5.5 \mathrm{~V}$ acioss the lamp for the following preliminary adjust ment of the peak and valley filters fir the uranium measurement. Process a calibration aliquot containing about $10 \mathrm{mg}$ of uranium in the usual manner (see Table B-11). After the tube is in the readout chamber, set toggle switch 2 to OFF to open the shutter. and toggle switch 6 to $O N$ to init iate photodiode current measurements which are displayed on the front panel difital meter. IRemove the screws holding the top cover on the monuchromator section and slicle the cover back to gain access to the interterence filter holders. Slide the cover hack jusl enough to :nake the adjustments. liecep the eover in the closed position except when making adjustments 10 maintain collstant cemperature inside the nonochromator. Ioksen the retaining screw on the filter bolcter that is in the op). :ical path and carefully rotate the filter to olsain minimum, current (ecpuivalene to maximusn poak ab). sorbancel. Tighten the retaining serew making sure that the minimum currebt value is momenined. Simultaneously set toggle switc's o to OFF and tonghle swilch i lo OX in mive the peak filter from the light path and replace it with the valley fiiler without their colliding with one another. Iakesen the retainimg serew on the valley lileer and carefully rotate the filter fo olotsin maxiznum current te- quivalent to minimum valley absorbance). Tighten the retaining screw, again making sure that the maximum current value is maintained. Close the cover and tighten its retaining screws. Set toggle switch 2 to $\mathrm{ON}$ to close the shutter.

The two pairs of plutonium filters are adjusted as described above using an extracted 10-mg quantity of plutonium. Selector switch positions 2 and 3 on the front panel control the filter pairs at the 501.4$\mathrm{nm}$ peak and $807.0-\mathrm{nm}$ peak positions, respectively. Toggle switches 0 and 1 again control the peak and valley filters at each of these two wavelengths.

After the preliminary adjustment of filters, the power supply for the lamp is adjusted to provide a high photodiode current consistent with the capacity of the analog-to-digital converter. Follow the manufacturer's instructions for the power supply operation. During this adjustment, monitor the voltage on the lamp and do not apply a voltage greater than $6.8 \mathrm{~V}$. For the power supply adjustment. use a tube containing a processed blank of 0.5 $\mathrm{m} /$ of $8 \mathrm{M} \mathrm{HNO}_{3}$ in the readout chamber. Set toggle switch 2 to OFF to open the shutter. Measure the photodiode current with the uranium and plutonium (518.0-nm) valley filters. If the currents (proportional to transmittance) agree to $10^{\prime} i$, proceed to make the final power supply adjustment as described later. If the currents disagree by more than $10 \%$, neutral density filters or a screen mask are added to both filters of the pair that have the largest transmittance to attain this digree of agreement. Make the final power supply adjustment using the valley filter with the largesi transmittance to attain a photodiode current closest to a reading of 1900 so long as the applied voltage does not exceed $6.8 \mathrm{~V}$. This completes the adjustment of the lamp intensity.

Readjust (line tune) all (ilter positionings using uranitım and plutonium solutions as described previously.

\section{SAMPIE TUBE OPTICAL RATH LENGTH}

All simple tubes are tesled for optical path iengt h. 'The recommended rejection crilerion is $0.1 \%$; relative (i) the avernge.

A convenient measturement pechnique is 10 prepare a large-batch uranium extraction at a con). centration of $10 \mathrm{mg}$ of uranium per il $\mathrm{m} /$ of the organic phase. Add $15 \mathrm{~m} / \mathrm{of}$ saturated Al(NO: (Apqerdix B3. Sec. Il.ß\}) followed by $5 \mathrm{~m} /$ of the arganic phase cont aining the extracted uranium into a twhe to be rested. Place this I ulo into a possition on tho curmoble, lensen slighlly the turntable locking 
nut, manually release the spring-loaded turntable lock, and manually rotate the turntable counter. clockwise to position the tube under the readout chamber. (Be careful not to rotate the turntable clockwise because the sample designation switches will be damaged.) Set the selector switch on the front panel to position 1 for the measurement of uranium. 'Hold the turntrible t"' prevent its rotation and activate the instrurient S'CART switch to at tain the absorbance measurement. After completion, remove the tube and repeat the sequence for each tube to be tested.

\section{OVERALL OPERATIONAL RELIABILITY}

An effective means to assess overall operational stability of the instrument is to process a series of aliquots of a uranium (or plutonium) calibration solution. This processing can be part of the initial, or a later period, calibration. We recommend processing a minimum of 10 aliquots at each of three levels (such as 2,6, and $12 \mathrm{mg}$ of uranium). Acreptable operational reliability can be decided by comparison to the accuracy and precision data presented in Sec. IV. Factors that cause unreliability include faulty reagent (especially the organic extractant) deliveries, improper time sequencing, inadequate stirring, inadequate ambient temperature control, out-of-specification sample tubes, and malfunctions in the readoci system. The reagent deliveries and sample tubes can be tested as described previously. The stirrer should rotate at $1200 \mathrm{rpm}$; this can be verified with a strobe light. The total readout system can be tested by making repeated measurements on one ext racted sample in one sample tube. Care must be used in interpreting these readings because some drift will be normal, due to heating the solution.

\section{APPENDIX B}

\section{OPERATIONAL PROCEDURES FOR URANIUM AND PLUTONIUM DETERMINATION}

The procedures given in this appendix are recommended for the determination of uranium and plutonium. Included are calibrations and their daily verification and instructions for cleaning tubes in a glovebox.

\section{CALIBRATION AND ITS VERIFICATION}

Wo recommend processing at least 10 aliquots of five levels each of a uranium and of a plutonium calibration solution following the procedures described later in this appendix. The levels should he spaced over the range of 1 to $14 \mathrm{mg}$ of uranium and 0.5 to $1 . t \mathrm{mg}$ of plutonium. A regression line should be computed for a second-order polynomial as described in Sec. IV for both uranium and plutonium.

Fach day that samples are to be analyzed, we recommend the processing of two aliquots $n t$ each of (ww) levels of the urnnium or plutonium calibration solution, as appropriate. Suggested levels are: one about midway letween the range center and the sensitivity limit and the other toward the upper linit. i.e., about 4 and $11 \mathrm{mg}$ for uranium or plutonium. lieject limits are calculated from the calibration data. ${ }^{5}$ For the 12-day calibraticn data presented in Sec. IV for uranium. Table B-I presents $95^{\prime}$; confidence upper and lower limits for the alerage of two measurements over the uranium range of 1 to $12 \mathrm{mg}$. The plot of allowable deviation as a function of the quantity of uranium is presented in Fig. B-1. This plot demonstrates that use of a quantity of uranium close to the sensitivity limit for verification purposes leads to high relative uncertainty. To establish more effectively whether the calibration is shifting. contro! charts should be prepared and used for each of the two verification levels. If aliqunts are delivered by weight, the quantity of uranium at a level will vary and, in this case, the quality control chart is prepared most easily by using relative percent limits. In use. when the two averages are within limits, the calibration is consider, $\mathrm{d}$ verified. In our laboratory. when either average is ous side linils, all four measurements are repeated. If both averages are now within limits, the calibration is considered verified. If, however, either average is again outside limits, operations are suspended and an investigation is undertaken to find cause for a malfunction. After correcting the cauze, the calibration verifica. tion is repeated and used as the criterion for sat isfactory operation. Certain corrections inay cause a shift 
TABLE B-I

\section{ACCEPTANCE LIMITS ${ }^{a}$ FOR VERIFICATION \\ OF CALIBRATION FOR URANIUM DETERMINATION}

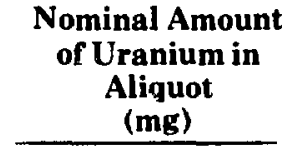

1

2

3

4

5

6

7

8

9

10

11

12

\begin{tabular}{c}
$\begin{array}{c}\text { Lower Limit } \\
\text { (mg U) }\end{array}$ \\
\hline \\
\\
0.9608 \\
1.9611 \\
2.9612 \\
3.9612 \\
4.9612 \\
5.9612 \\
6.9612 \\
7.9612 \\
8.9612 \\
9.9611 \\
10.9610 \\
11.9607
\end{tabular}

\begin{tabular}{r}
$\begin{array}{c}\text { Upper Limi } \\
\text { (mg U) }\end{array}$ \\
\hline \\
1.0392 \\
2.0389 \\
9.0388 \\
4.0388 \\
5.0388 \\
6.0388 \\
7.0388 \\
9.0388 \\
9.0388 \\
10.0389 \\
11.0390 \\
12.0393
\end{tabular}

"At a 95 "; confidence level tor the average of two measurements.

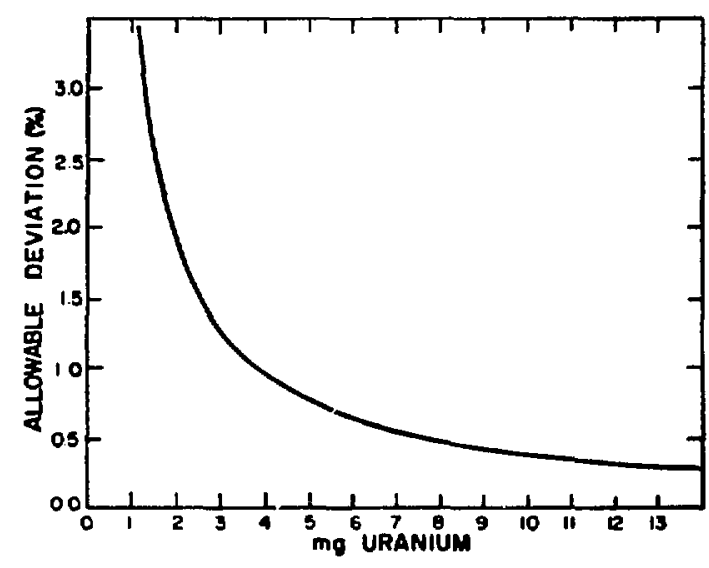

Fig. B-l.

limits for verification of a calibration.

in the instrument response to require the preparation of a new calibration.

\section{REAGENTS}

The organic extractants 2-nitropropane and MIBK, and the tetrapropylammonium hydroxide were obtained from Eastman Kodak Company and used without purification. All other chemicals used are analytical reagent grade. Quartz-distilled water and acids were used at all times. The uranium and plutonium calibration solutions were prepared from NBS . ;RMs or equivalent. Uranium oxide or metal was dissolved in nitric acid and diluted to the desired concentration (on a weight basis) using $8 M$ $\mathrm{HNO}_{3}$. Plutonium metal was used as described by Swanson et al. ${ }^{6}$ The two solutions that require special preparation are the salting-complexing solution and the organic-phase raising solution.

Silver (ll) oxide ( $\mathrm{AgO}$ ) powder was obtained from K \& K laboratories, Inc., Irvine, CA. Cylindrical pellets (1-mm thick, $3.2-\mathrm{mm}$-diam) weighing $40 \mathrm{mg}$ were prepared from the powder in a Parr Pollet Press using a 1/8-in. $(3.2-\mathrm{mm})$ die.

\section{A. Salting-Complexing Solution}

Weigh $1050 \mathrm{~g}$ of $\mathrm{AL}\left(\mathrm{NO}_{3}\right)_{11} \cdot 9 \mathrm{H}_{2} \mathrm{O}$ in a 2.1 heaker. add water to a volume of $800 \mathrm{~m} /$, and heat. After dissolution slowly add $135 \mathrm{~m} /$ of concent rated $\mathrm{NH}_{4} \mathrm{OH}$. Stir until the aluminum hydroxide precipitate dissolves. Cool to below $50^{\circ} \mathrm{C}$, add $50 \mathrm{~m} /$ of $10^{\circ}$; tetrapropylammonium hydroxide, and stir until the 
precipitate is dissolved. Measure the volume of solu. tion. then determine the free acid concentration. ${ }^{4}$ Add the calculated volume of concentrated $\mathrm{NH}_{4} \mathrm{OH}$ to increase the basicity to $2 N$. Transfer to a $1-1$ volumetric flask and dilute to volume with water. The final composition of the solution is $0.025 \mathrm{M}$ tetrapropylammonium hydroxide-2.8M $\mathrm{Al}\left(\mathrm{NO}_{3}\right)_{3-}$ $2 \mathrm{M} \mathrm{NH}_{4} \mathrm{OH}$.

\section{B. Organic-Phase Raising Solution}

Add water to $\mathrm{Al}\left(\mathrm{NO}_{3}\right)_{3} \cdot 9 \mathrm{H}_{2} \mathrm{O}$ stirring vigorously; stop the addition before complete dissolution is attained. After the mixture warms to ambient temperature. decant the solution. Let it stand for about 2 days and, if a precipitate forms. add sufficient water to dissolve it. Do not use a supersaturated solution in the instrument.

\section{PROCEDLIRES}

Before processing any samples, including calibration aliquots, cycle at least two empty tubes on the instrument to flush all reagent lines. The procedure for uranium sample processing is given in Table BII: plutonium sample processing is given in Table BIII.

\section{CLEANING OF TUBES}

After analysis, remove the liquid by surtion to a recovery bottle in the glovebox. Rinse the tube sequentially with 2-nitropropane (or MIBK if it has been used as the extractant), twice with water, and finally with acetone, aspirating to the recovery botthe between each rinse. Introduce the rinses in small quantities to and around the upper periphery of the tubes by directing a stream from a plastic squeeze bottle. 
TABLE B-II

\section{IRANIUM SAMPLE PROCESSING}

Operation

1. Deliver a sample, preferably $0.5 \mathrm{~m} /$ or less, containing 1 to $1 \mathrm{fmg}$ of uranium, into a tube.

2. If necessary, add $1 M$ $\mathrm{HNO}_{3}$ to increase the volume to $0.5 \mathrm{~m}$.

3. Add a $2.5-\mathrm{cm}$-long by 1 cm-diam, cylindrical, Teflon-covered, stirring bar.

4. Transfer the tube to the instrument.
Comment

Weight or volume deliveries may be used. If the volume is greater than $0.5 \mathrm{~m} /$, evaporate to $0.5 \mathrm{~m} /$ or less in the tube. The maximum volume of sample added to a tube is $4 \mathrm{~m} /$ and sequential 4-m/volumes can be evaporated. See Sec. II for a dis. cussion of this aspect of the analysis as well as a discussion of interference and tolerances.

Use an external magnet and guide the stirring bar to the tube bottom to avoid splashing.

Record the tube position and sample designation. Load tubes clockwise start ing at the position adjacent to the mixer station. If the tube is placed in a position following an empty position, activate the momentary contact switch on the front panel to reset the sensing mechanism when the tube rotates to the mixing station.

5. Set the filter set switch to position 1.

6. Start the inst rument operation by activating the momentary contact switch on the front panel. 


\section{PLUTONIUM SAMPLE PROCESSING}

\begin{abstract}
Operation
1. Dejiver a chloride-free sample. preferably of $0.5 \mathrm{~m} / \mathrm{or}$ less, containing 0.5 to $14 \mathrm{mg}$ of plutonium. into a tube.
\end{abstract}

\section{If necessary, add $1 M$}

$\mathrm{HNO}_{3}$ to increase the volume $100.5 \mathrm{~m} /$.

3. Add an AgO pellet and immediately lay the tube in its side.
4. Add a $2.5-\mathrm{cm} \cdot \mathrm{long}$ by $1-\mathrm{cm}$ diam. cylindrical. Tefloncovered, stirrir.g bar.

5. Transfer the tube to the inst rument.
6. Set the filter set switch to position 2 or 3 .

7. Start the inst rument operation by activating the momentary contact switch on the front panel.
Comment

Weight or volume deliveries nay be used. If the volume is greater than 0.5 $\mathrm{m} /$, evaporate to $0.5 \mathrm{~m} /$ or less in the tube. The maximum volume of sam. ple added to a tube is $4 \mathrm{~m} /$ and sequential $4 \cdot \mathrm{m} /$ volumes can be evaporated. Fume chloride-cont aining samples to dryness twice with $0.5 \mathrm{~m} /$ of $16 \mathrm{M} \mathrm{HNO}$. then dissolve the residue in $0.5 \mathrm{~m} /$ of $2 M \mathrm{HNO}$. . Siee Sec. II for a dircussion of this aspect of the analysis as well as a discussion of interferences and tolerances.

Leave the tube in its horizontal side position during the entire reaction to restrict spattering to the opposite wall of the tube. Complete oxidat ion is indicated when the solution remains dark brown for several secunds after the AgO dissolves. Add additional $\mathrm{AgO}$ pellets, if necessary, to at ain this condition.

Use an external magnet and guide the stirring bar to the tube bottom to avoid splashing.

Record the tube position and sample designation. Load tubes clockwise starting at the position adjacent to the mixer station. If the tube is placed in a position following an empty position. activate the momentary cont act switch on the front panel to reset the sensing mechanism when the tube rot ates to the mixing station.

Normally use position 2 for the more sensitive measurement. Use position 3 for chromium-cont air ing samples (see Sec. II). 


\section{APPENDIX C \\ MECHANICAL COMPONENTS}

Reduced engineering drawings of the mechanical portion of the automated spectrophotometer are provided in this appendix. The full-size engineering drawings may be ordered from the Technical Infor- mation Center in Oak Ridge, TN.* These full-size drawings provide adequate information for construction by experienced machinists.

"See last page of report for information about ordering full-size engineering drawings.

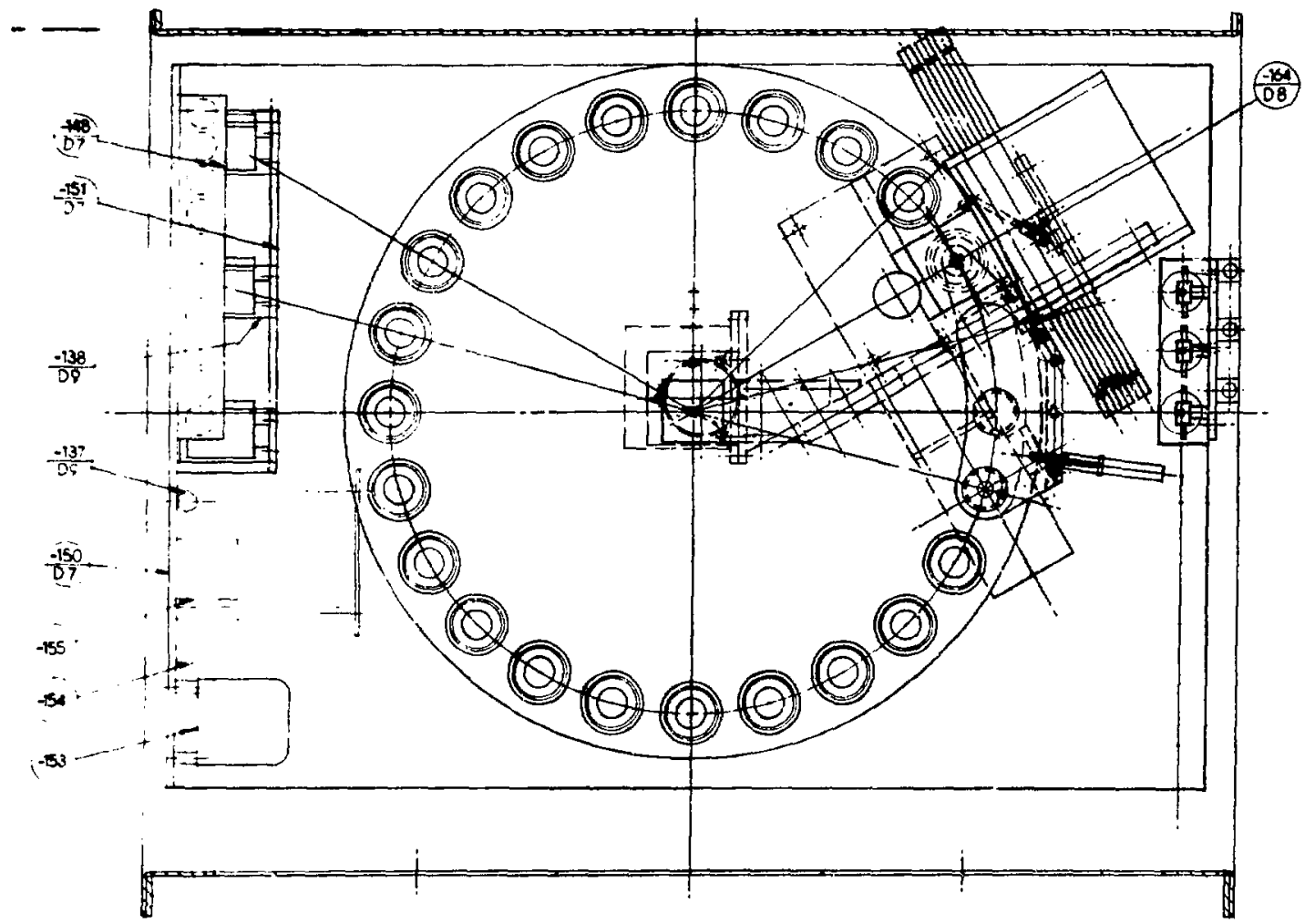

a. Top view.

Fig. C-1.

General layout of automated spectrophotometer. 


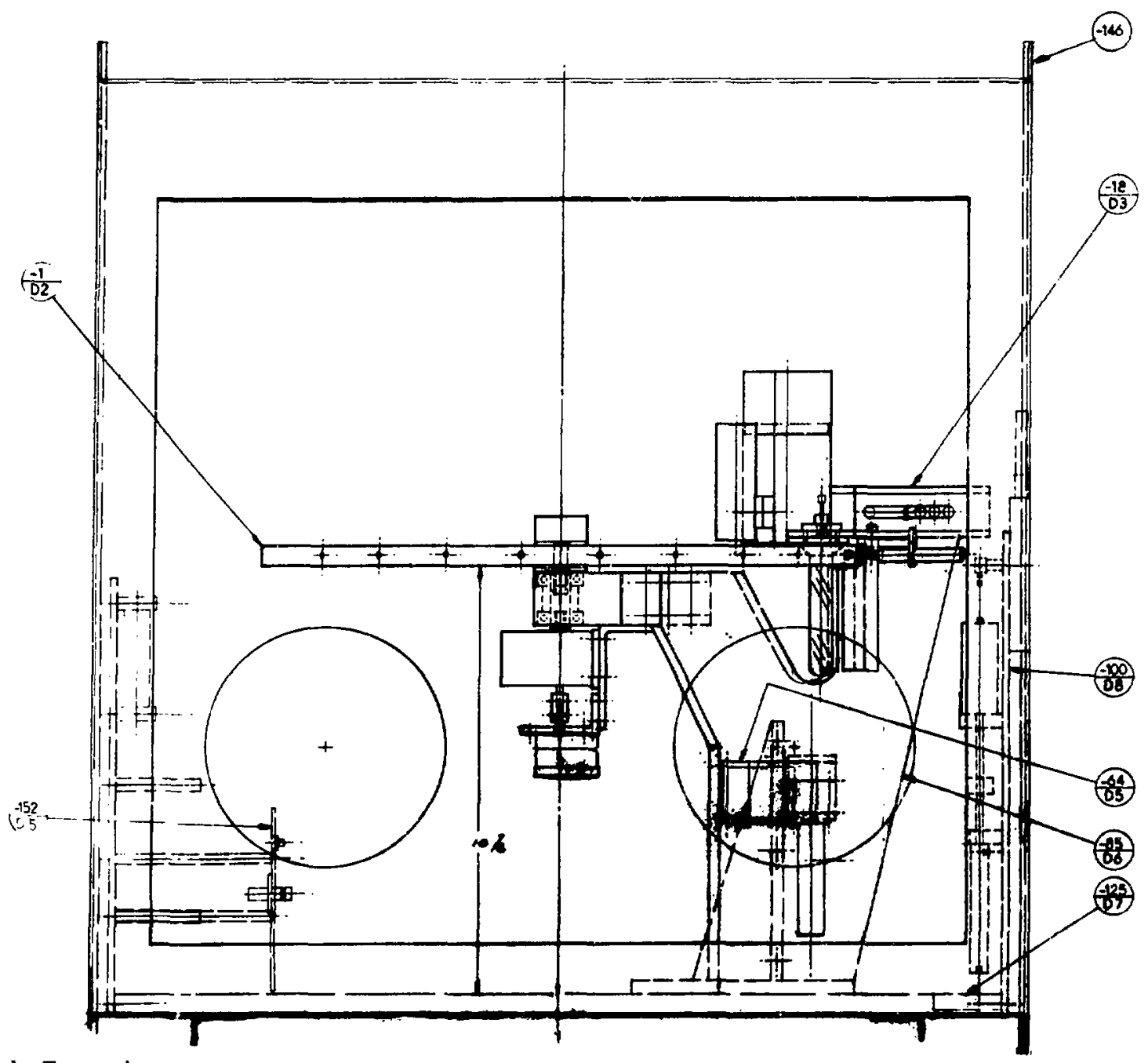

b. Front view.

Fig. C-1 (cont).

General layout of automated spectrophotometer. 


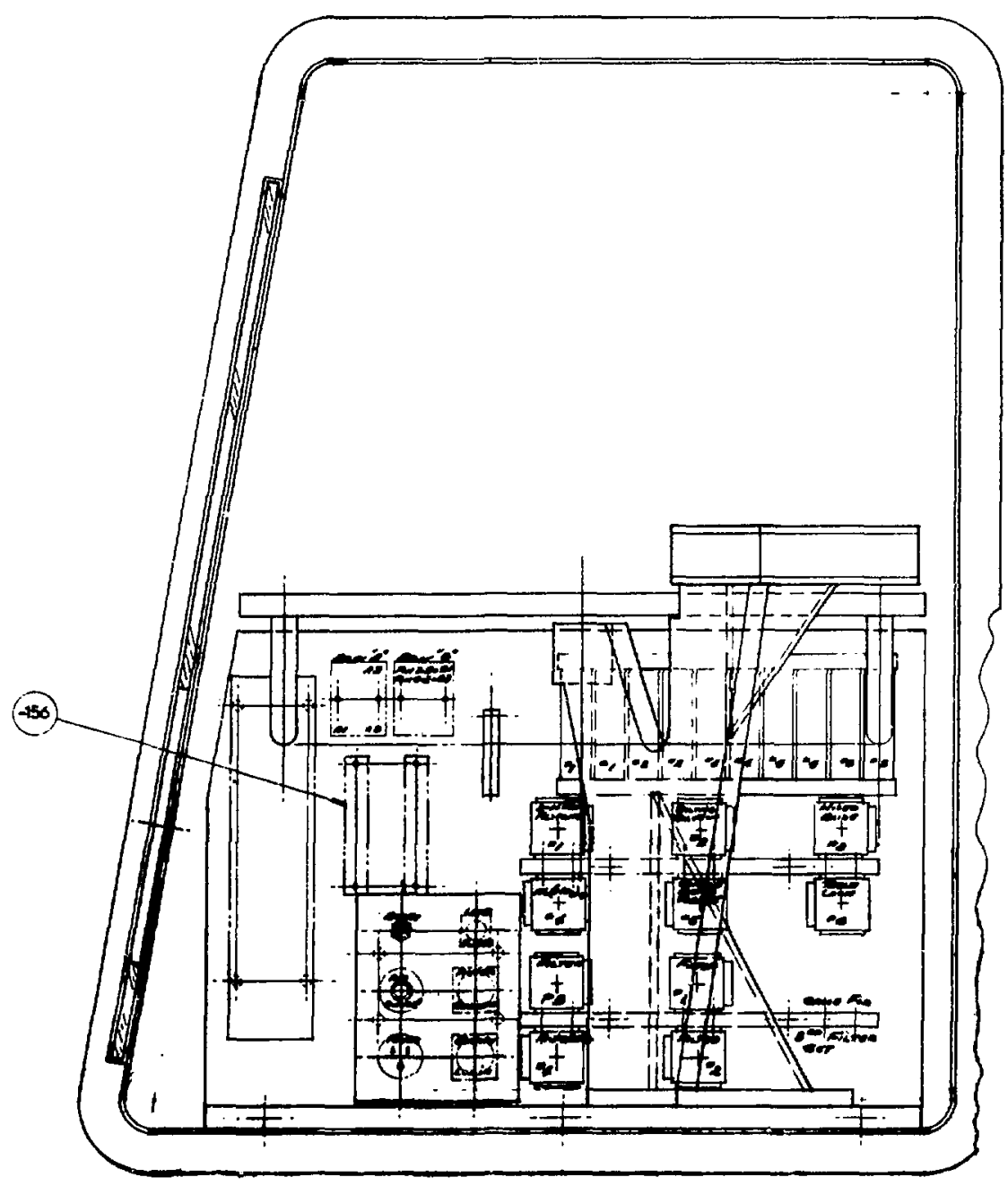

c. Side view.

Fig. C-1 (cont).

General layout of automated spectrophotometer. 


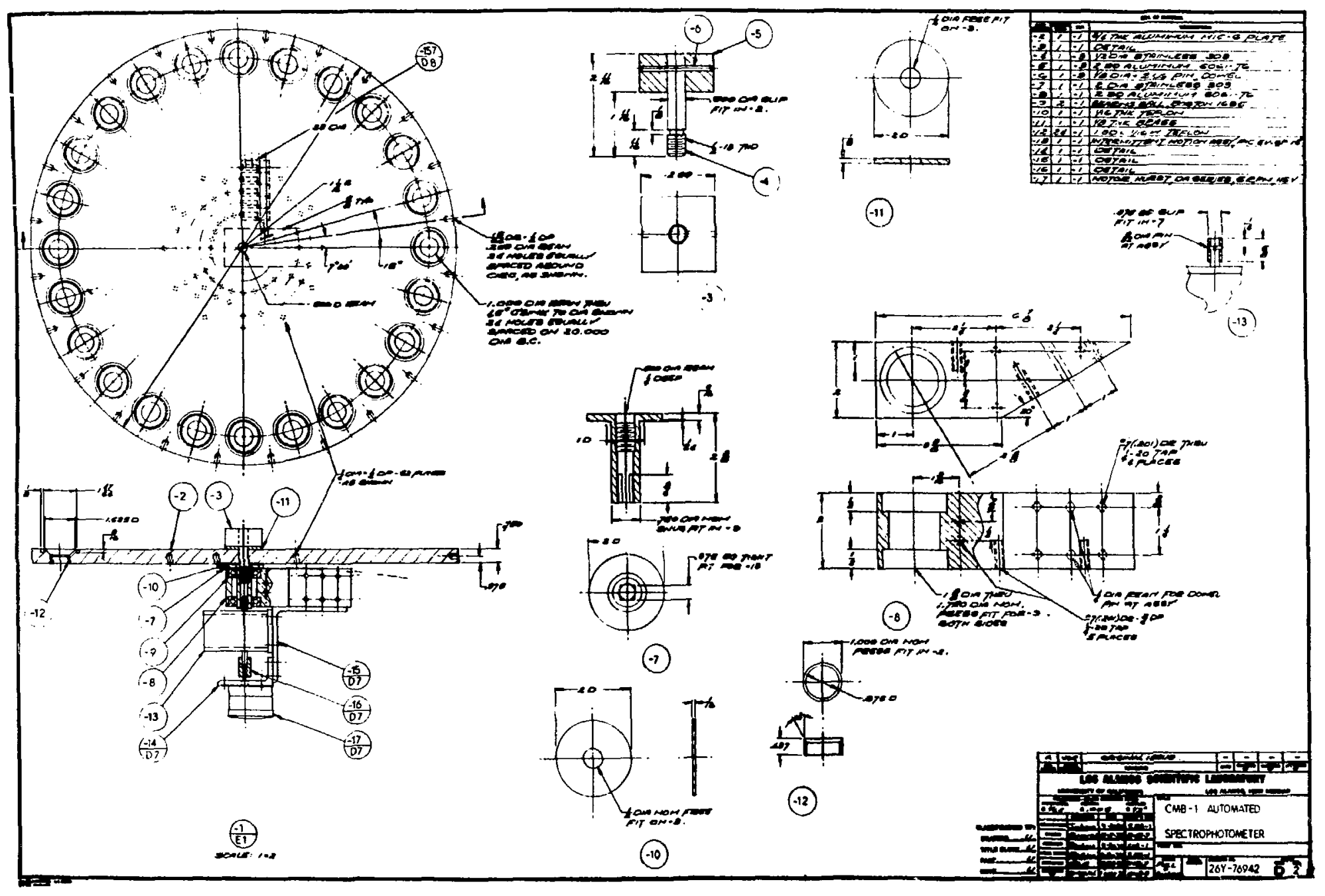




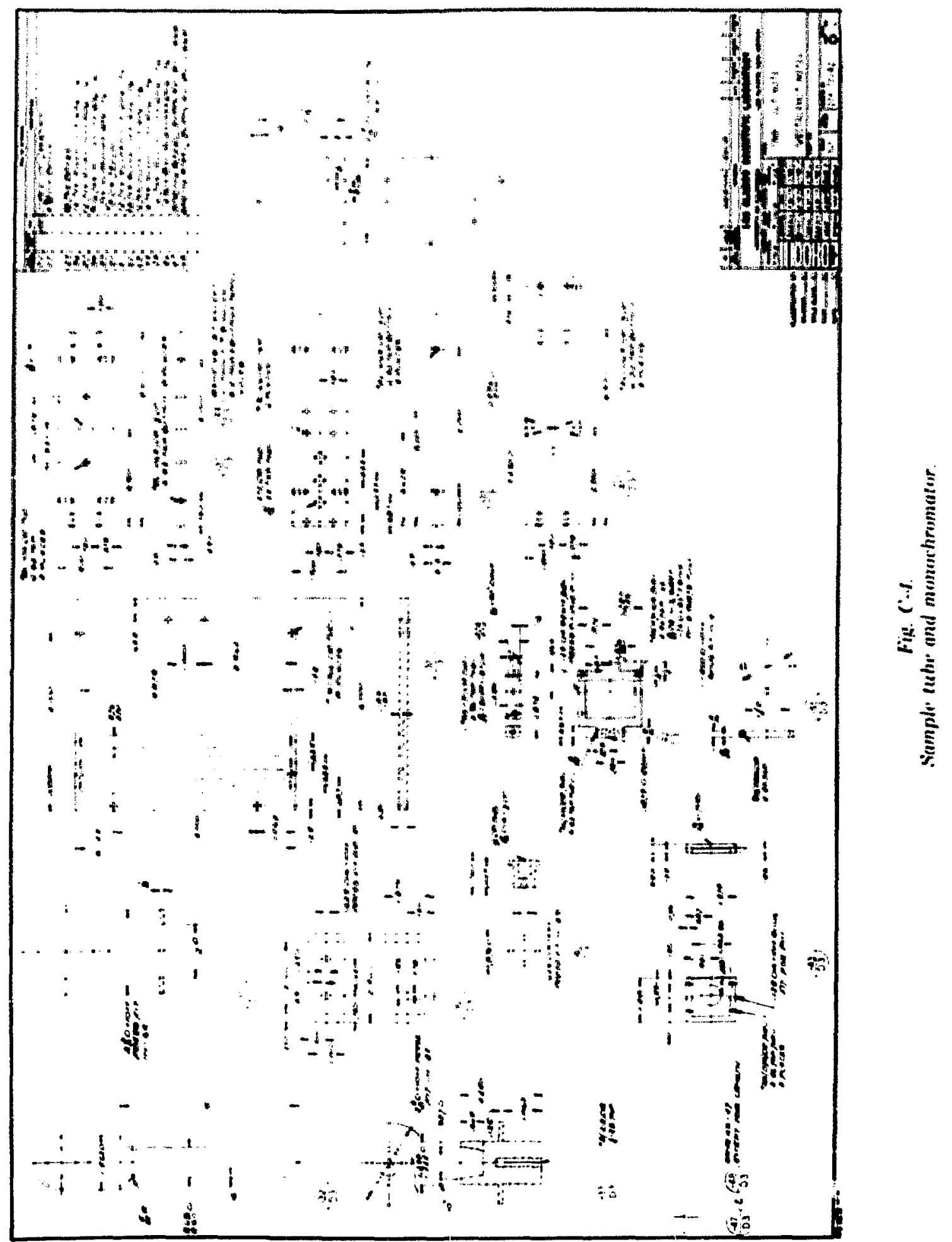




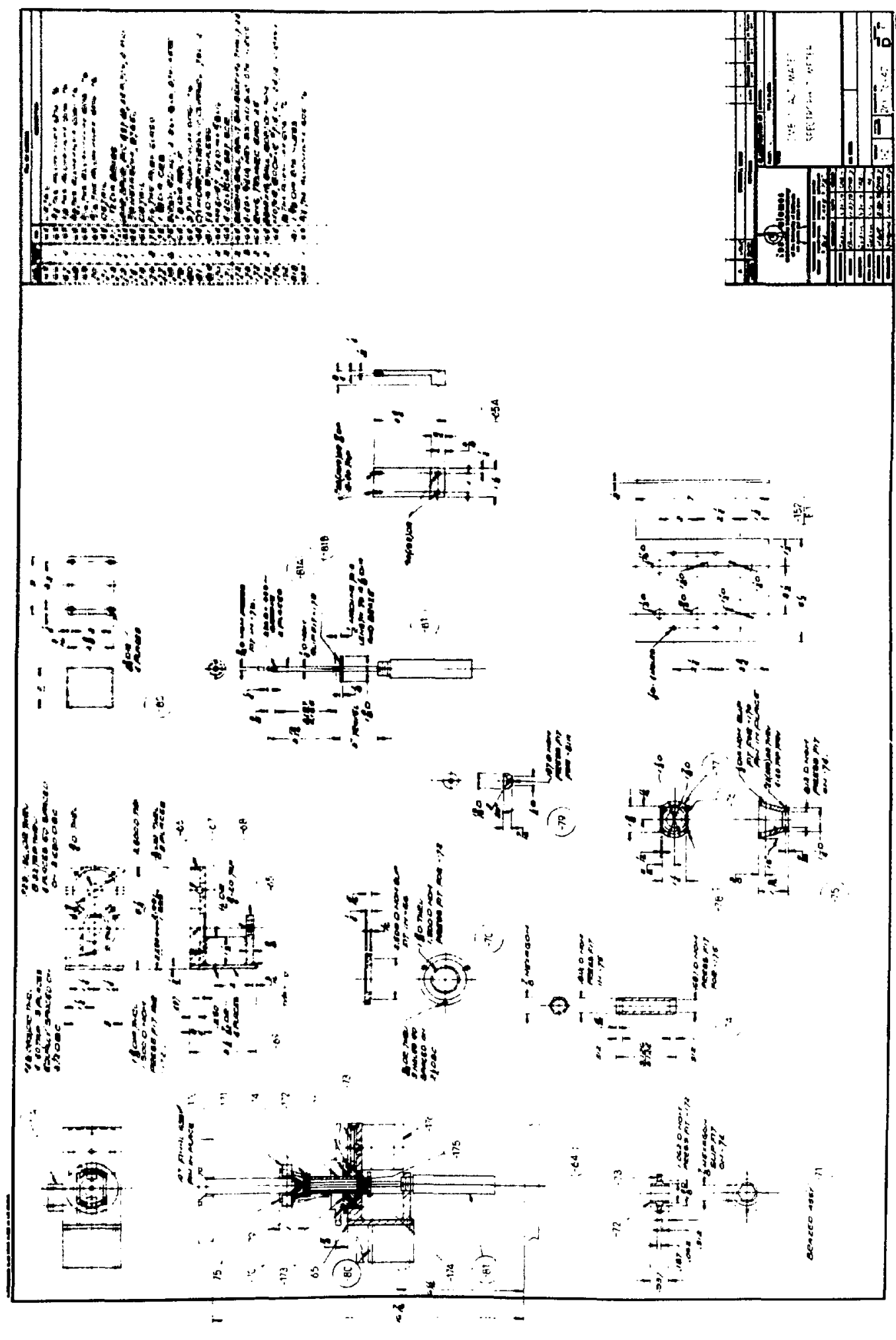

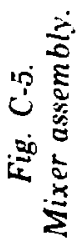




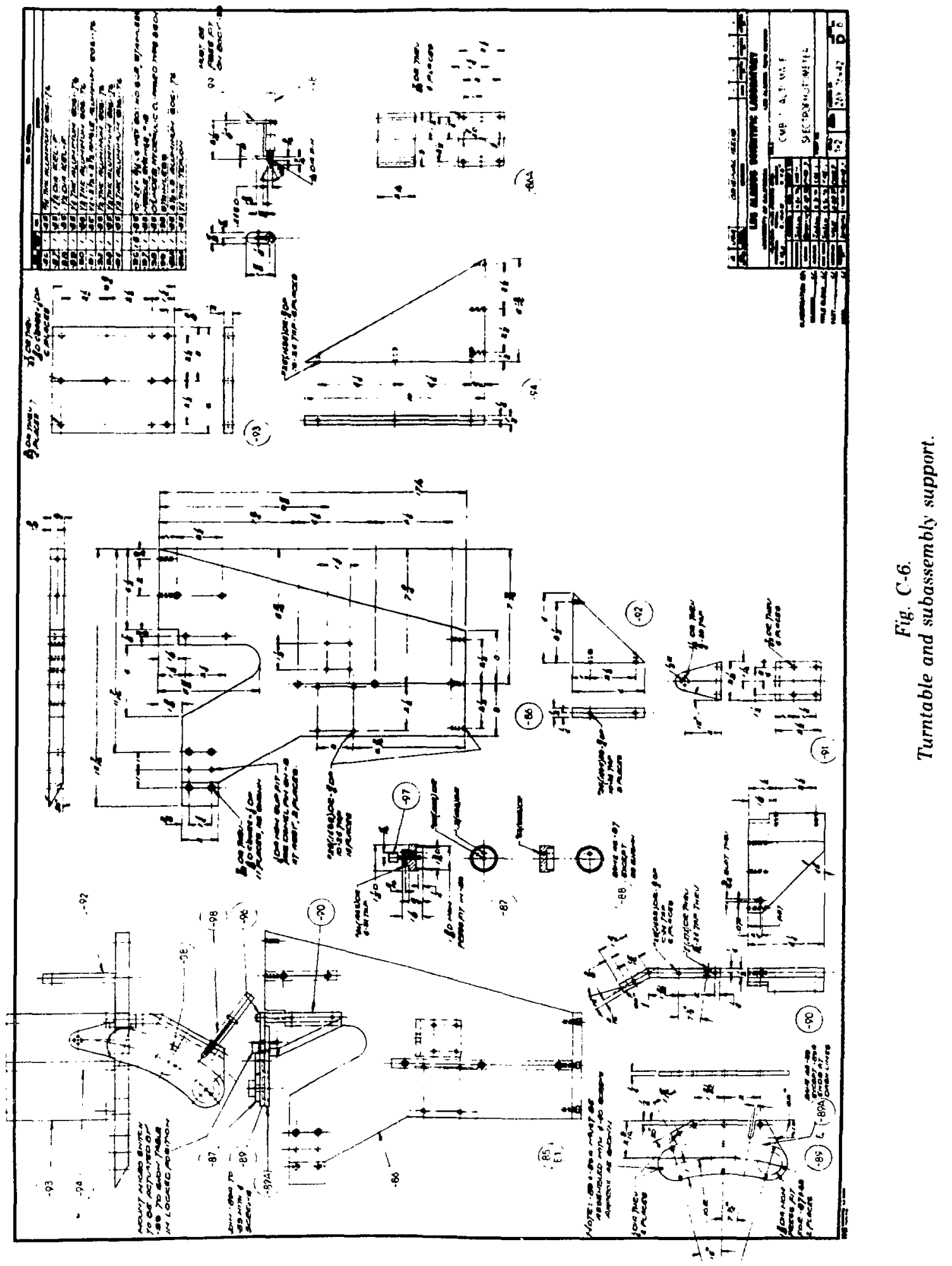




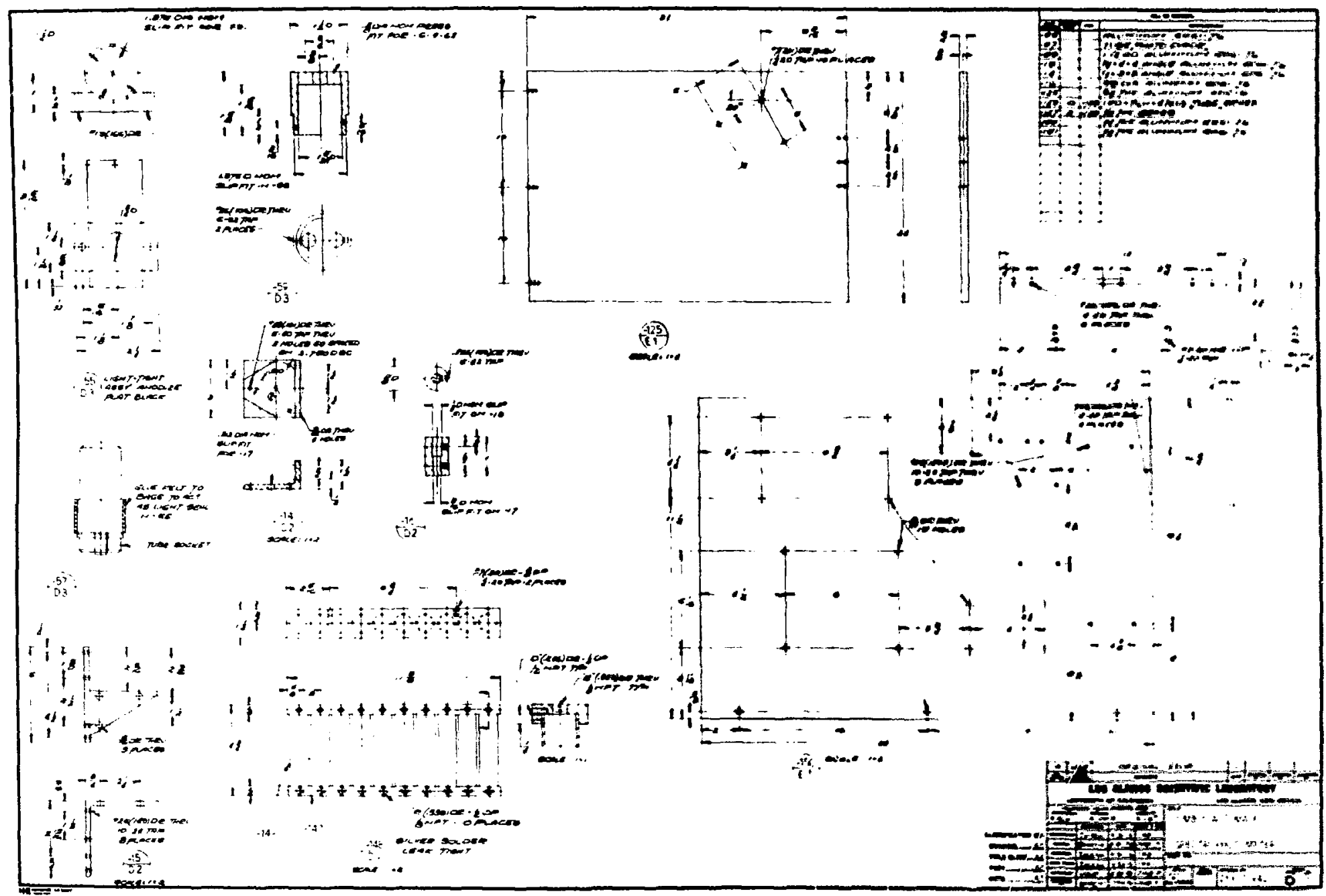

Fig. C.7.

Instrument base and photodinde holder. 


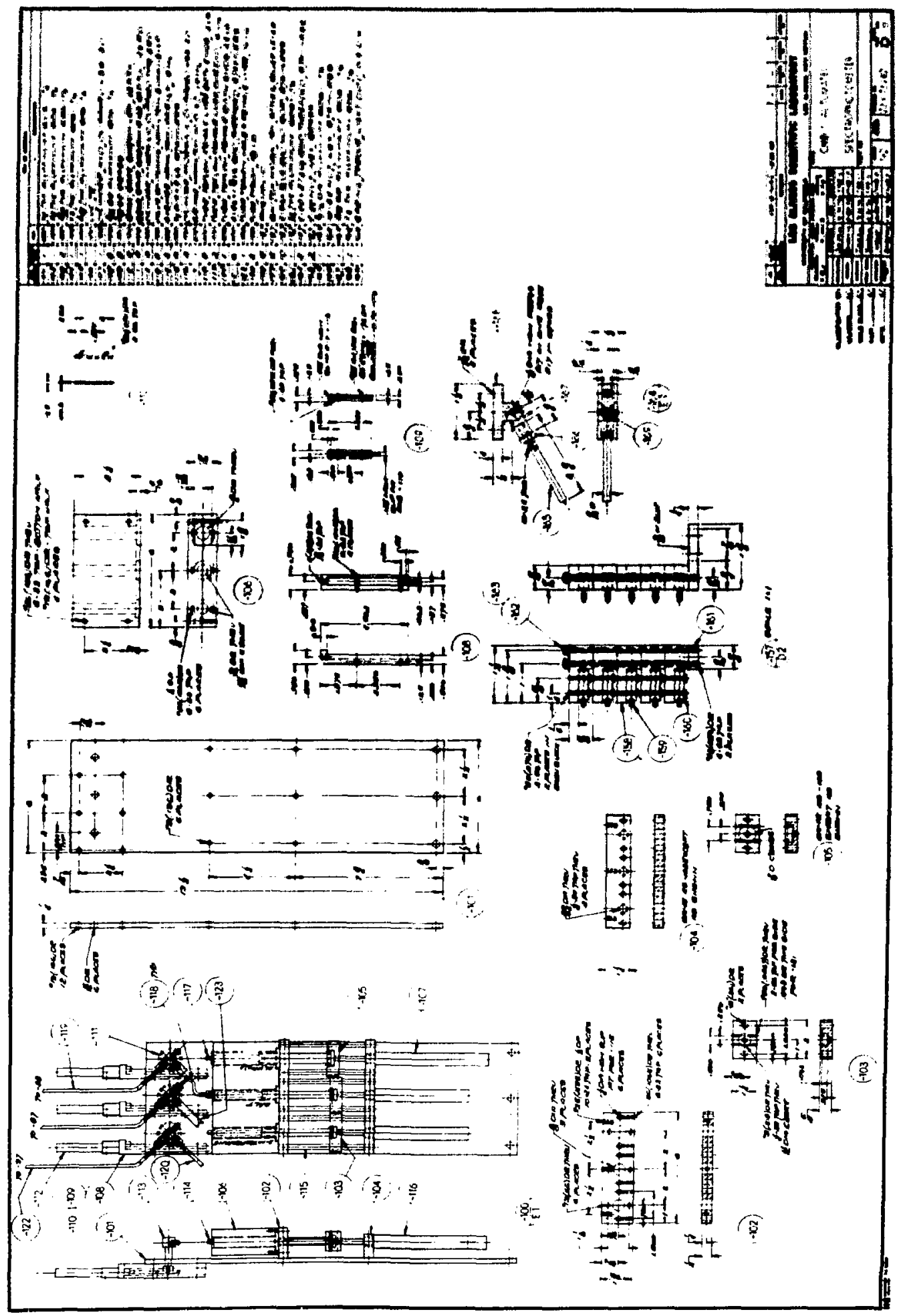

告 


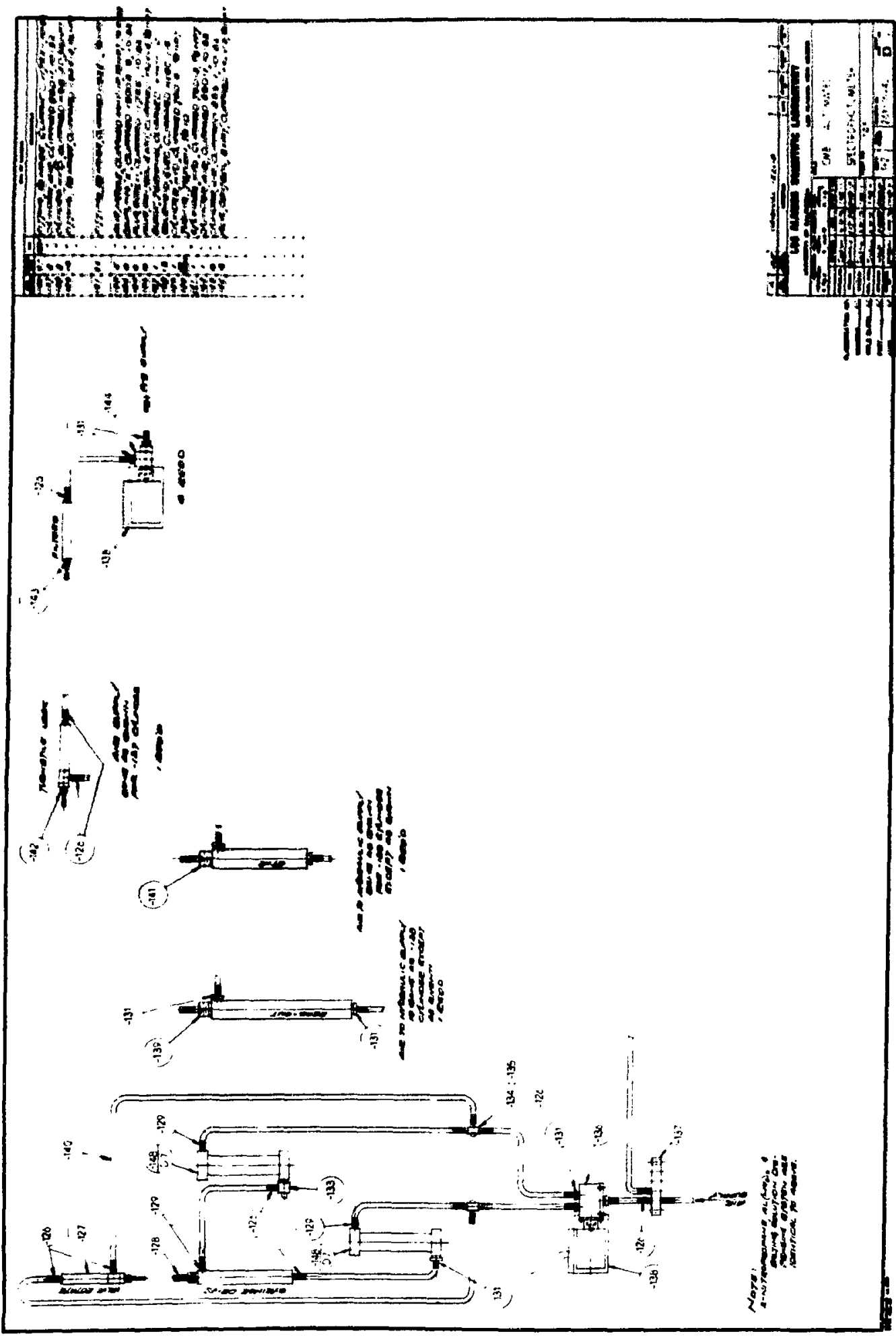




\section{APPENDIX D}

\section{bikcthical conthol. CIRCUIThy}

Figur( D)-1 gives the circuitry that conerols the sorfutenced argorationss of turntable rotntion. reagent deliveries, stirrer prssitioning and rotation, and tube rasising and lowering at the absorbance measurenent station. Figure D-2 gives the timing for these operations as controlled by the sequencer timer (RV. 6.11.15.130, General Time, Thomaston. CT.) 

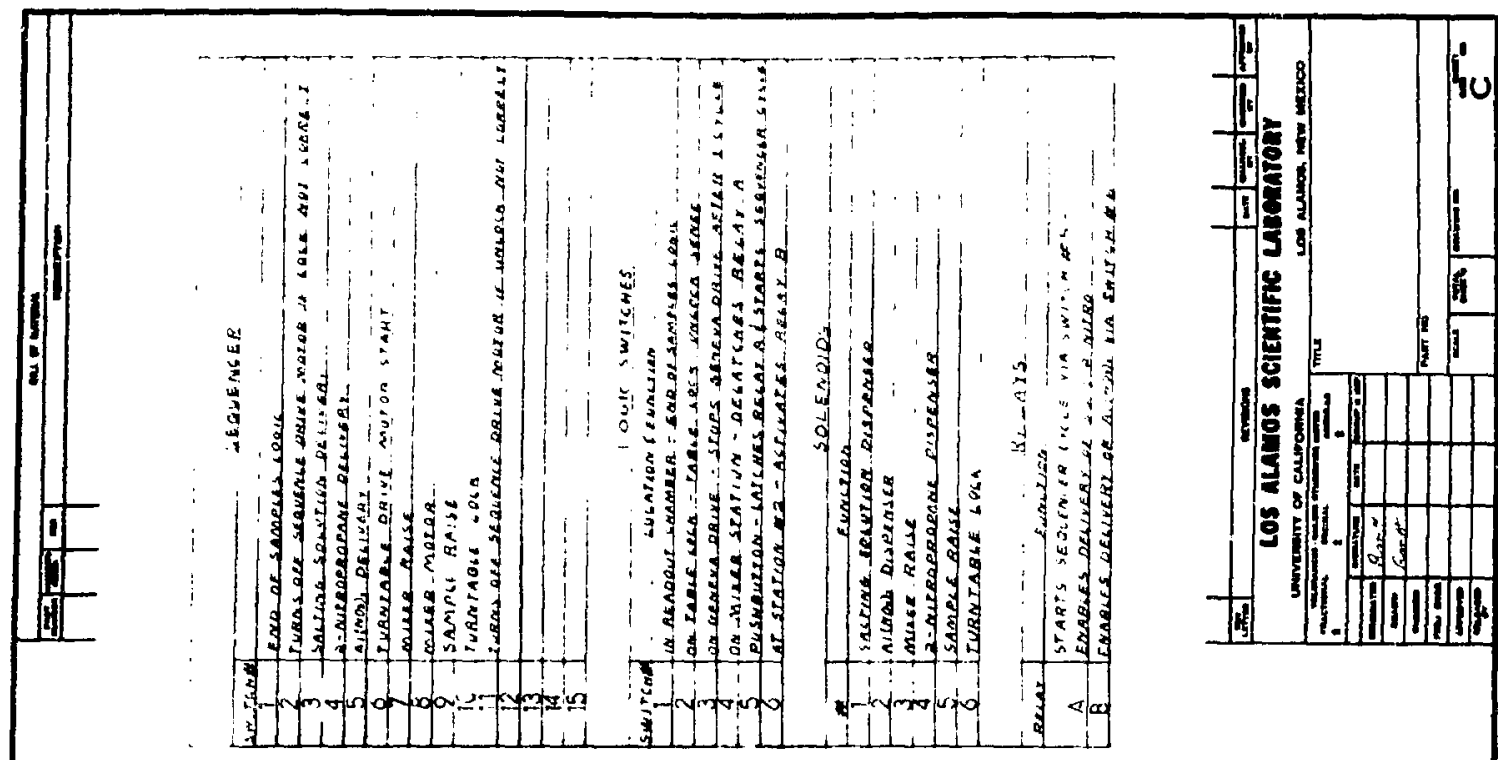

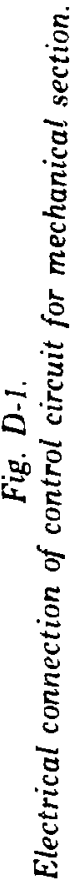




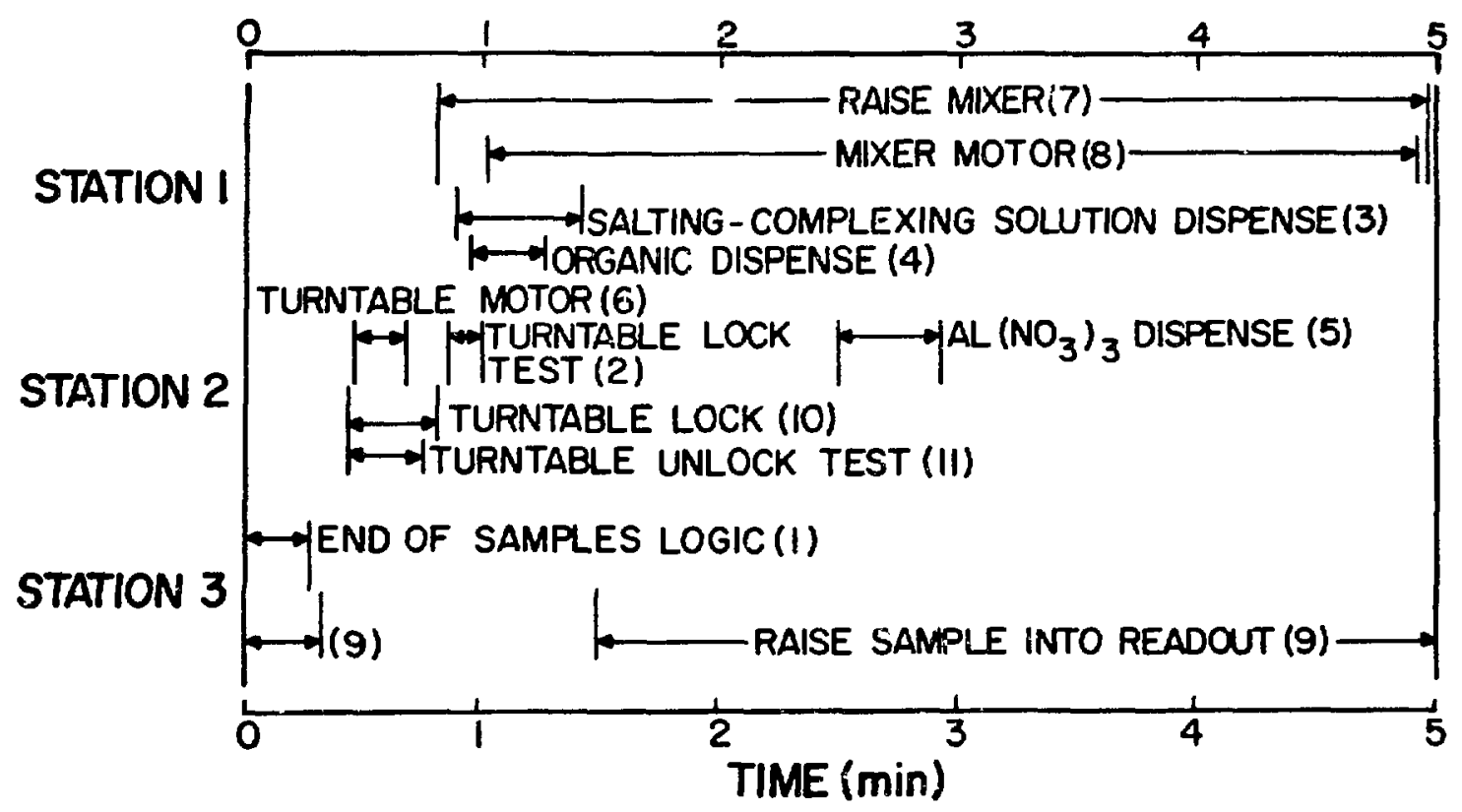

Fig. D-2.

Timing for Sequencer switches. (The number in parentheses is the suitch designation.)

\section{APPENDIX E}

\section{READOUT SYSTEM HARDWARE}

Reduced schematic drawings of the readout system electronic circuits are provided in this appendix. The full-size engineering drawings may.be ordered from the Technical Information Center in Oak Ridge, TN.* These full-size drawings are intended to serve for construction by experienced electronic personne! and, with the software information in Appendix F, for maintenance. Control is provided by a microcomputer based on an Intel 8008 Microprocessor (Intel Corp., Santa Clara, CA) and programmable read-only memory rather than with discrete logic. The integrated circuits (IC) are placed in wire-wrap sockets interconnected by a semiautomatic, wire-wrap machine. Maintenance is performed at the IC level, not at the circuit board level.

The system hardware is packaged in a chassis mounted in a standard 19-in. rack. Also mounted in

*See last page of report for information about ordering full-size engineering drawings. the rack are the lamp power supply (Power/Mate (INI-30-E, Power/Mate Crop., Hackensack. NJ), the photodiode high-voltage supply (Assembly Products No. 1677-11A. Assembly Products Co.. St. Albans, VT), and the digital printer (HP.5055A. Hewlett Packard, Palo Alıo, CA).

Figure E-1 describes the drawing conventions and layout that apply to the schematic drawings and the assignment of interrupts. input port bits, and out put port bits. Figure E-2 illustrates the system in block diagram form. Figure E-3 is a detailed drawing of the electrical system including connector-pin assignments for the cables. Figures E-4, E-5, E-6, and E- 7 respectively describe the analog-to-digital converter. the photo-isolated relay connections, the printer interface, and the manual control switch register. Figures E-8 through E-17 present details of the microcomputer system. 
.

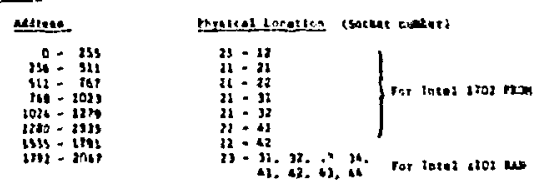

santevere.

능

$r$ (atowas)

?

?

3

,

1

o (10mat)

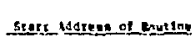

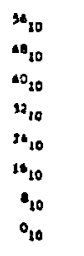

Intertupe wen

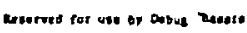

Prlater Dsem

oim coestert cooplete

semplo to prase

not interseted

tot imiaristes

Poute sos tetertats

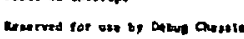

issut porse

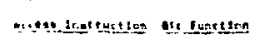

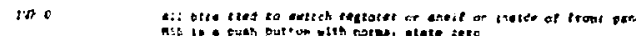

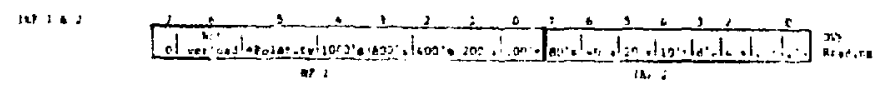

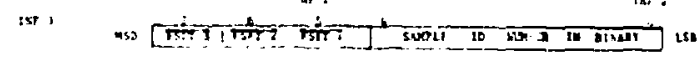
nin - Muta st

$\operatorname{sing}$

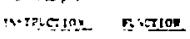

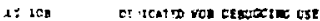

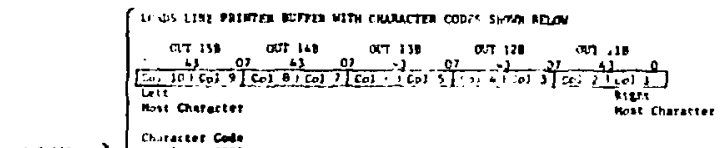

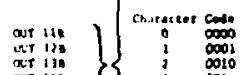

$\left.\lim _{a \rightarrow 1} \rightarrow\right\}$

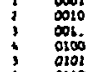

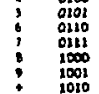

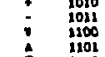

a

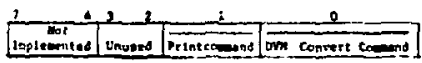

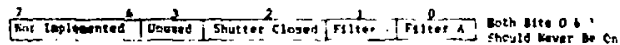

at 1 18
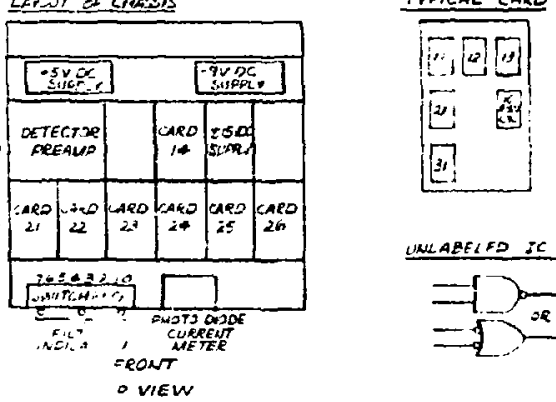

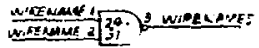
GATE IE TSATED ON THE COWN THE AN CARC TRON TAE LET

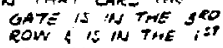

UMLABEL FD IC TRPES

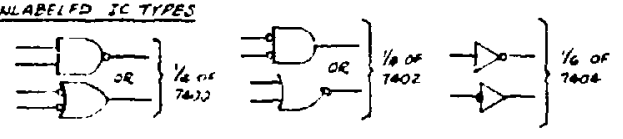

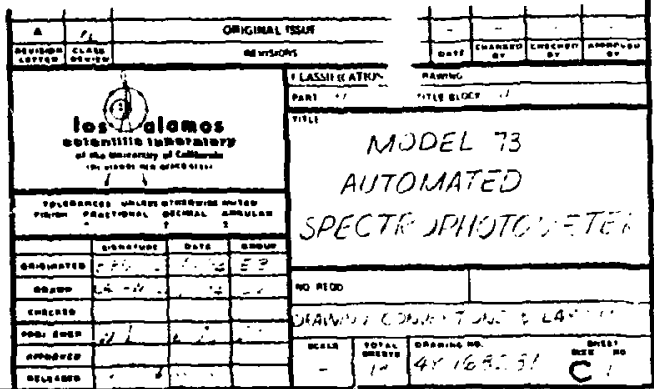

and

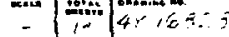

Fig. $E-1$.

Drawing conventions and layout for the readout system electronic circuits.

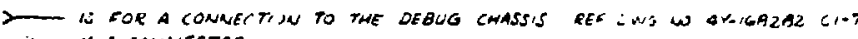

QD- IS A SGNAL WITH ITS SOUReE ON SMEET

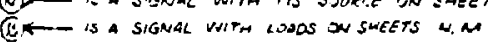




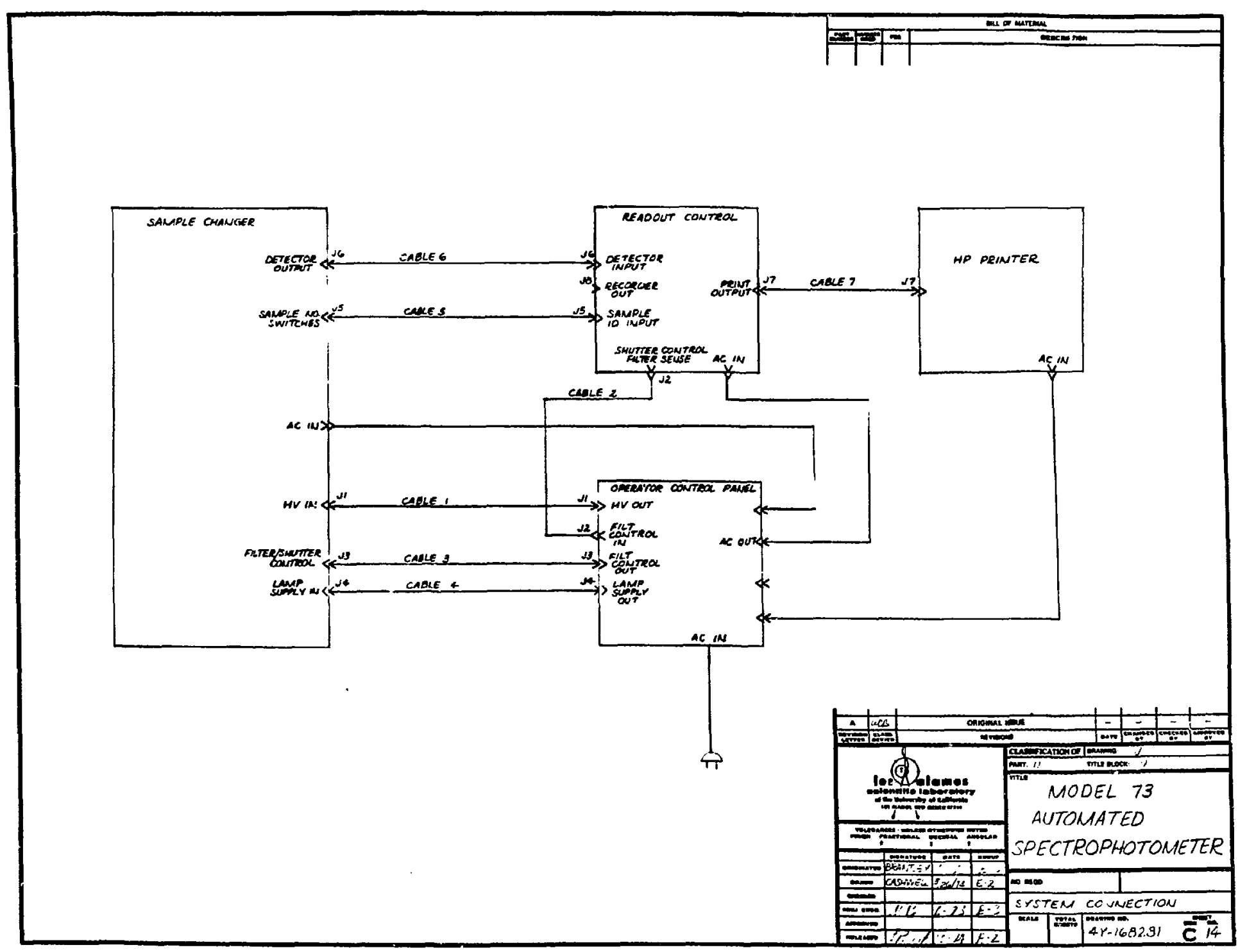




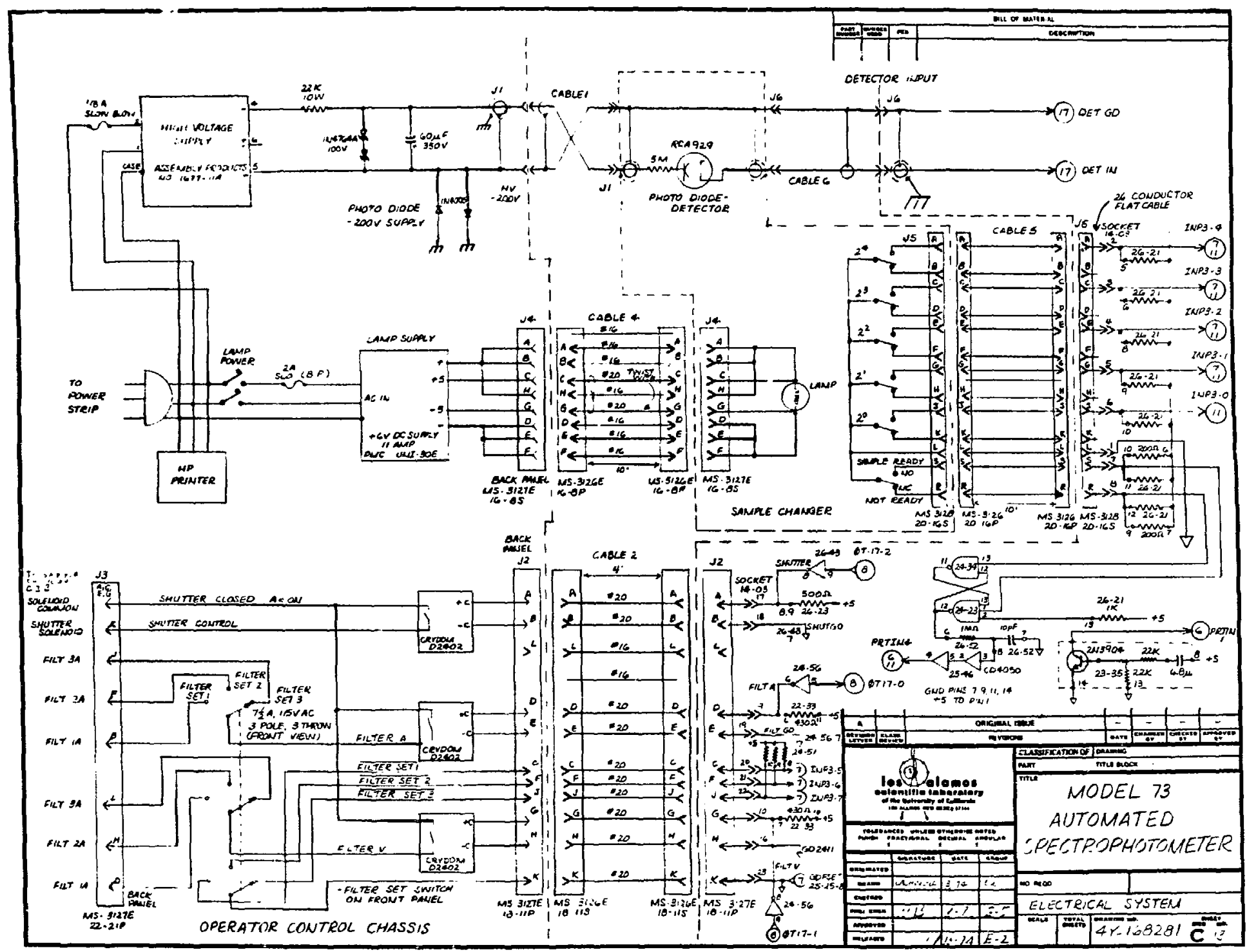

Fig. E-3.

Electrical system. 


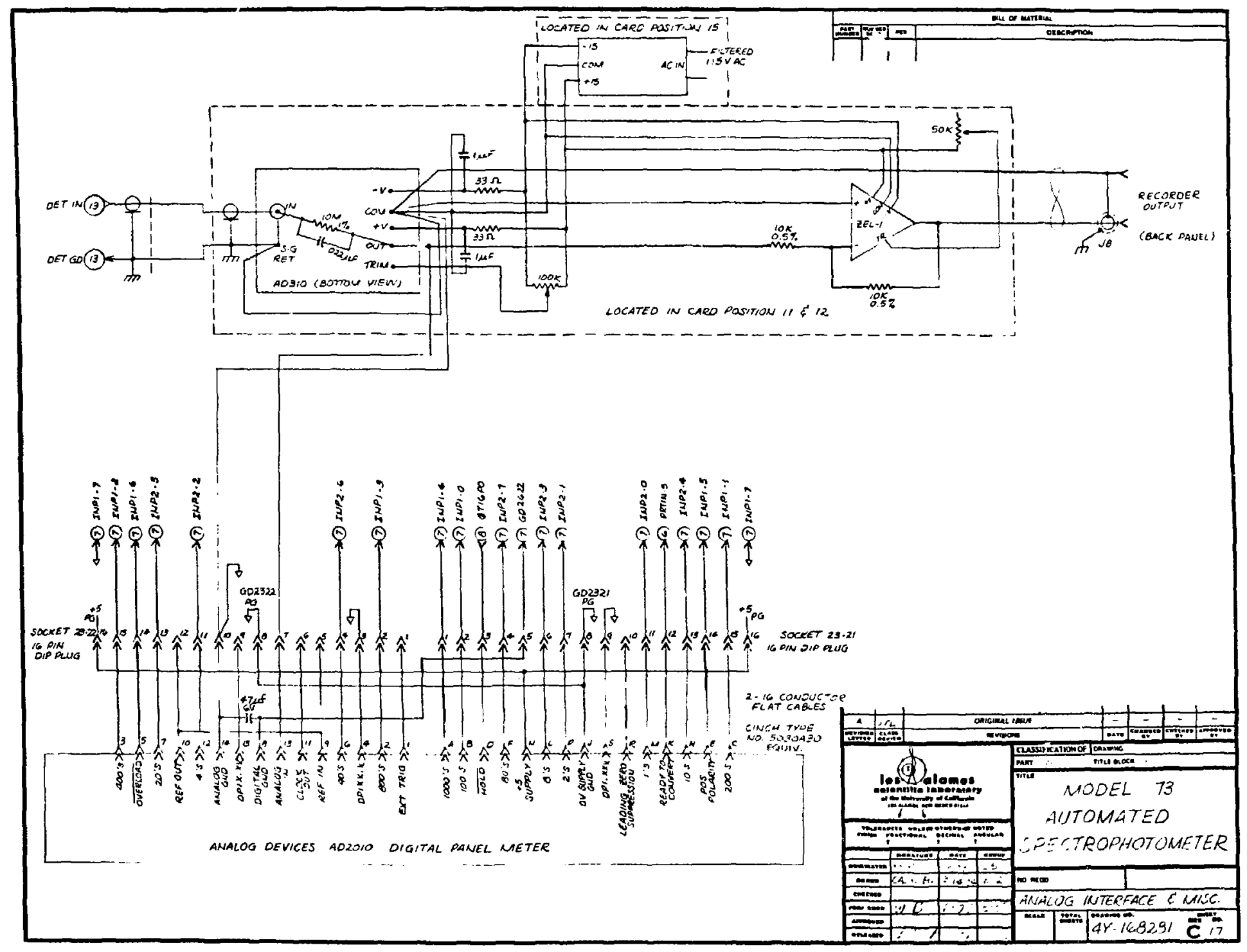




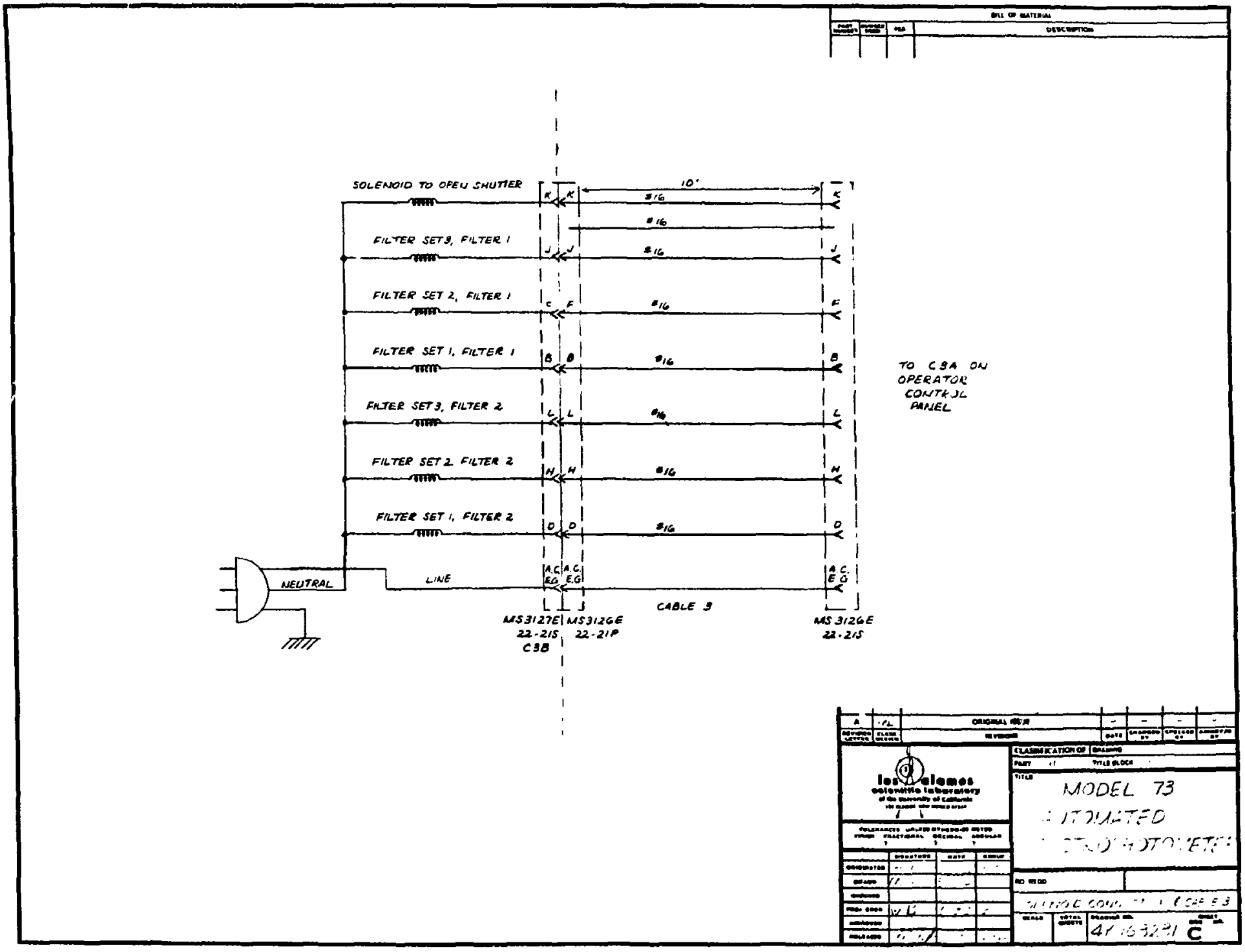

Fig. $E-5$.

Solenoid connection and cables. 


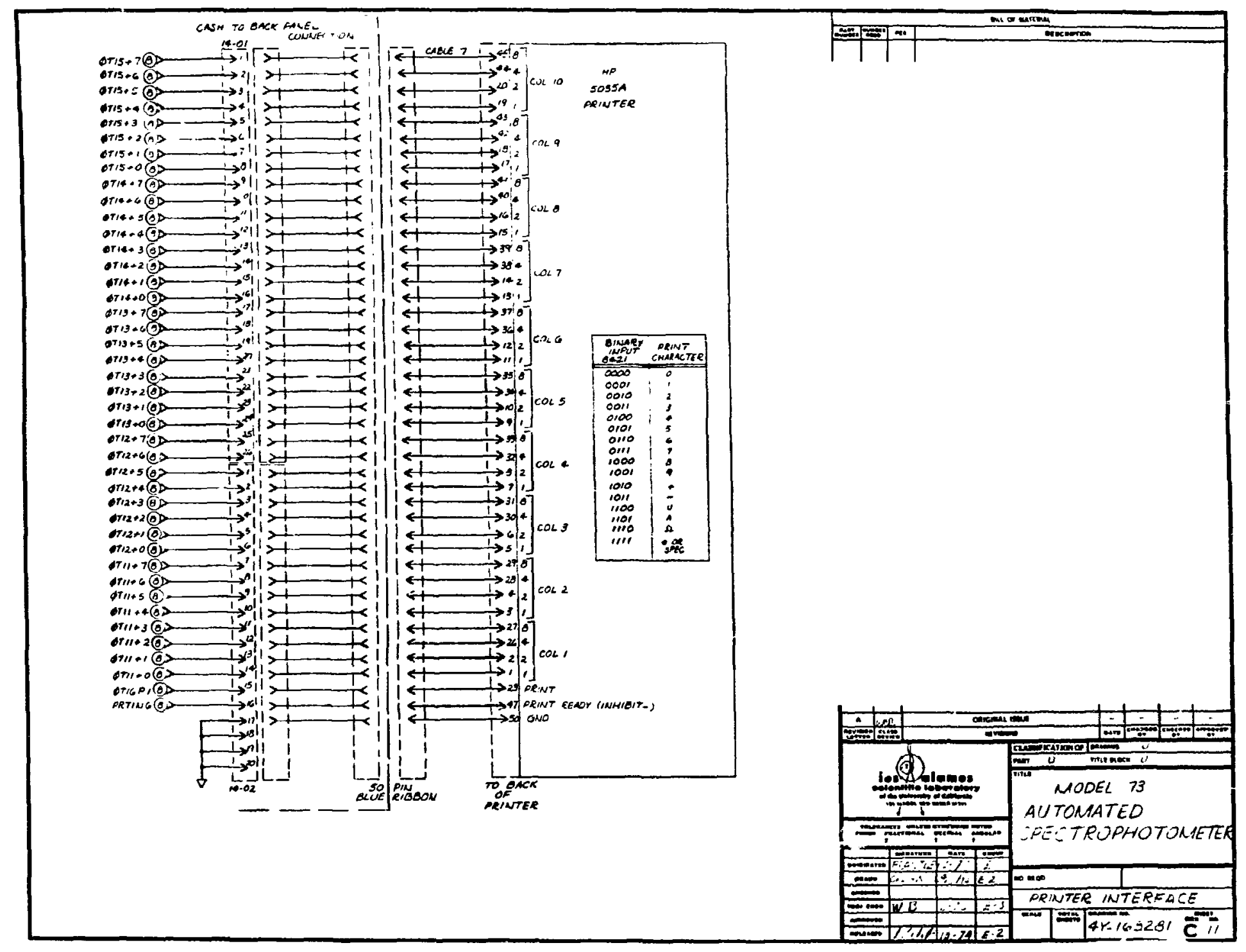




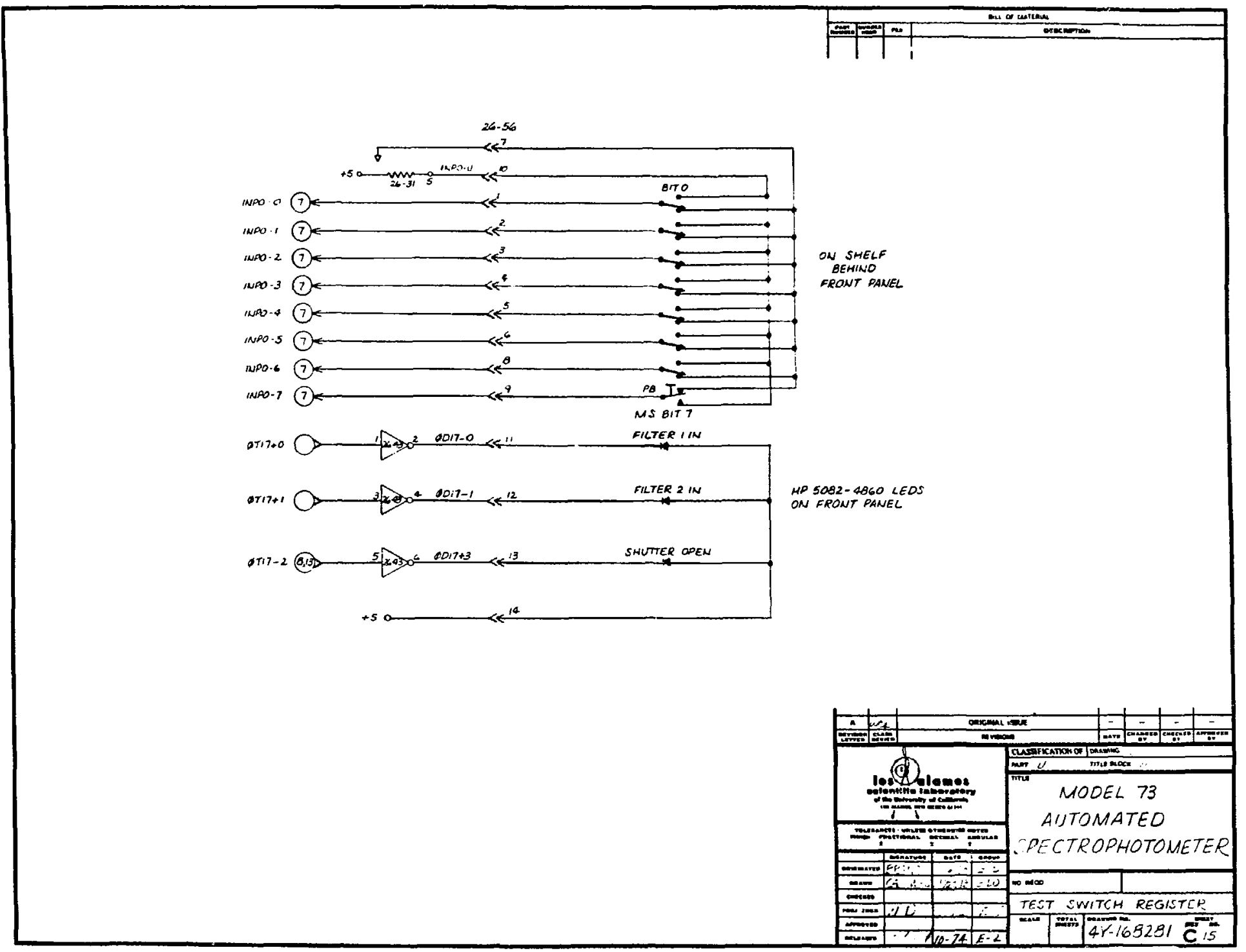

Fig. E-7.

Test switch register. 


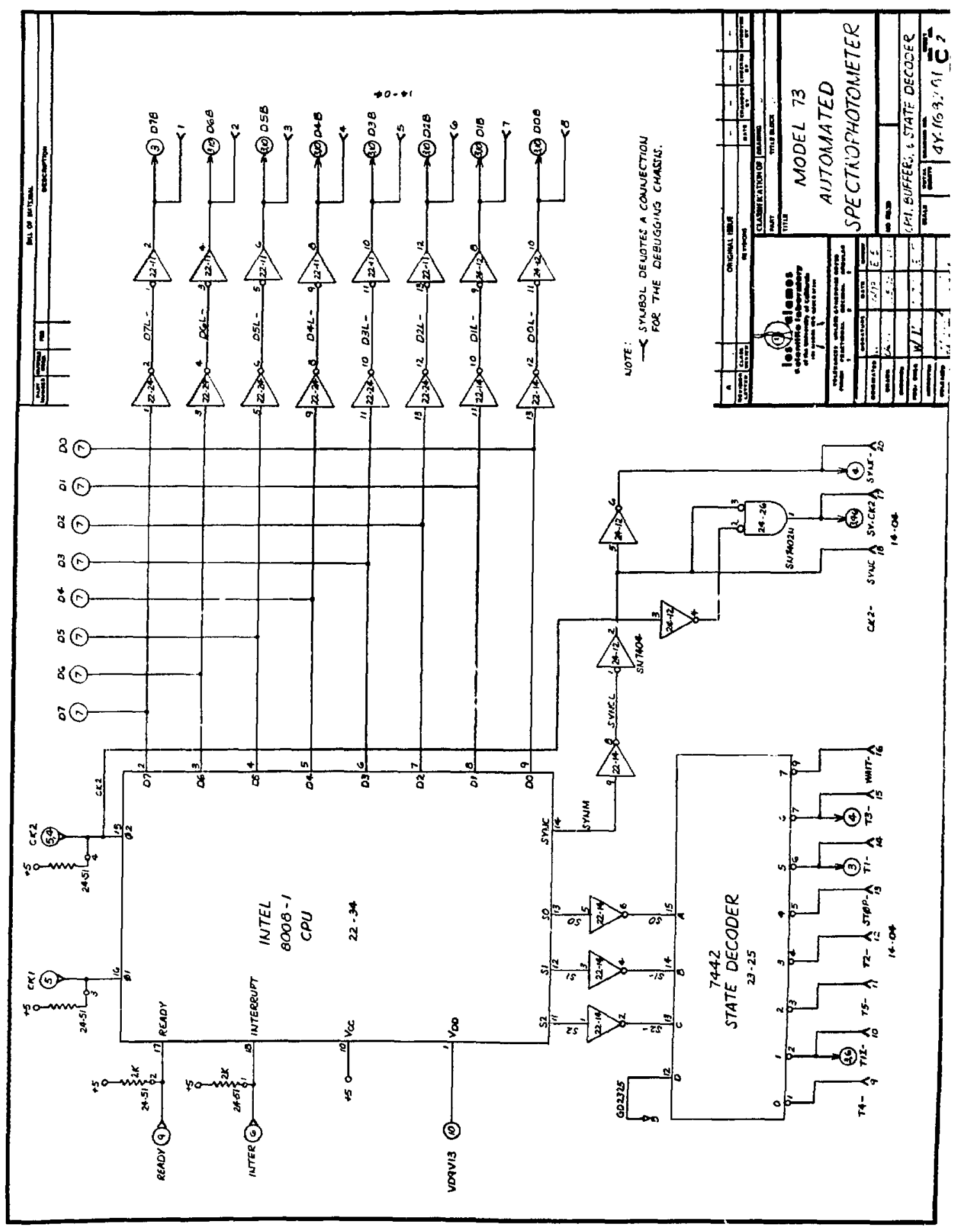

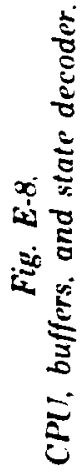




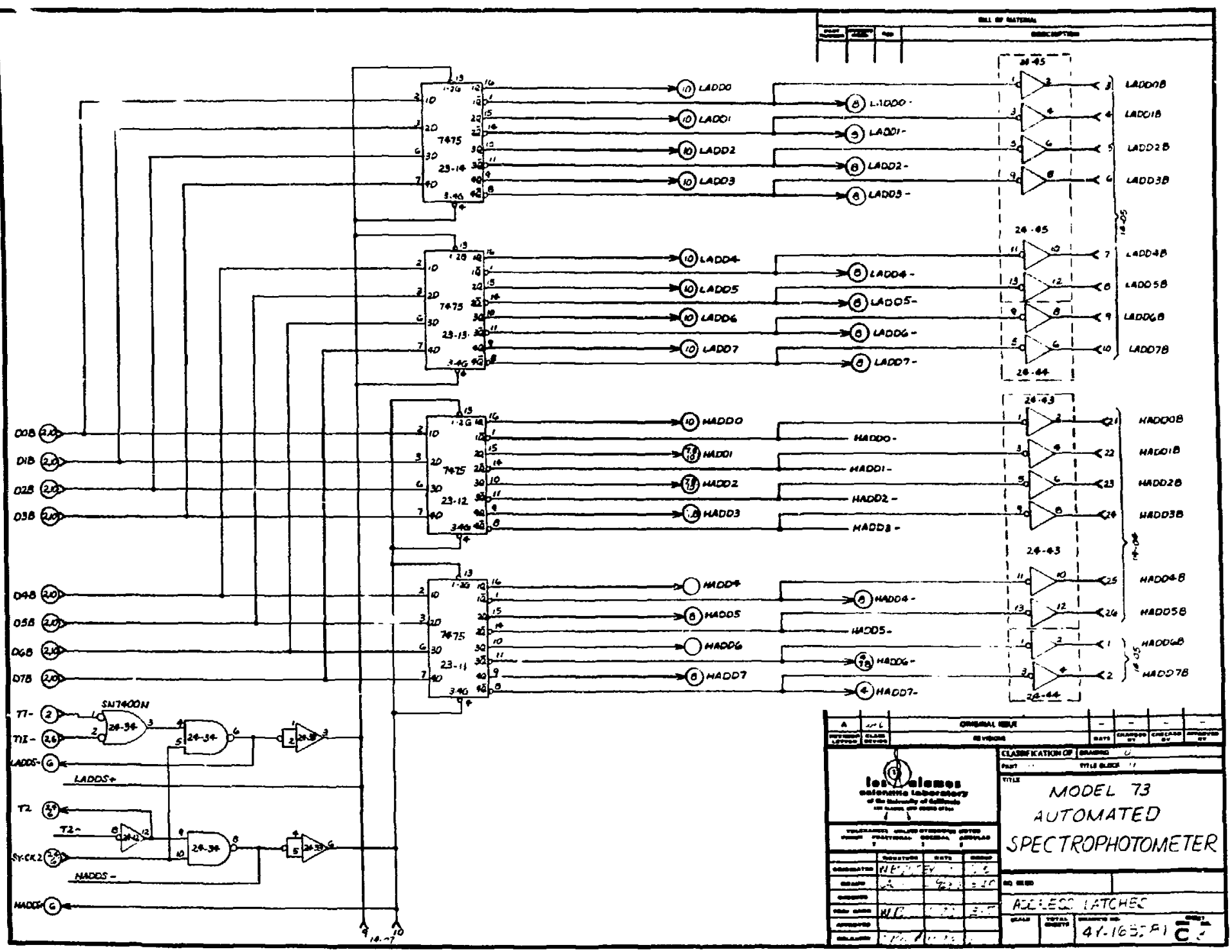

Fig. E-9.

Address latches. 


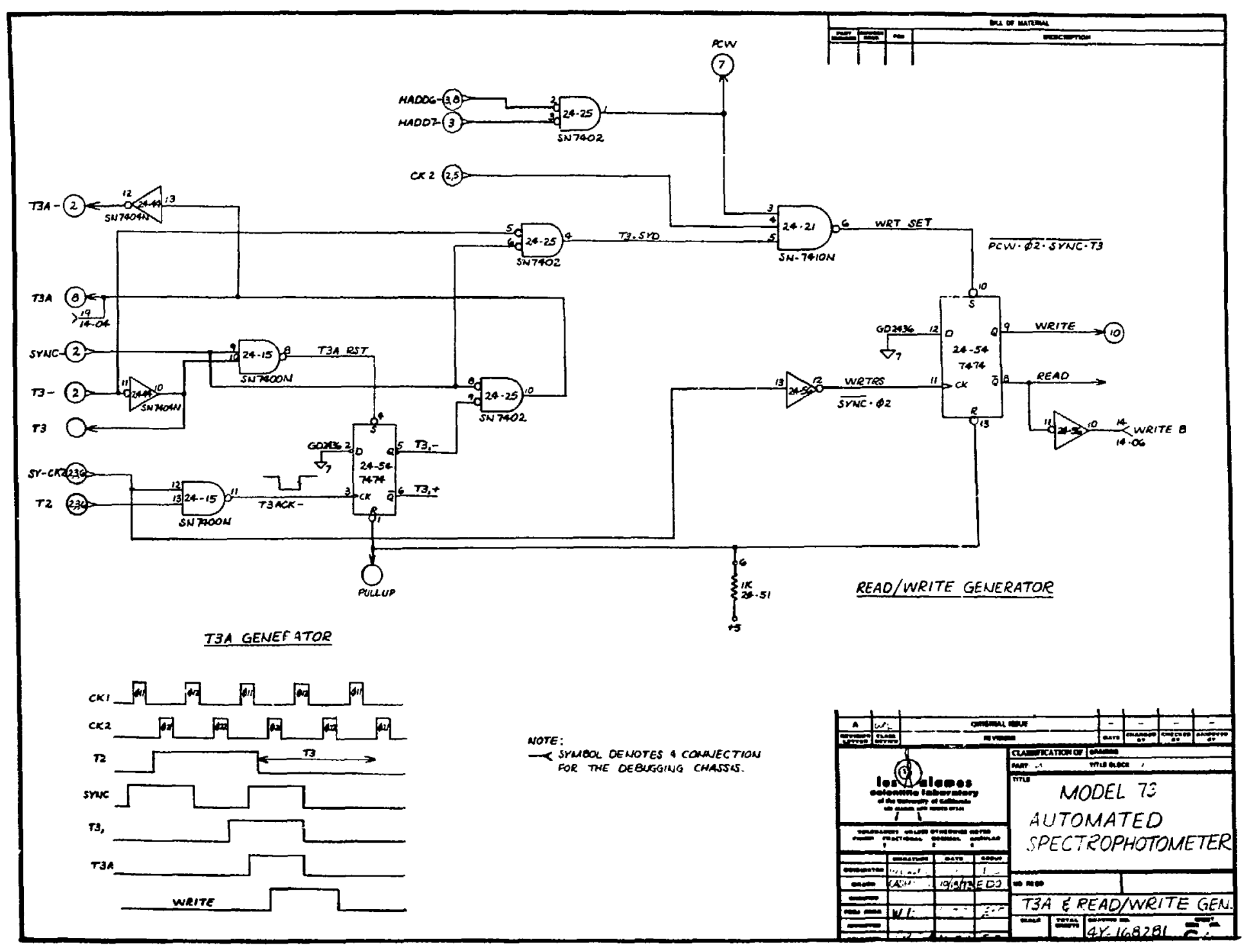




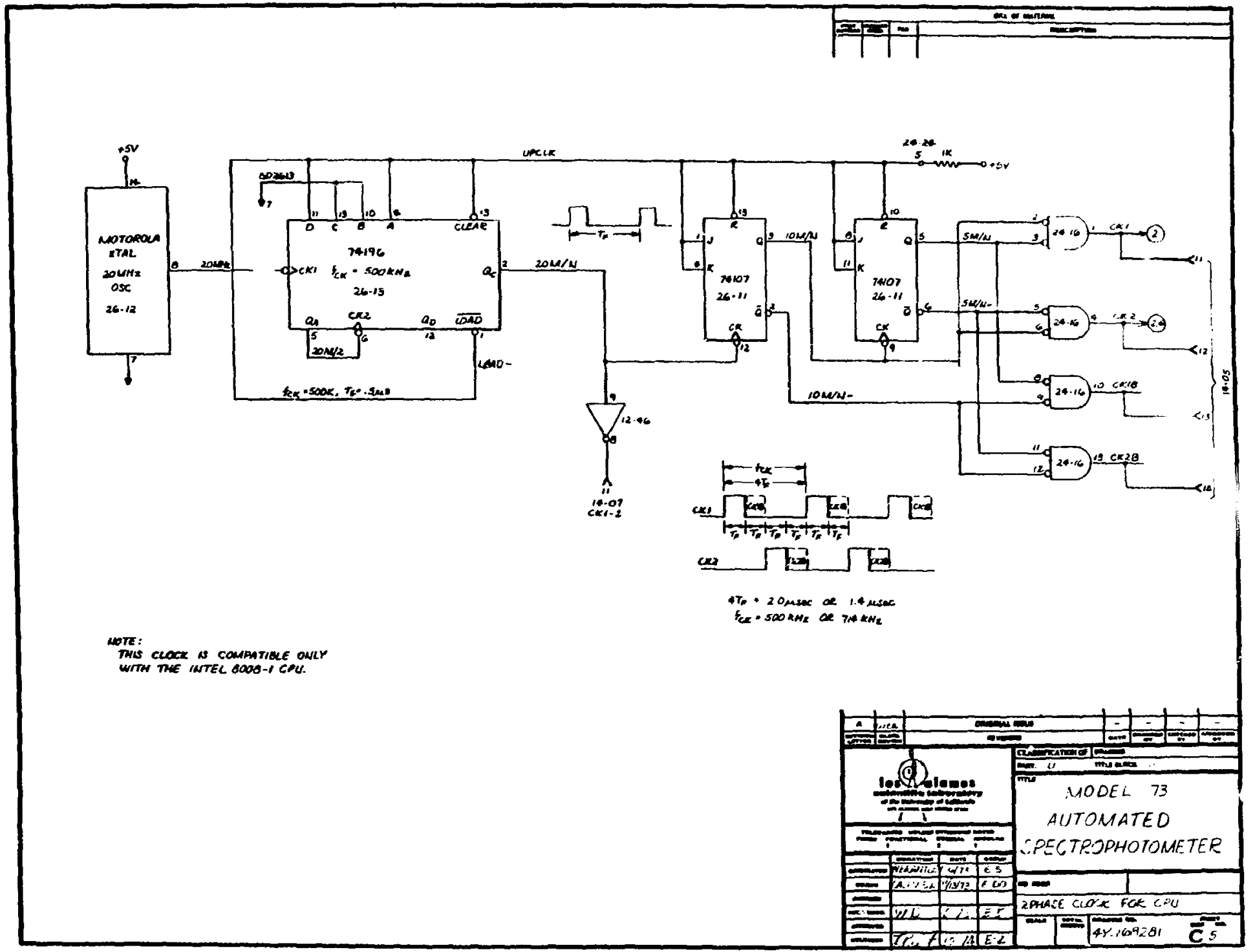

Fig. E-11.

CPL' tuo-phase clock. 


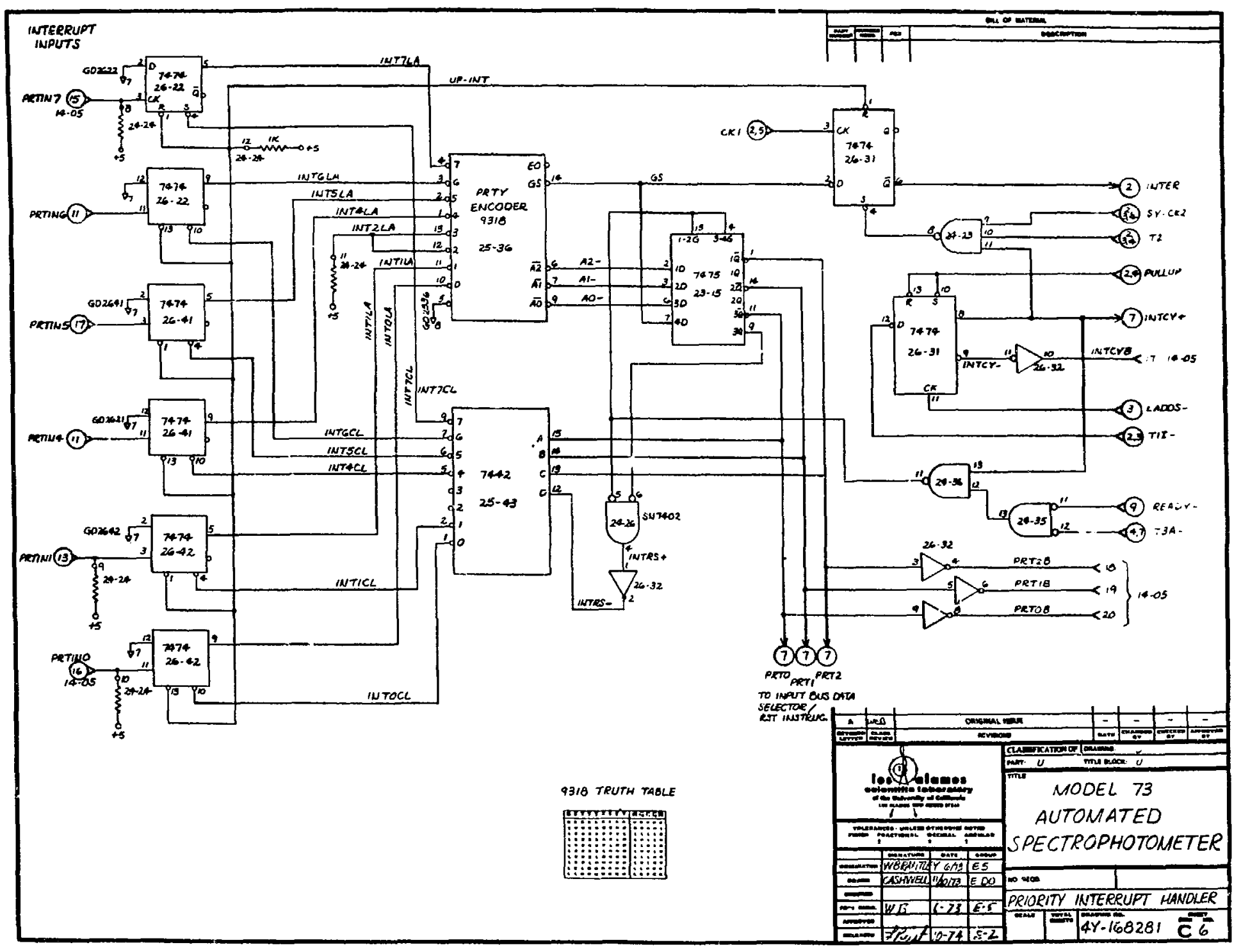




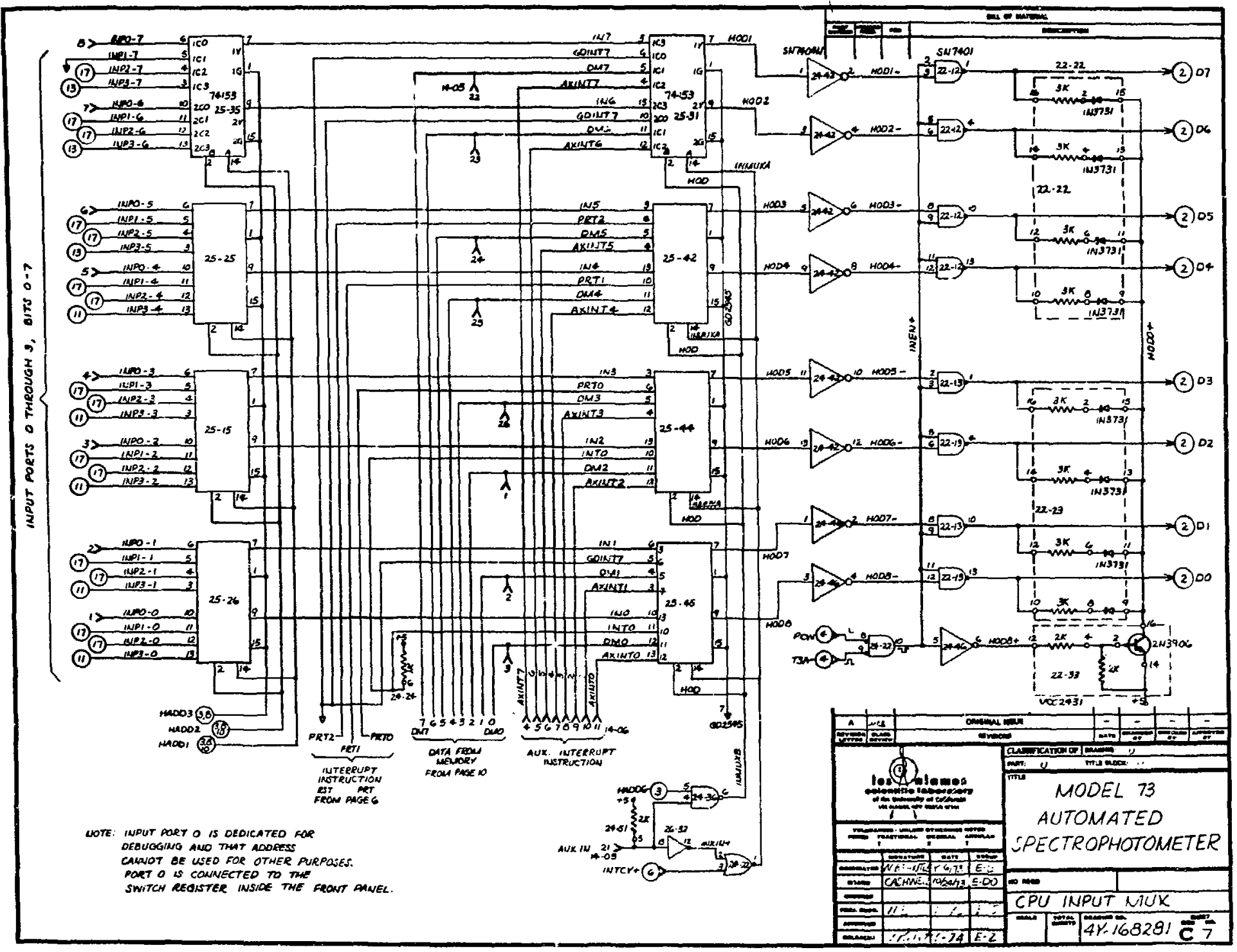

Fig. E-13.

CPU input multiplex. 


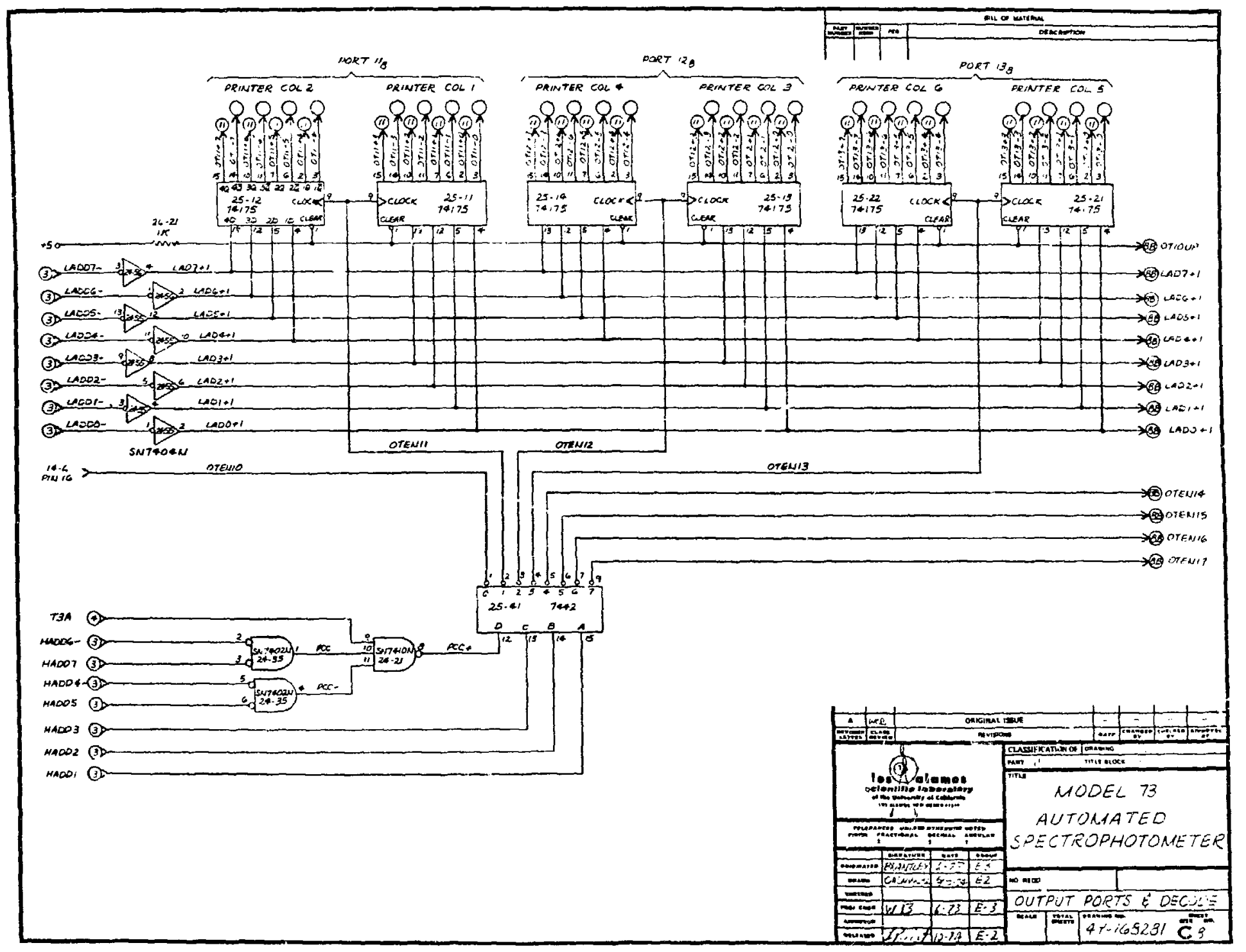




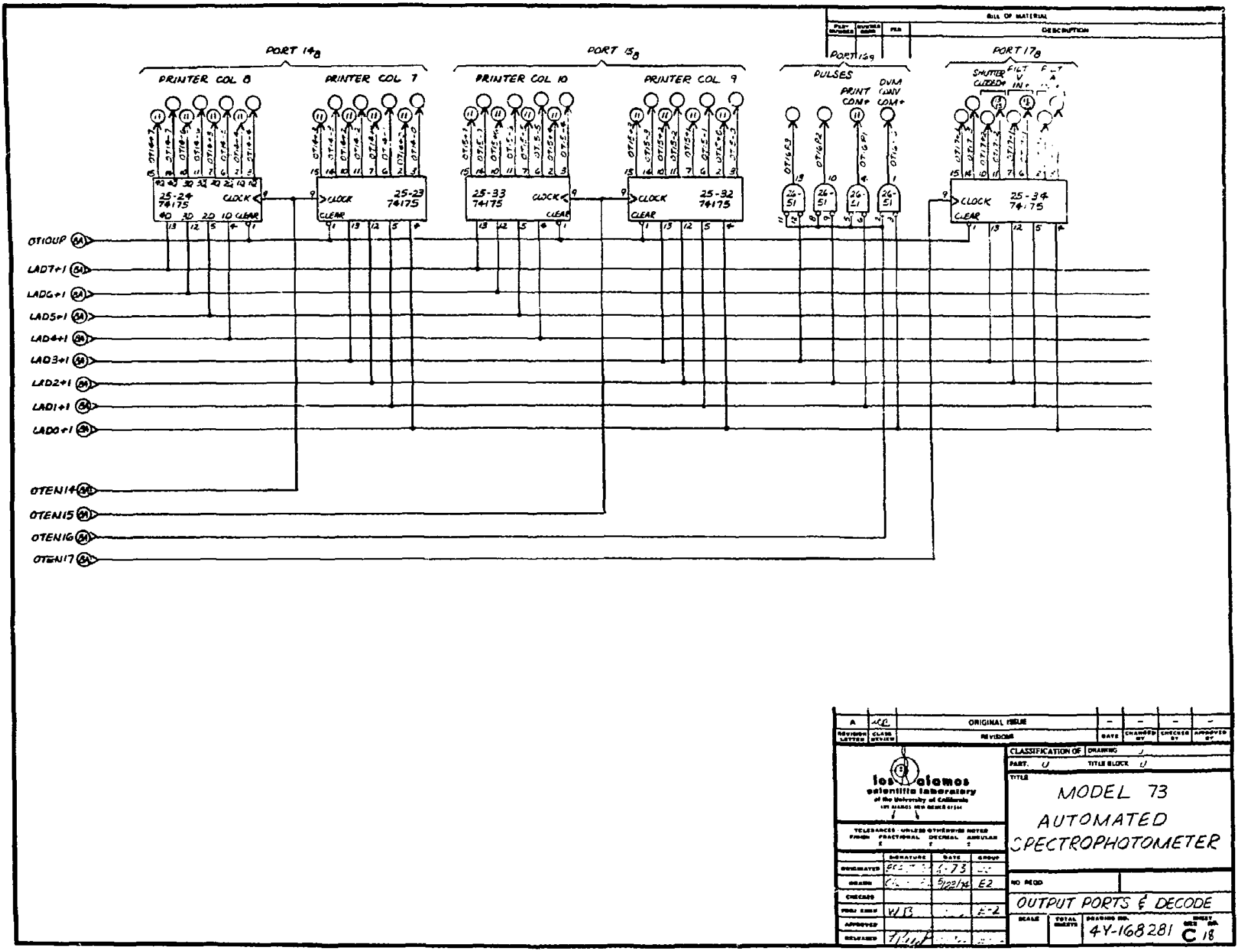

Fig. E-14 (cont).

Output ports and decode. 


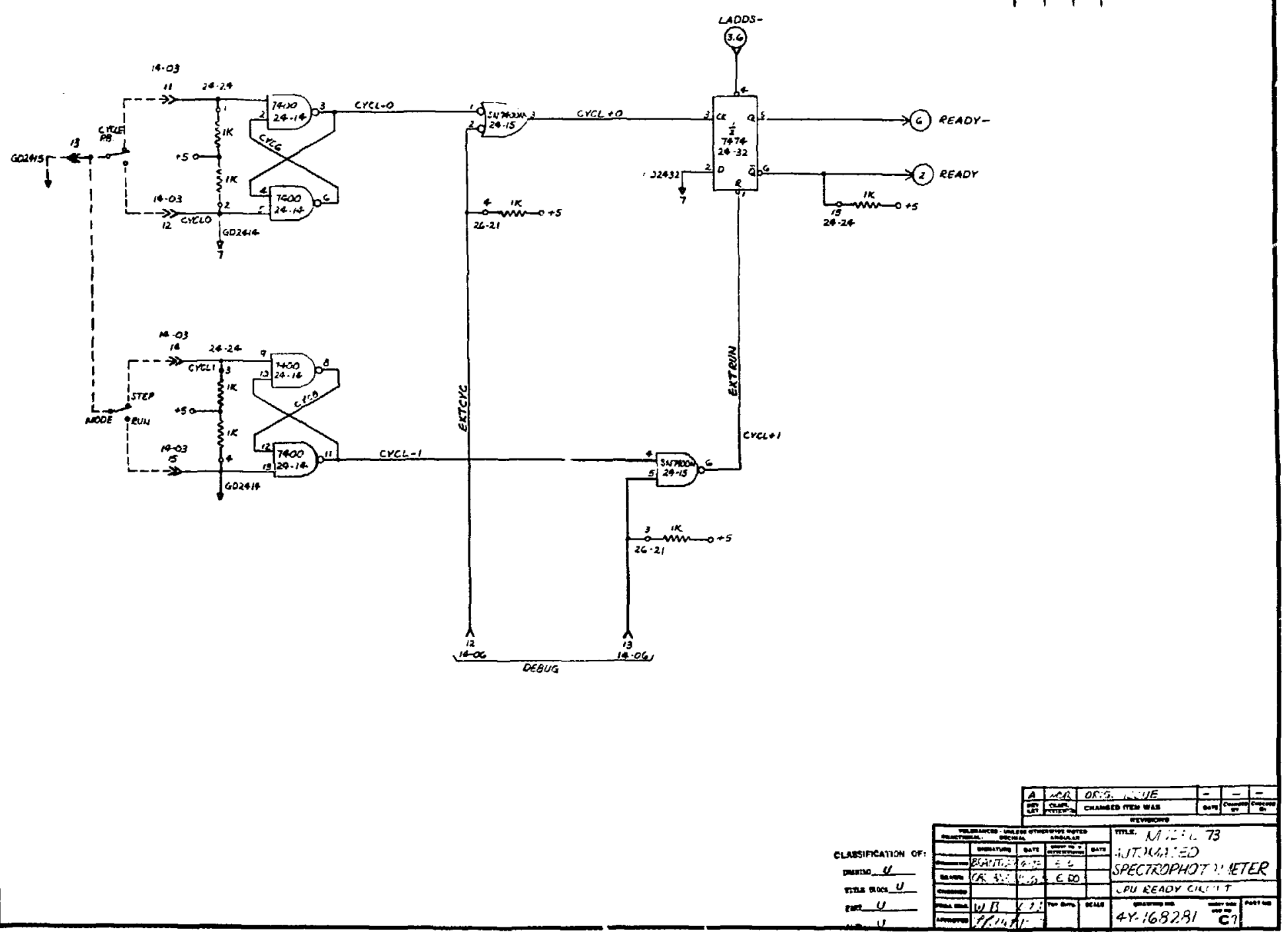




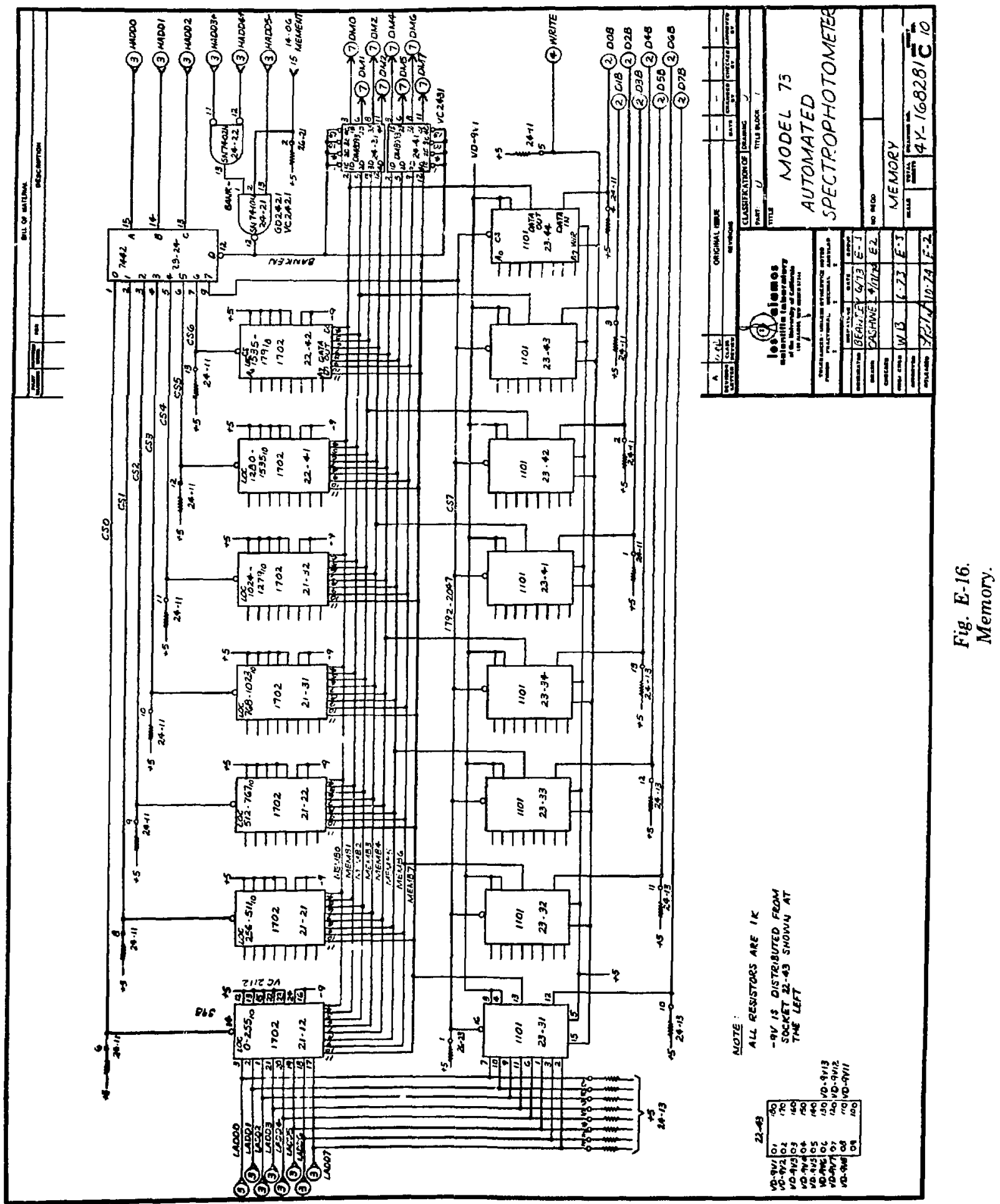




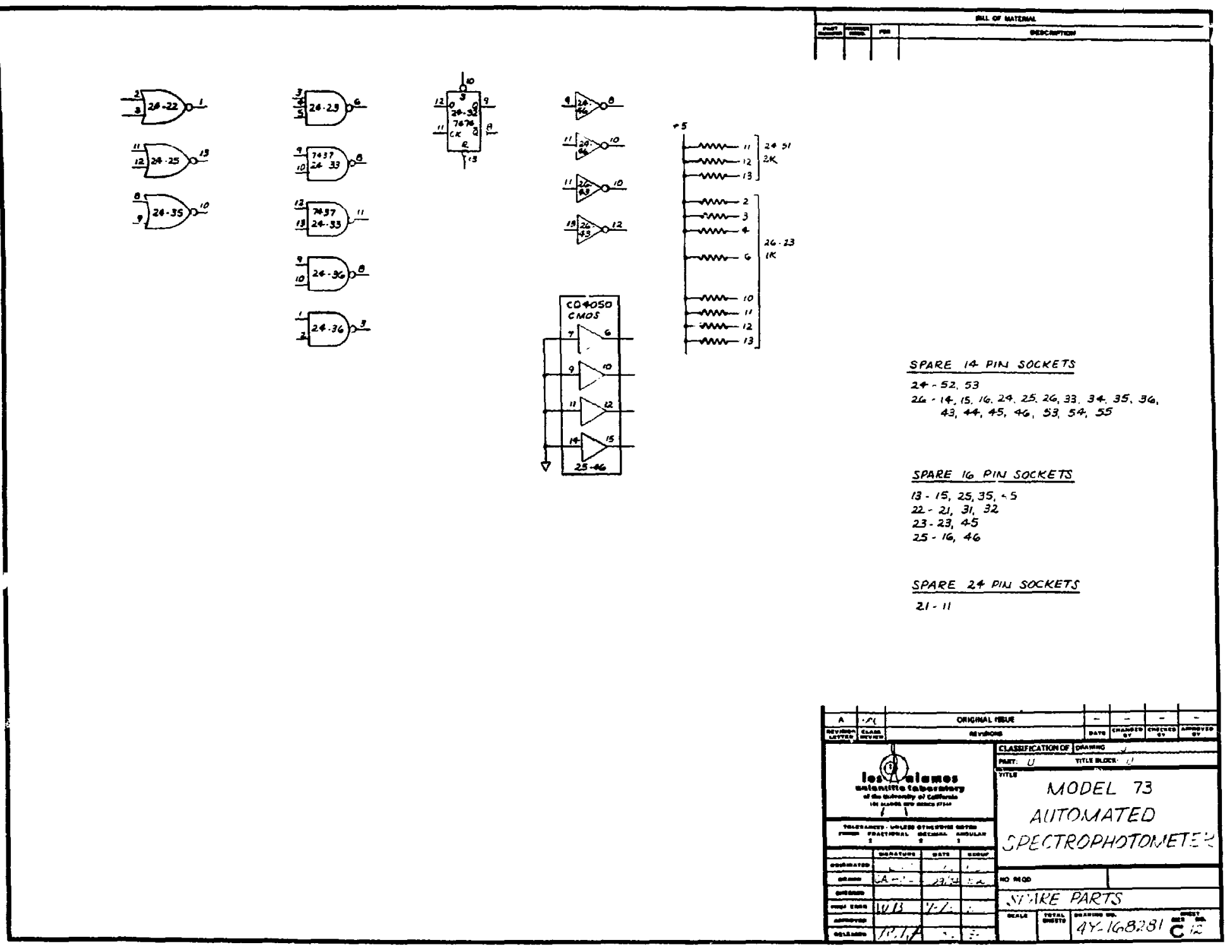




\section{APPENDIX F \\ READOUT SYSTEM SOFTWARE}

This appendix gives flow diagrams and listings of the two programs used by the microcomputer to (a) control the sequerice of operations for the absorbance measurement, (b) compute the four-digit number proportional to the peak-minus-valley absorbance, (c) read the filter pair selected and the turntable position. and (d) control the printer to print out a four-digit number proportional to the peak-minusvalley absorbance, a designation of the filter pair selected, and a turntable position identification number. Figures F-1 and F-2 respectively show flow diagrams of the automated operation program and the manual control program which includes subroutines for turntable position designation and print. Tables F-I and F-II, respectively, give listings for the automated operation program and the manual operation program.

The absorbance measurement cycle is initiated when a sample tube rising into position in the measurement chamber activates a microswitch. The program determines which filter pair is in use and stores this fact in the printer buffer. The turntable position, coded in binary, is converted to binary. coded-decimal (BCD) and stored in the printer buffer. The shutter is closed and the valley filter $(\mathrm{V})$ is positioned. After a 10-s delay, dark current is measured, converted from BCD to binary, and stored complete with sign. The shutter is opened and after a 120-s delay, filter $\mathrm{V}$ is replaced in the light path with the peak filter (A). After a 10-s delay for system stabilization, the photodiode BCD current is read and, if no overflow uccurs, is converted to binary, corrected for dark current, and accumulated for four readings. Filter $A$ is replaced with filter $V$ and the sequence is repeated. Averages of the two sets of readings are computed, $\log _{1} 1$ of each average is calculated. $\log _{10} \mathrm{~A}$ minus $\log _{10} \mathrm{~V}$ is converted to $\mathrm{BCD}$ and printed as a four-digit number along with the previously stored filter pair designation and turntable position.

To facilitate the adjustment and testing of the instrument, a manual control program is provided. This program permits control of the shutter, filters, analog-to-digital converter, and printer by a series of eight toggle switches mounted inside the front cover. 


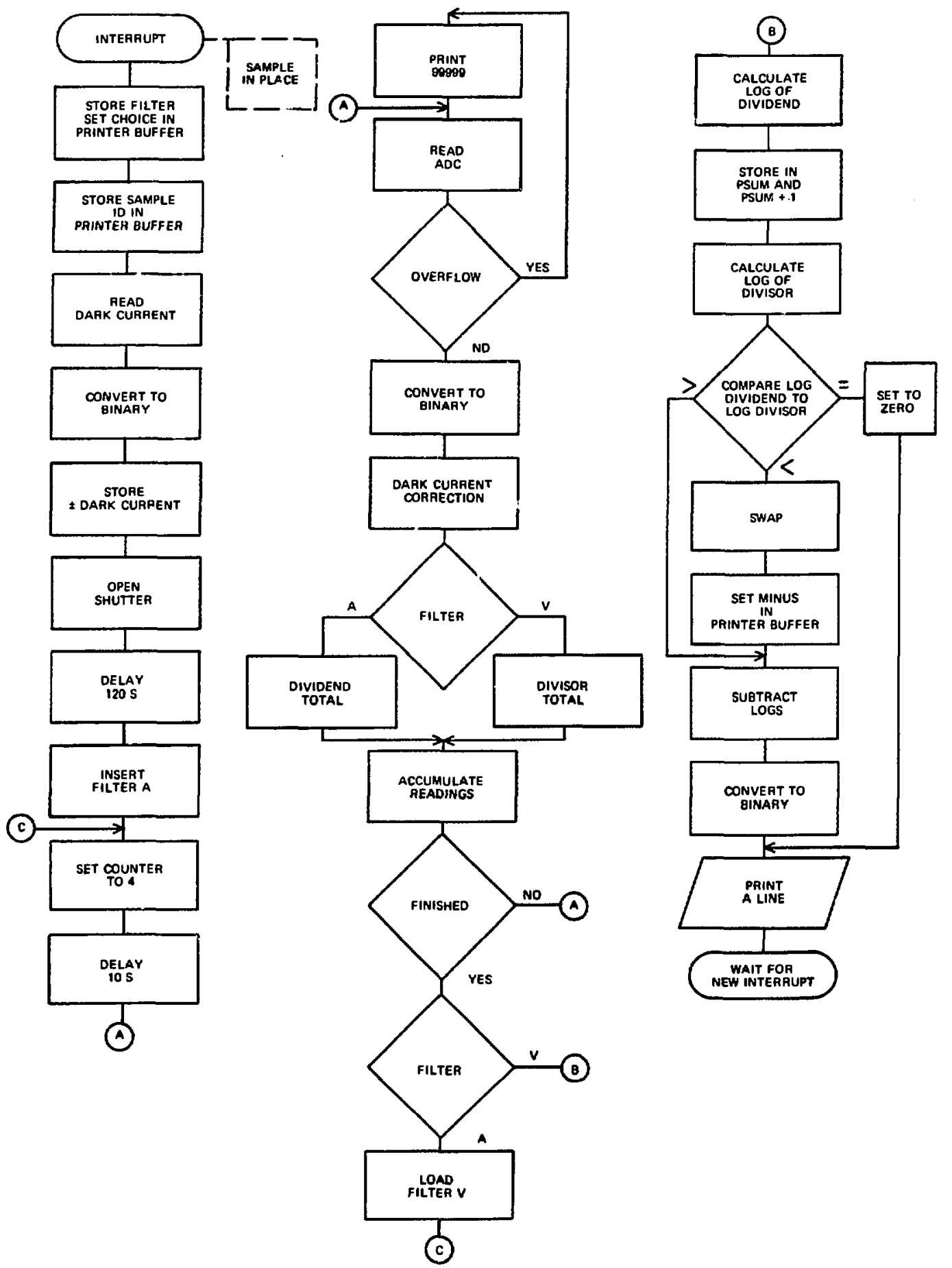

Fig. $F-1$.

Automated operation program flow diagram. 

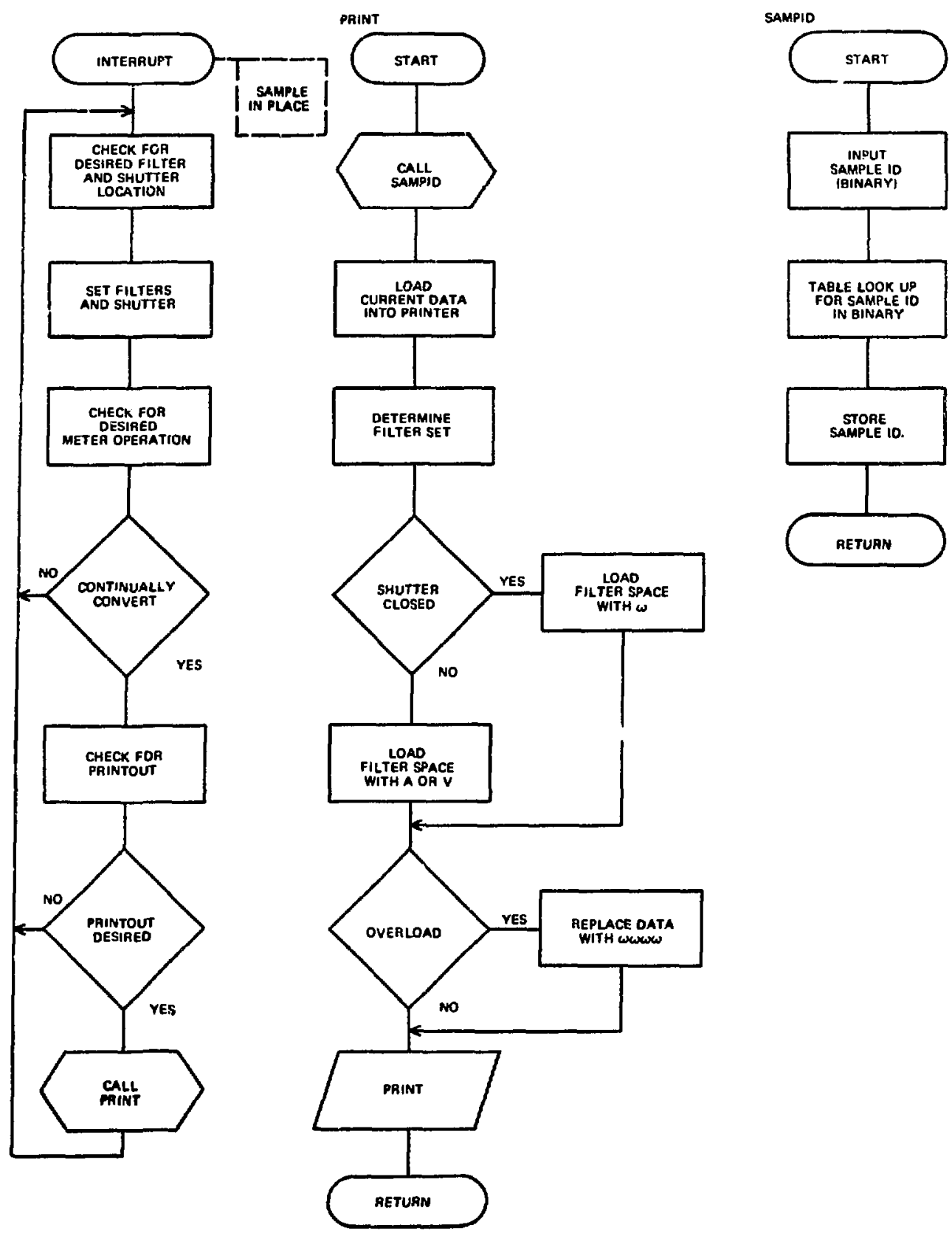

Fig. F-2.

Manual operation program flow dingram. 
TABLE F-I

AUTOMATED OPERATION PROGRAM LISTING

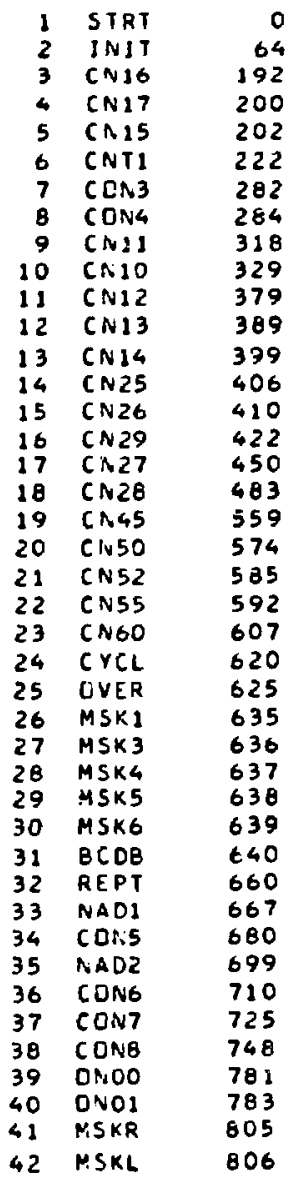

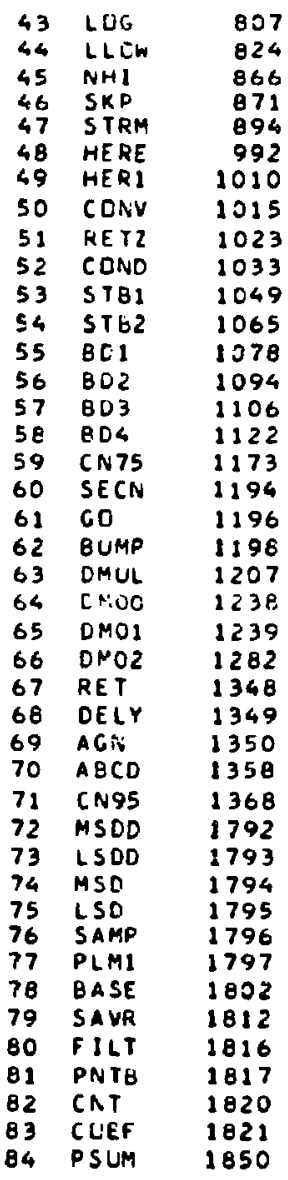




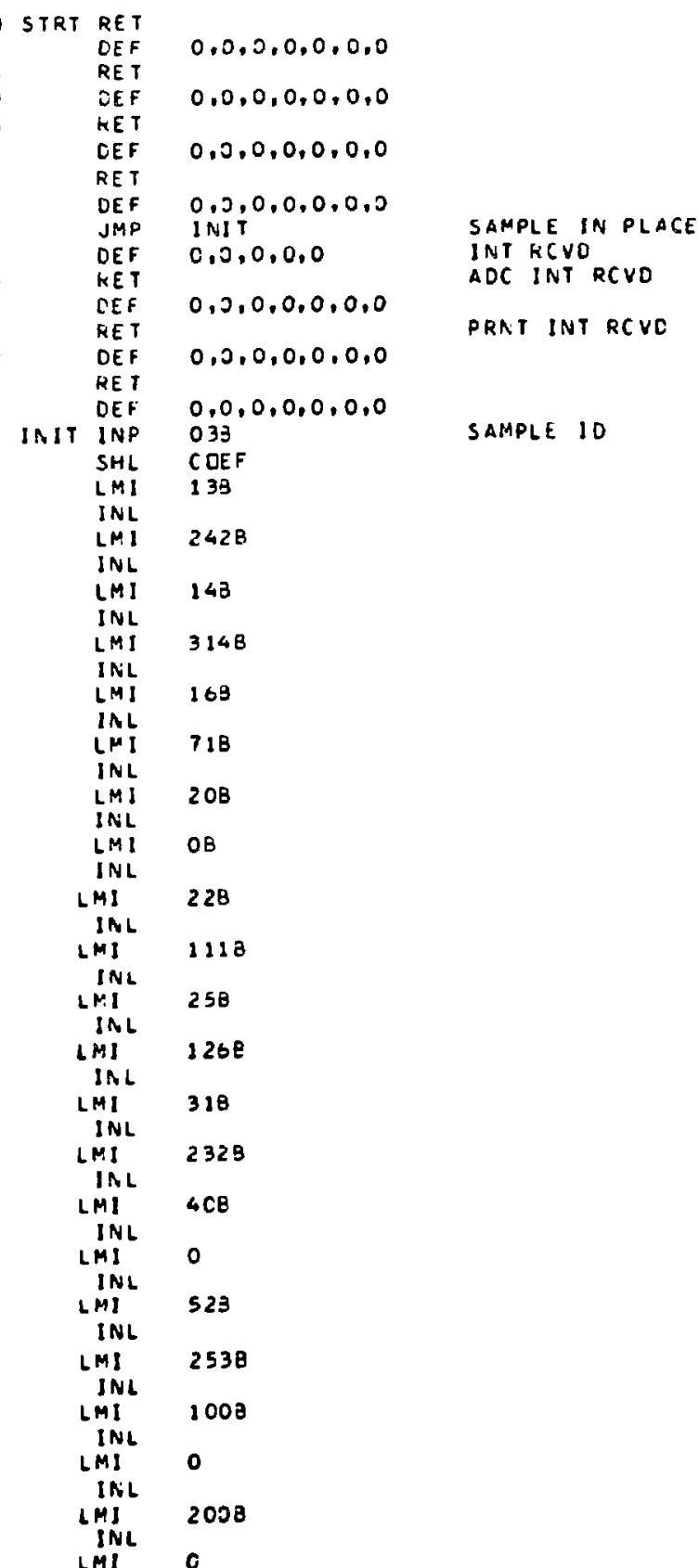




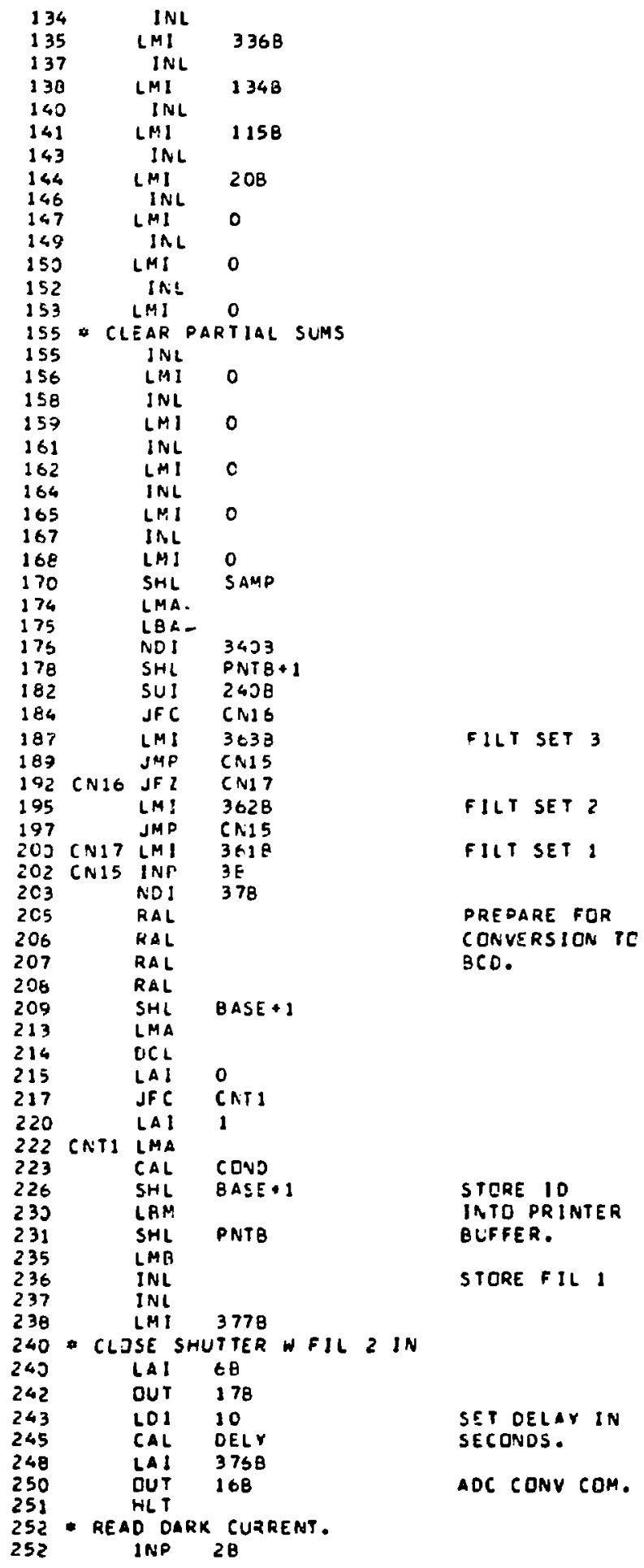




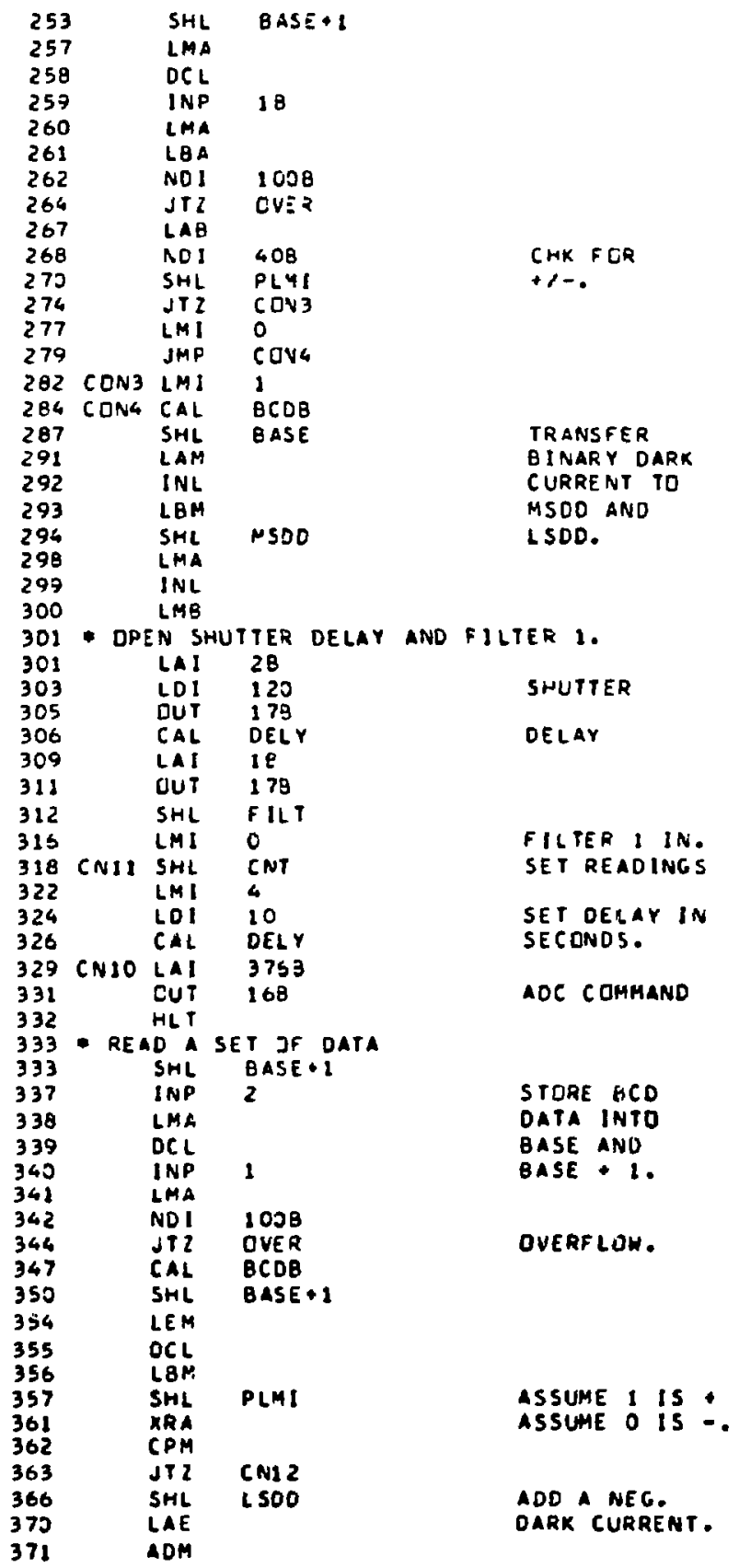




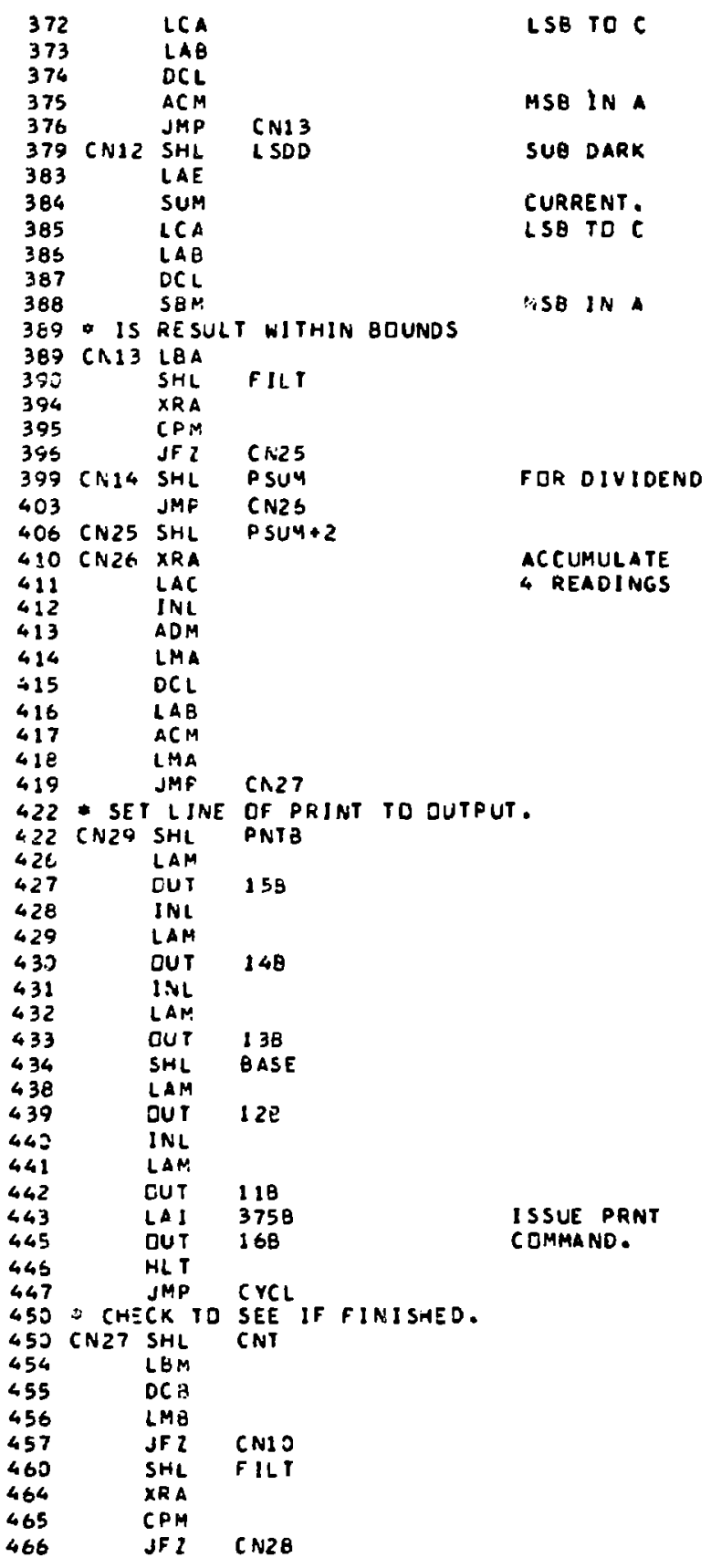




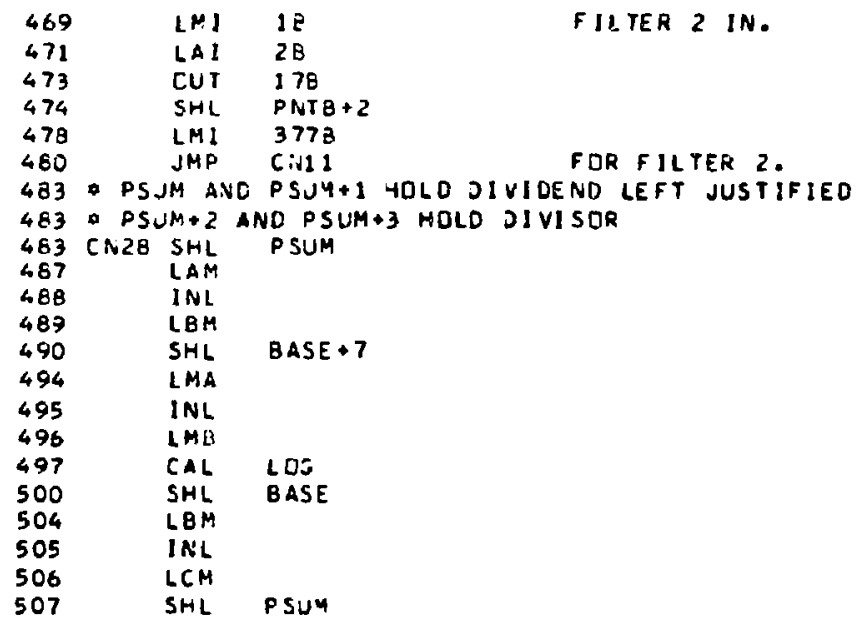




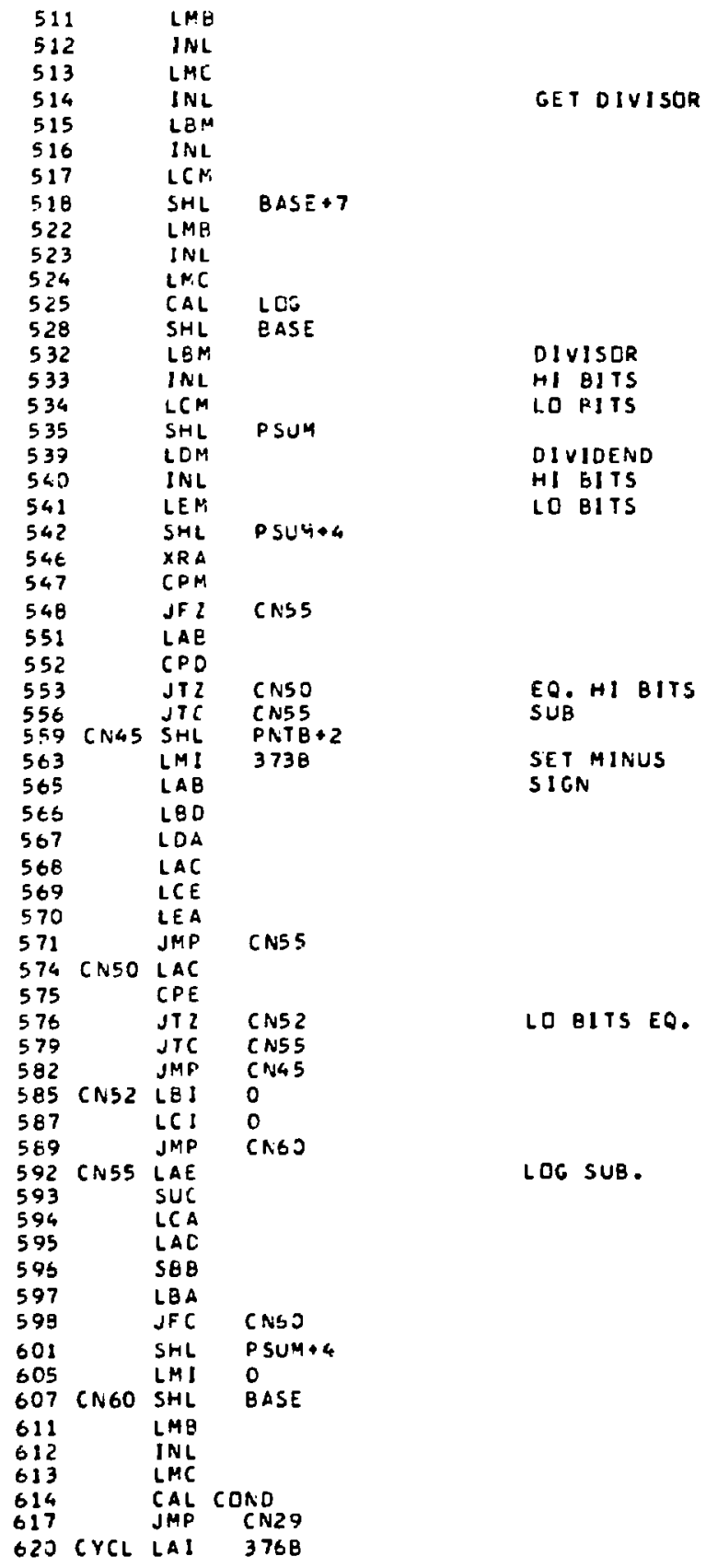




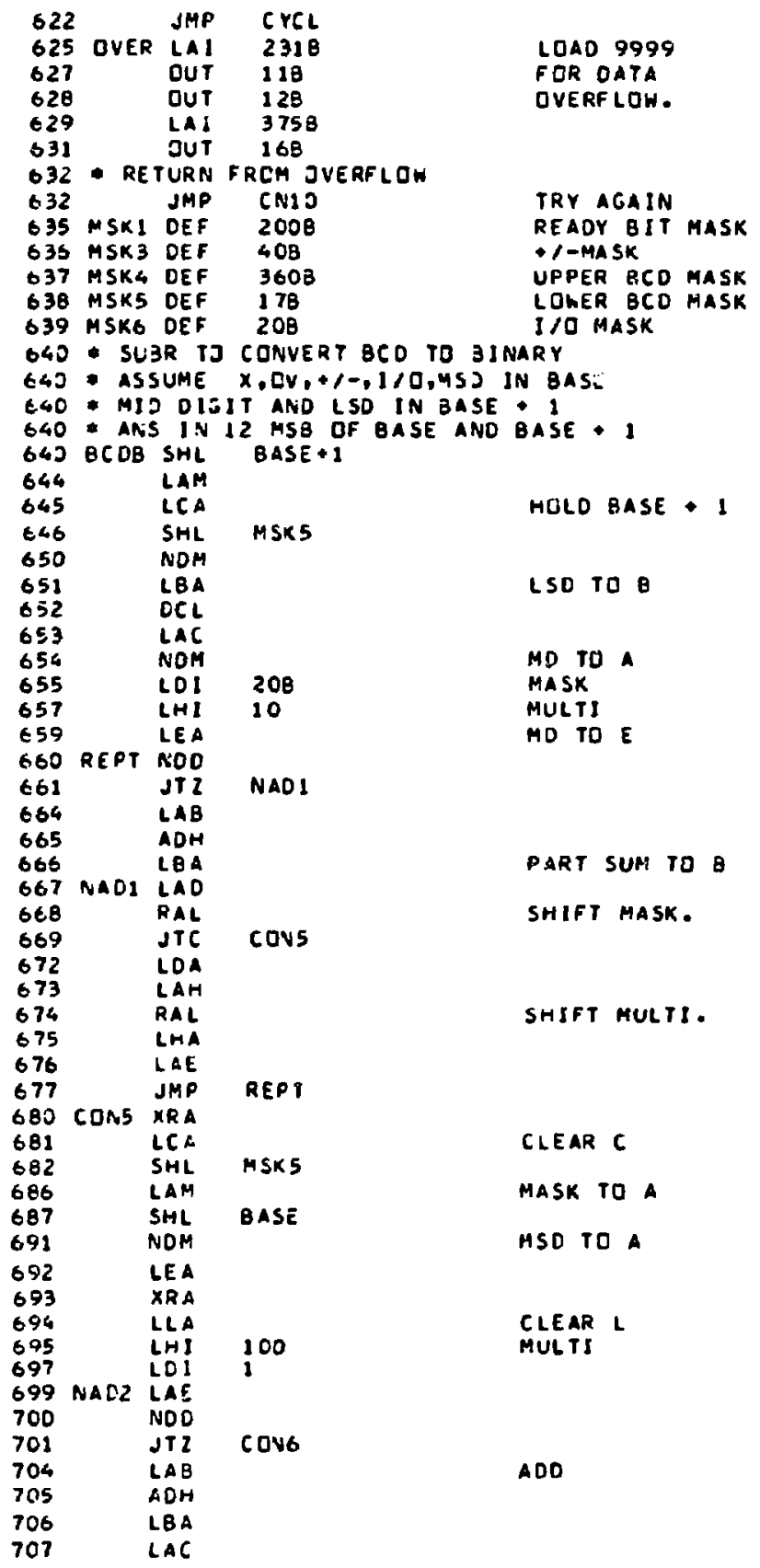




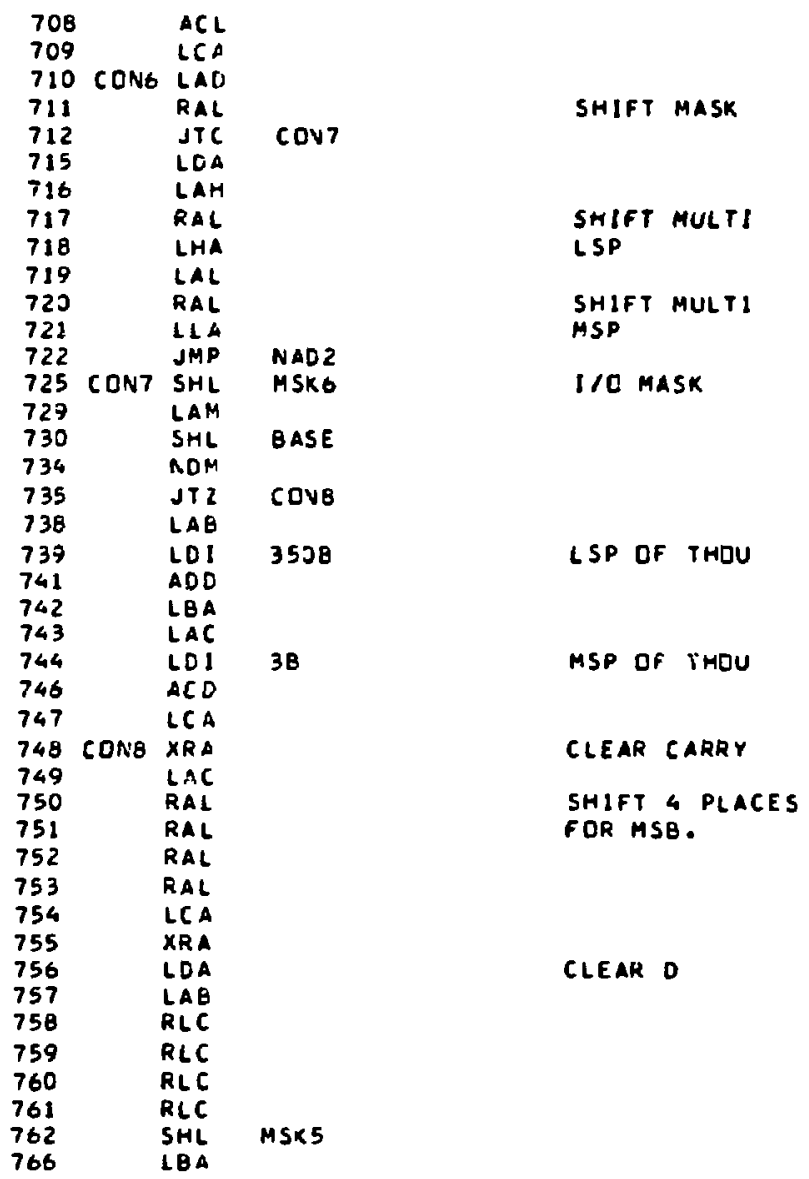




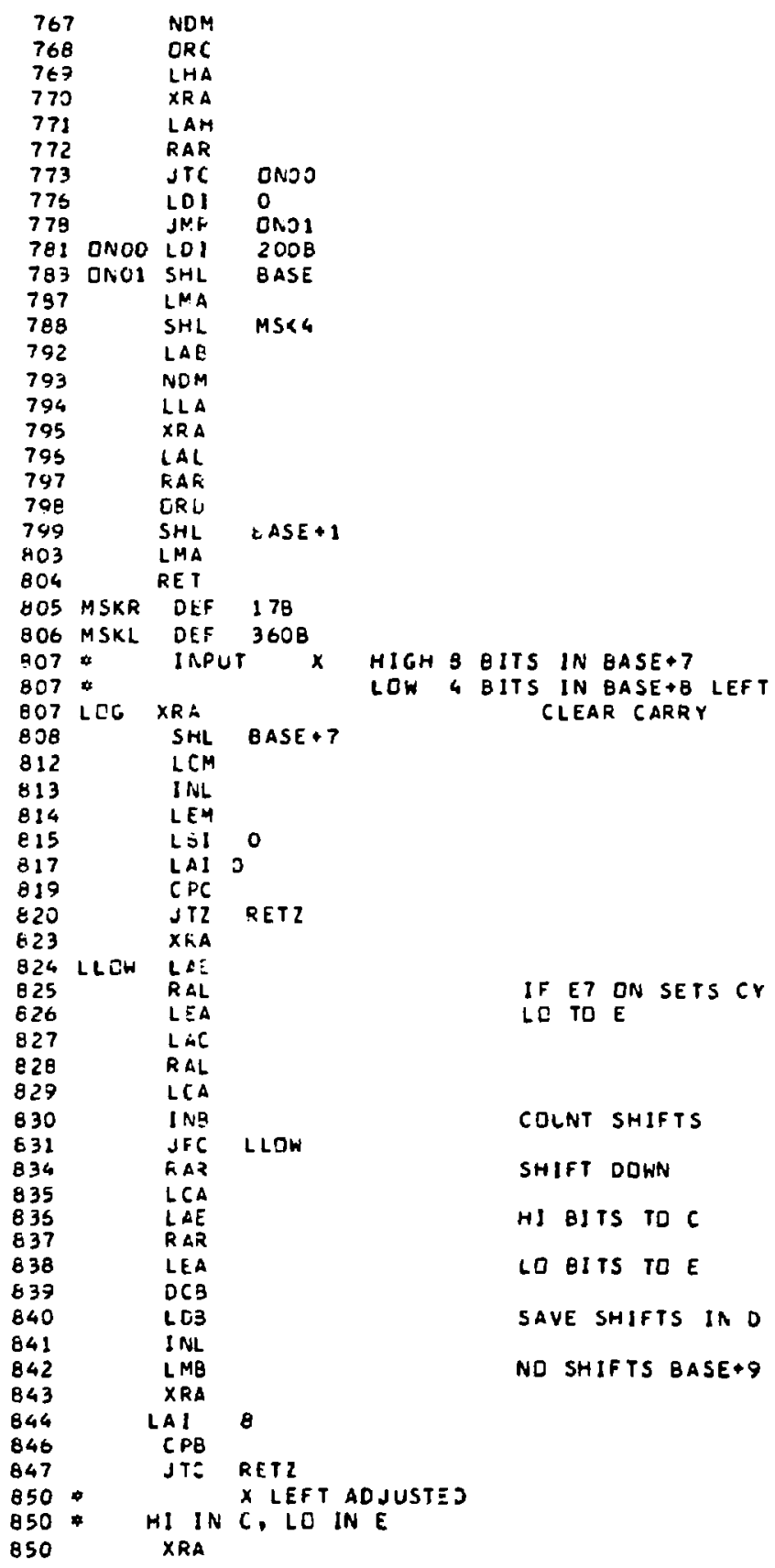




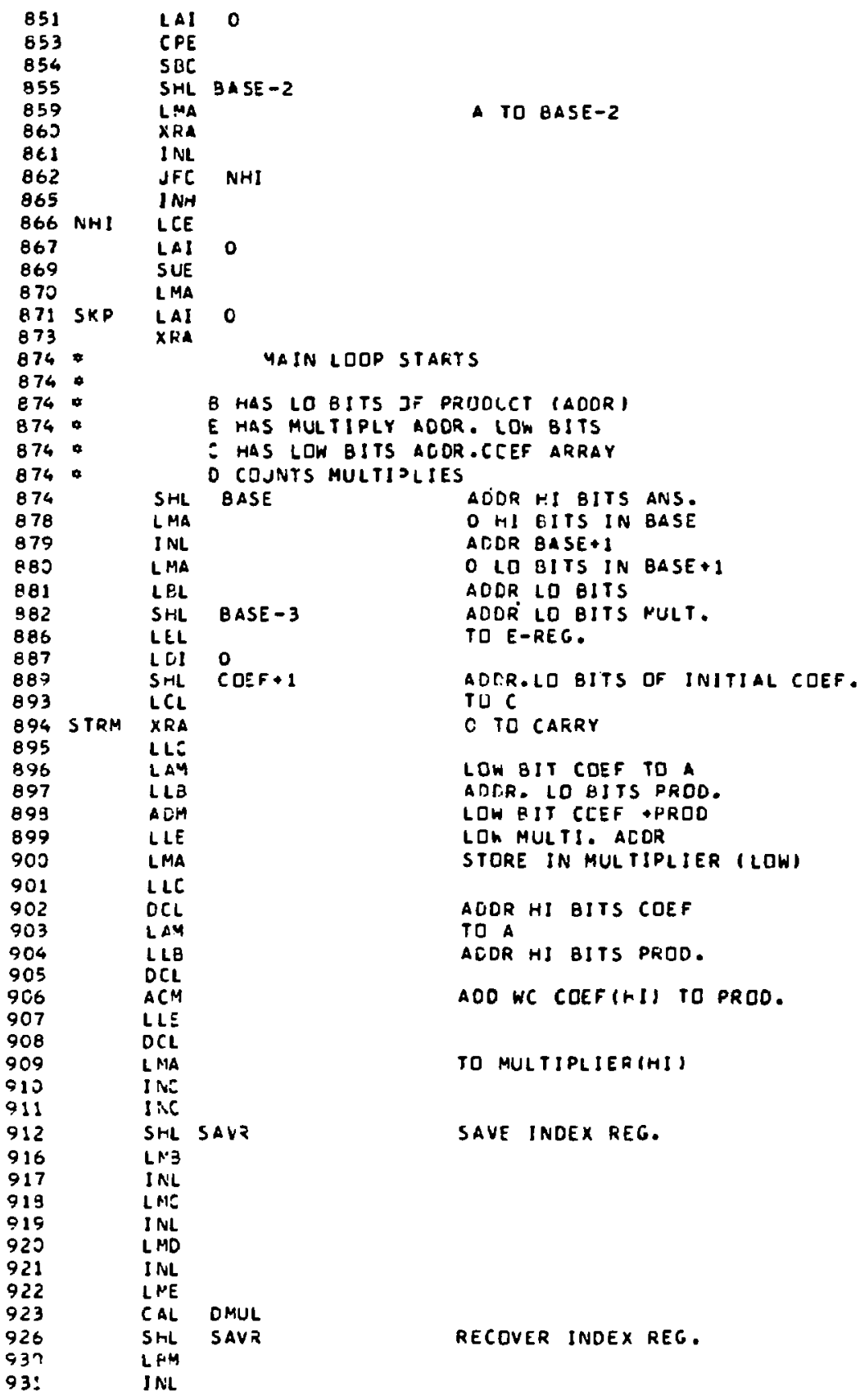




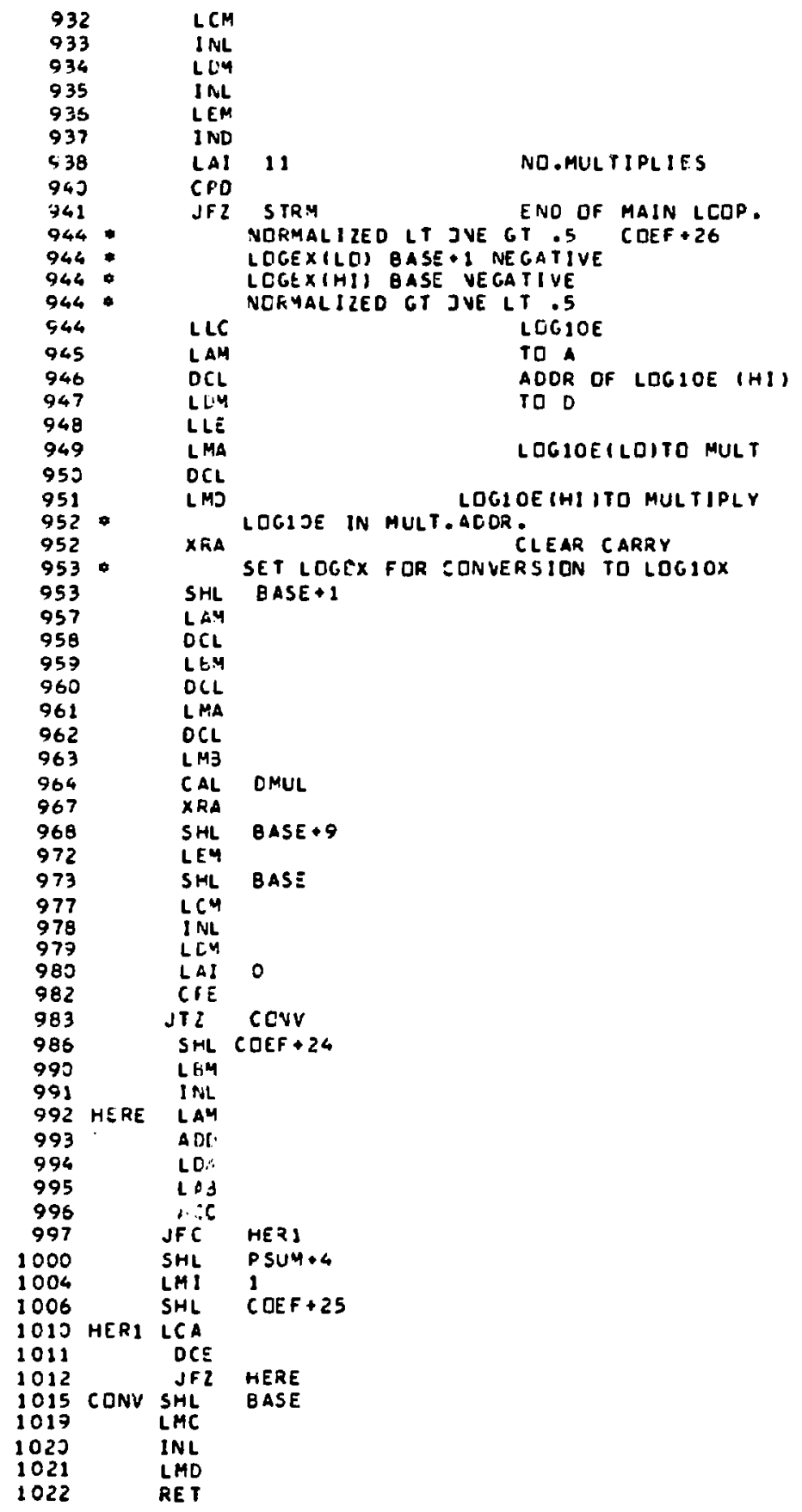




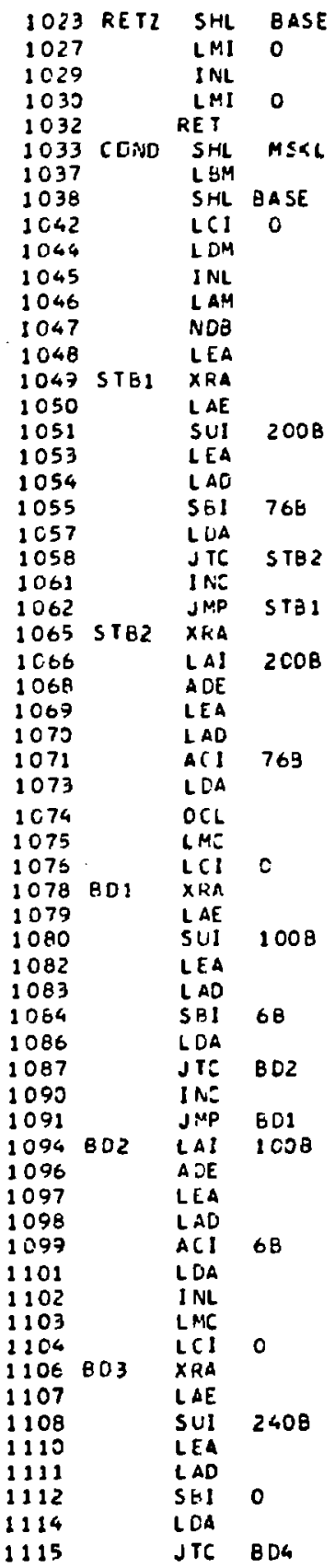




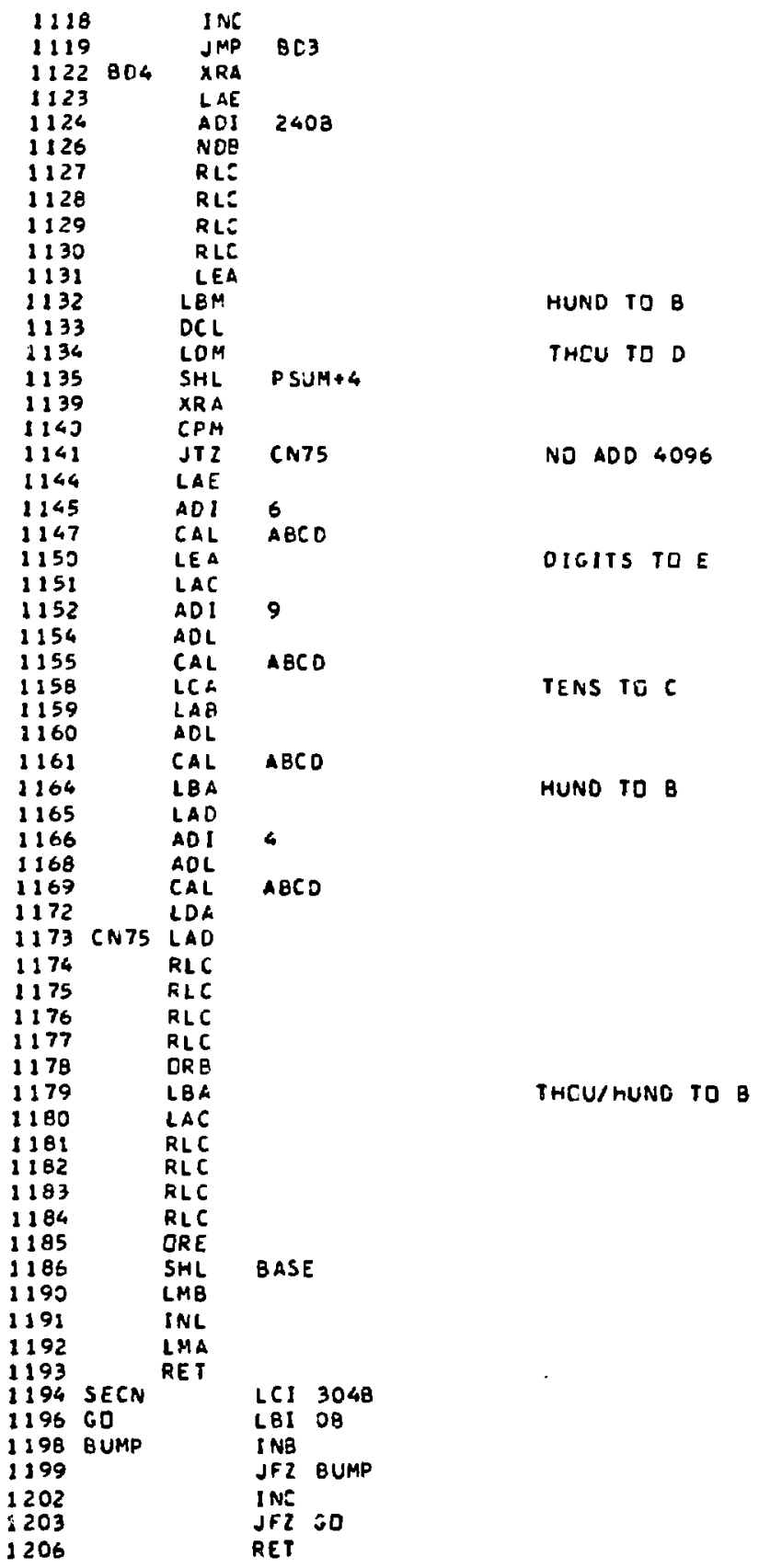




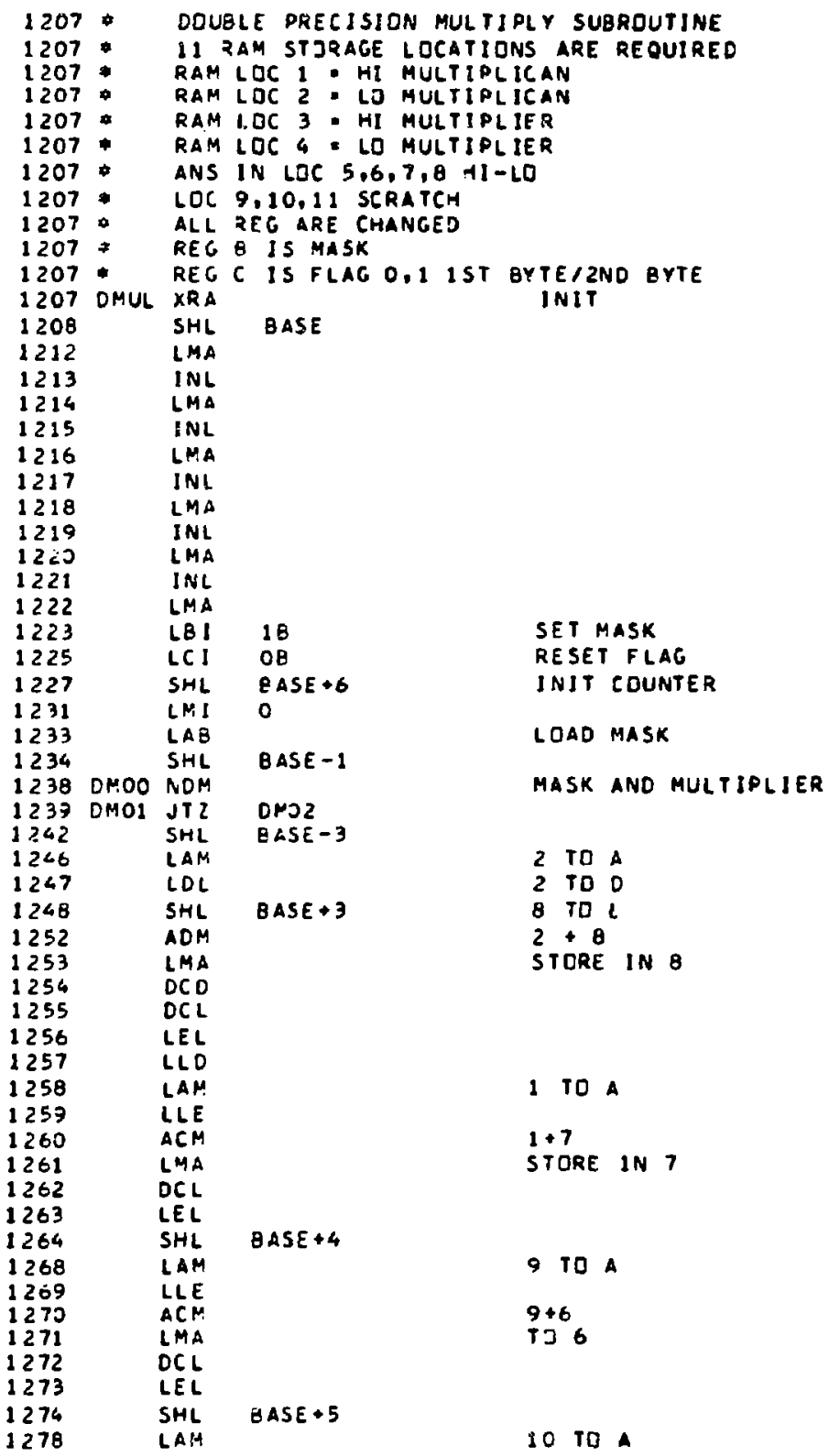




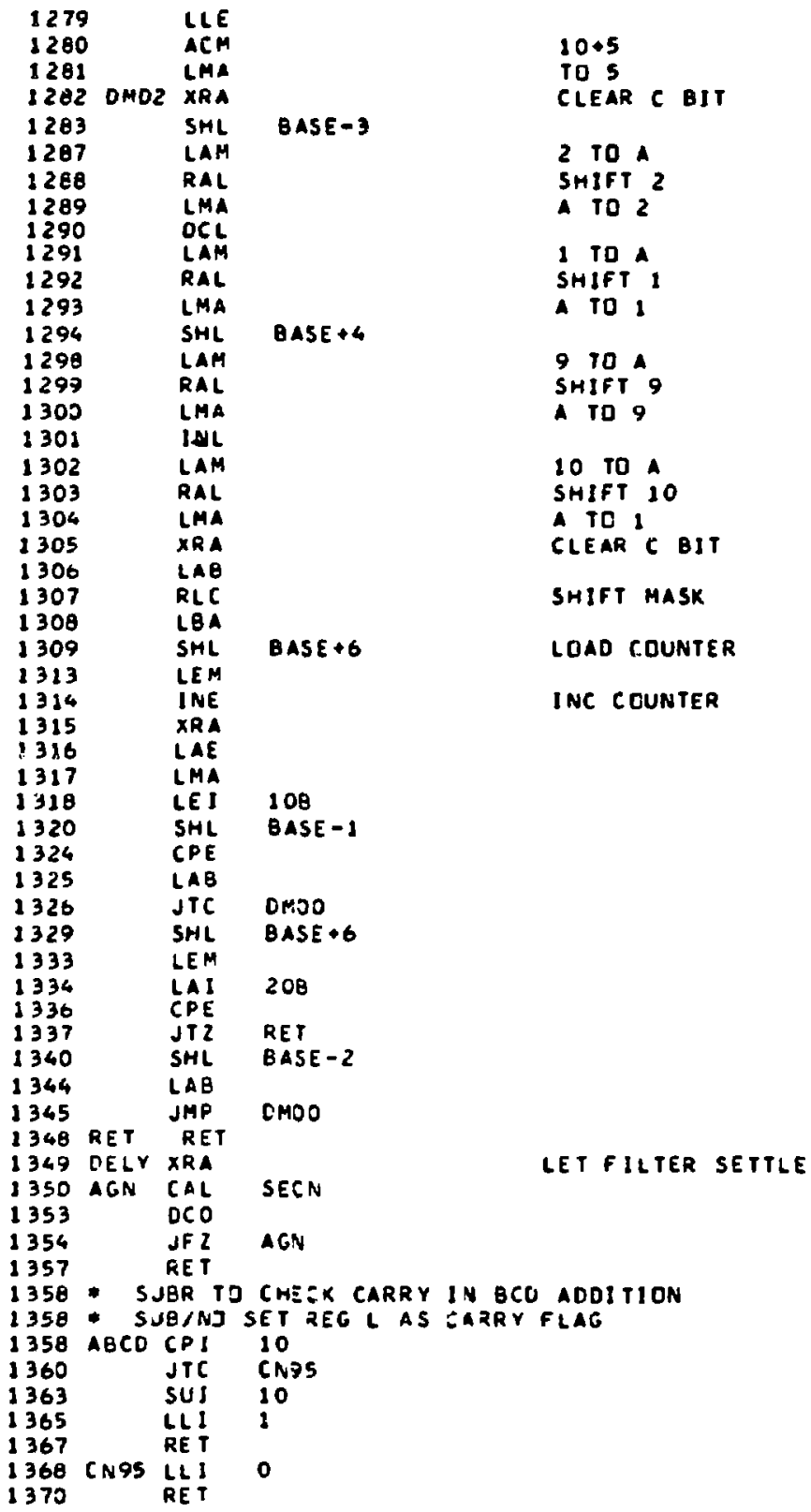




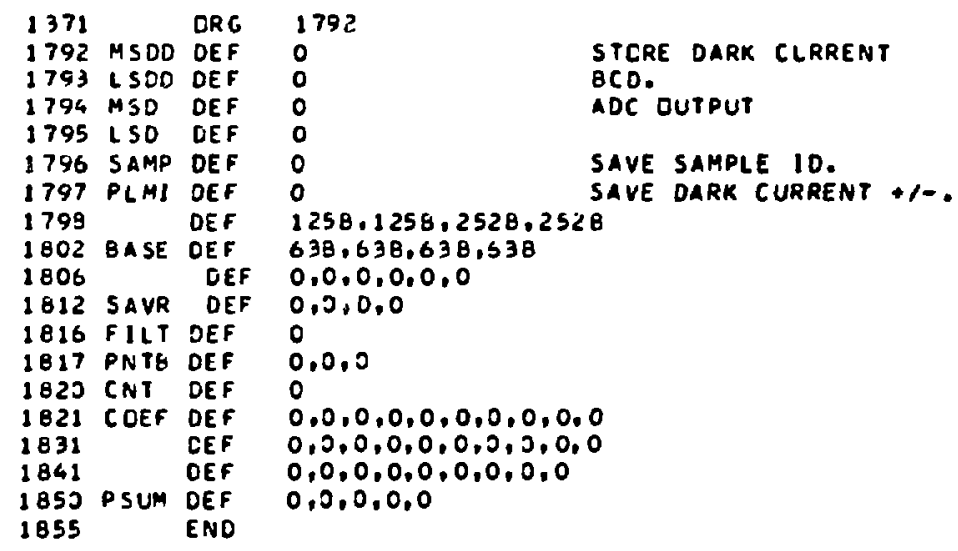




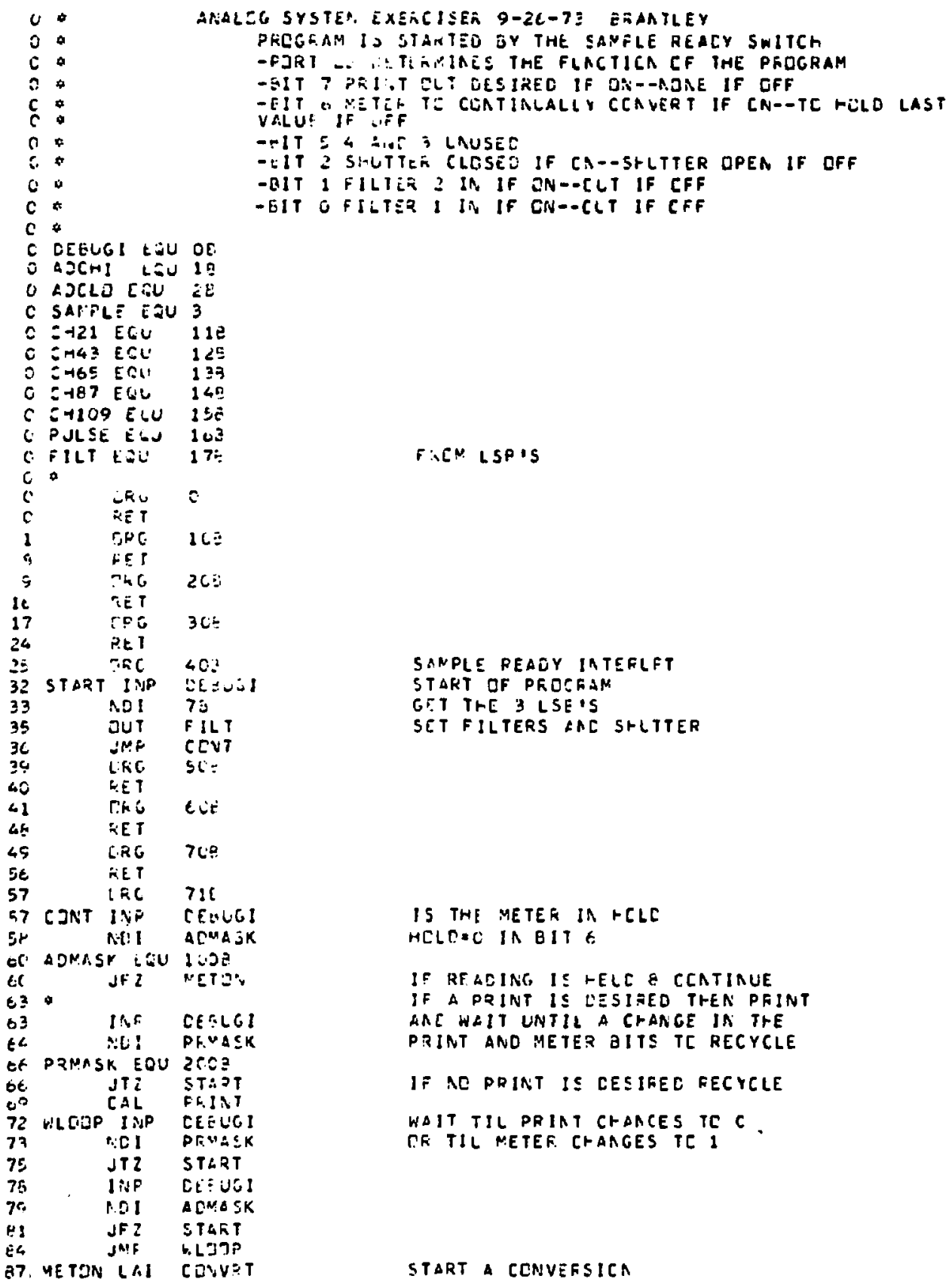




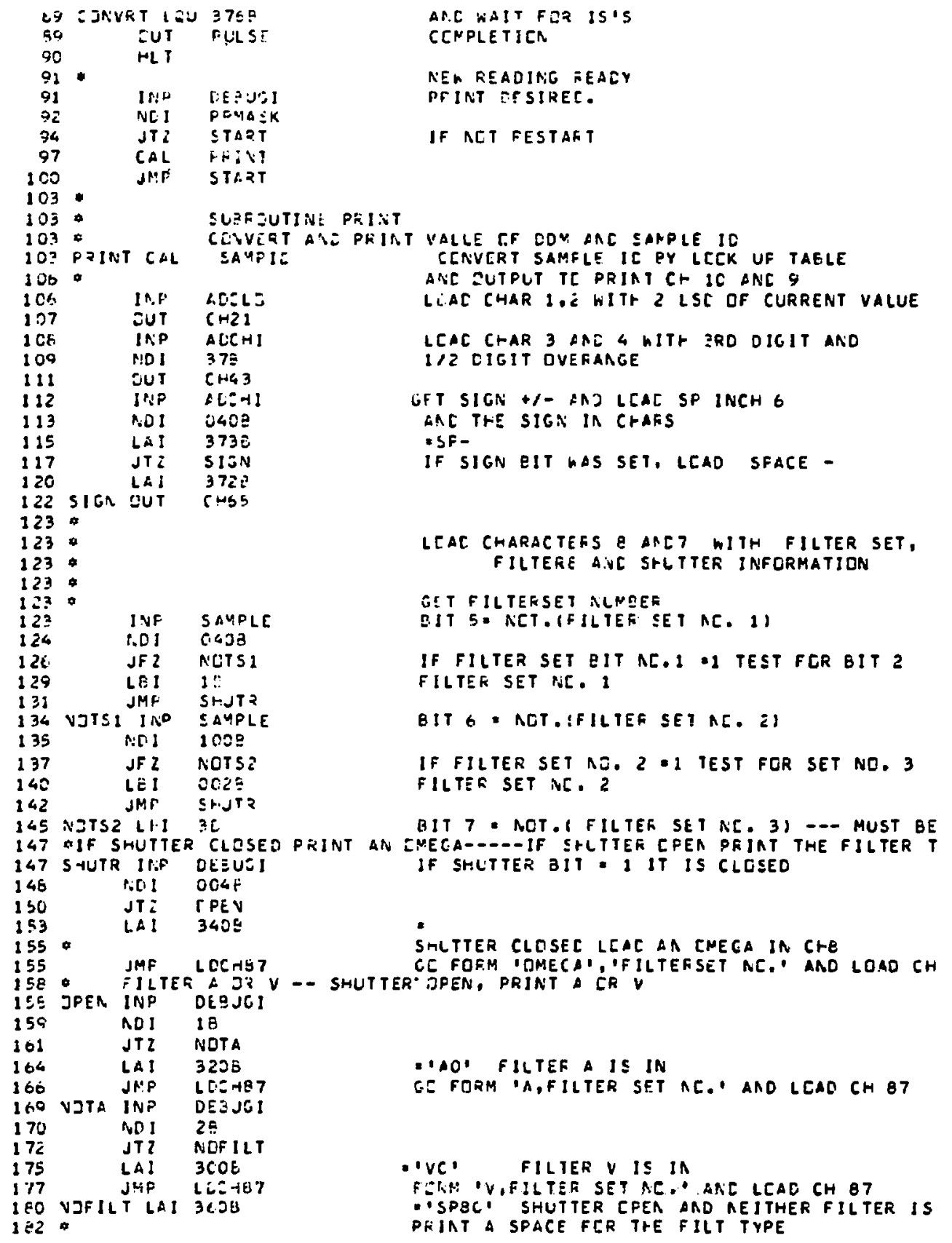




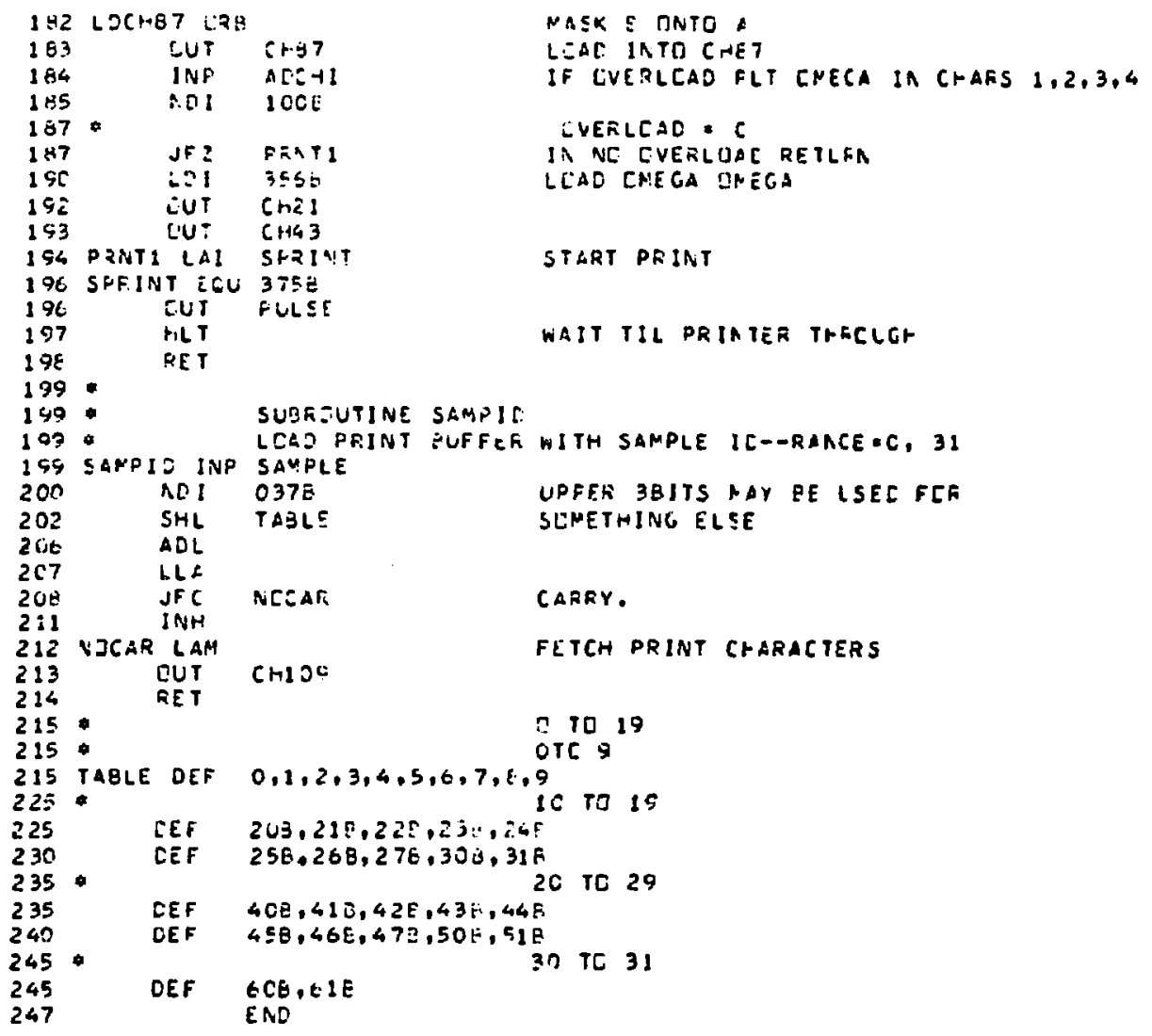




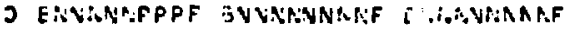

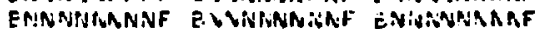

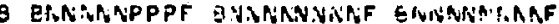

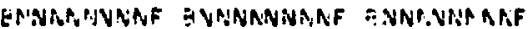

16 ENNANADPPPF EANARANAYYF

24. EA,NNANP.PPPF

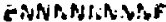

32 ER.PPRATIVF

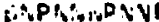

45 EAMTMVIREPPF ERININRNNNAF

48 [AF:NANThPFPF ENNNALAYYAT

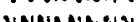

EVVighn'vishe ENANETNNG.NF

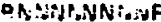

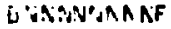

do Mriva. inkF

e STRIVMANAF

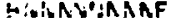

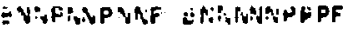

EAAPPPNRFF F"UNBUAAAF

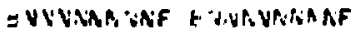

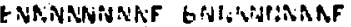

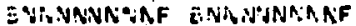

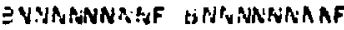

SE E T:NRYYIFPPF ENP:ARANSF

aNPquNt: DF

B:NIFFIATARF

4 PMNDNAPANF EINYANRNNNF

SNENPNPFFF

BVINVYVANAF

GPNANNNANF diVPfIYPRANF

IVFNANPPAF EAPFVAPPPF

ENAPANPNAF E'F INANSTANF LNAPNidNNNF

J BR.PNNBNNANF PAP:HNAPNAF

8 B PPPPPFFPYF GNNPRIXPYNF

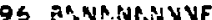
BN:P PAt:ANF NN!:

104 EPPANAFPPF ENP RNASENPFF

112 [NT.PANNYPPF EPPPPFYPPF

125 EANRNAPP P FRAPR:PANF

125 ENfANinN YNF

136 SAPSAMVVYF ENRINNTPP YE

144 E.NYNR. NR. NANR:F EANPIARFY

152 PR.MANASURAF EPMPPI.PPVF

160 BMNRANNAPF EA:NANA.PPNF

$1 \in 9$ ERANRAS NATiOF GT:PPF, F VANAF

175 EPP NNINNAF FiNRABPFAT

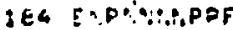
CPP:PASPSF

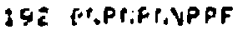
EUPNPEF IPF

260 HANPFHATUF DANPPEPPANF

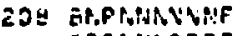
EPFANARPPF

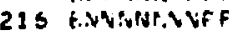
AnRhNive VFF

224 QANAAHFYAPF ENNA!P NNPFF

232 fMINYPIPPPF ENAFM:IVYPF

240 EPANPNAPNPF EI:NPAN UTPF

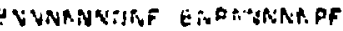

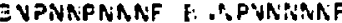
BNPANPNALF ENNENRAAAF JVPNPPPAPF LINARYMIYANF 3PUNANNASIUF EAPCNFMARF

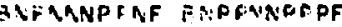
ANNPNNNASEF SIVANANAANF ENANANNNAF GRIPMNAFAPF 3YNPYNPANA LIHNNPPPPPF SNAPANP MAF HUIVENARIARF I VPFPANNAF WUPOPFNOAF EPPPPPNF INF UISPINFNPFEF LNPANIYAYF KNOHAFAANF

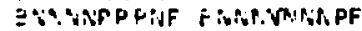

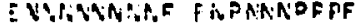

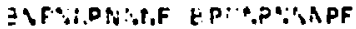

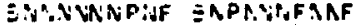

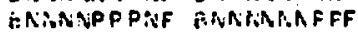
2VINANPIANF E INPPAPVIAF PNANANPFAF EPPRVNAANF 3NNNIUNAVNF E:PP.VINALPF ONPPNPNNAF GPLANFAAPF EPFNPNNNAF GINFANTIFAAF SYFNMNNJPF E!.NPVNPANF EPAPPNPIENF E: IV? WHINANF PUPUANPN;AF EVIFPNPFNF EPPPPANIINF EPARFNHA PF E VNPNNPAINF ENOPAMARAF ZNANANNNNA GUATIPPPENF GYPAPNPAPF EV VIT VIPPFIF = VIVANN1,NF BisinVR-FPF BNR.NFPDFPF EPINPFAPFNF

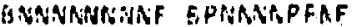
SF PNPNPNAF SO ViRANRYMLF ENI UPPTIEPF O JMAR QIFTPF

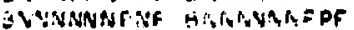

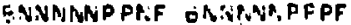

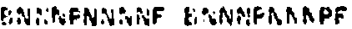

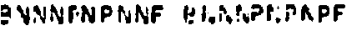

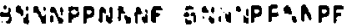

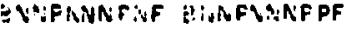
GNNPNNPFNF FNA ONA:PFPF

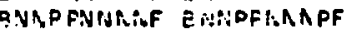
MNGNANNNAS GiqRigh:INANF

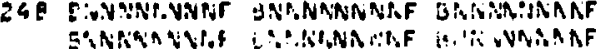

EANEANAA ANF aARNNINA A F esinananhaf ENANNNARAF EANANTHAMF BANAN:ZARAF ERANANBAAF BAMANivA AAF ENPNPPFFPF GNANNEAARF BNNANNABAF GNANANA BAF BNANIVAIA ARF BNNANiNA AAF EN:PNNNA RAF ENPJJNNA A F BANENALARF BNANNNA ANF BMPPNPAANF BANPNAFAAF BAARNIIAANF BRANNAFFAF BRPNNNAAPF BANFPINARAF ENNNNNSARF EAPNNNFFIT ENPNPNA FFF RNPNPNEAFF ANNKNATE FAF GRNINRNARAF BNPNNNFFPF BPliUNAEFAF GNPNINNSFAAF BANPNNEANF INNANASA ARF BFANPAAFFF BA PINNNA A FF B PNNPPFFNF ENPRNAFAAF griptpNiyfanf ENANNIYAAAF DPNPPNFFAF ENAPSNANA FAF GNANUNI F FAF PNAPSNANANF BNPNPFANPF BAPMINPAANF QPPPNPFFAF PFPPPPFAPF IP:PNINNFFPF ITPNFNFFFF BPPPPNAAAF GNNFNPANAF ENNNIUNA AAF ENNMNNFAMF BNAMNPAAAF BNANPNA FAF ENMRP NF FEFF GMNPNNARAF ENNPNNFANF GNAPNFAMAF GRNHNASANF ERARNNAMAFF ERANANGMAF 


\section{ACKNOWLEDGMENTS}

Design of the automated spectrophotometer entailed the efforts of many LASL personnel. In particular, credit is due to W. Brantley for design of the electronic readout system, J. F. Buchen for electronics consultation, A. Criscuolo for preparation of the readout system hardware writeup in Appendix E. J. A. Johnson for development of the readout system software, H. C. Owens for aid on the readout system software, T. Romanik for mechanical drawings, and R. K. Zeigler and M. M. Horita for consultation on statistical concepts and detailed treatment of data.

\section{REFERENCES}

1. W. J. Maeck, M. E. Kussy, G. L. Booman, and J. E. Rein, "Spectrophotometric Extraction Methods Specific for Uranium," Anal. Chem. 31. 1130-1134 (1959).

2. W. J. Maeck, M. E. Kussy, G. L. Booman, and J. E. Rein, "Spectrophotometric Extraction Method Specific for Plutonium," Anal. Chem. 33, 998-1001 (1961).

3. W. J. Maeck, G. L. Booman, M. C. Elliott, and J. E. Rein, "Separation of Uranium from Diverse
Ions: Methyl Isobutyl Ketone Liquid - Liquid Extraction System," Anal. Chem. 30, 1902-1907 (1958).

4. G. L. Booman, M. C. Elliott, R. B. Kimball, F. O. Cartan, and J. E. Rein, "Determination of Free Acid in the Presence of Hydrolyzable Ions," Anal. Chem. 30, 284-287 (1958).

5. N. R. Draper and H. Smith, Applied Regression Analysis (John Wiley and Sons, Inc., NY, 1966) pp. $21,24$.

6. G. C. Swanson, J. E. Rein, S. F. Marsh, and G. R. Waterbury, "Preparation of Plutonium Nitrate Solution Working Calibration and Test Materials," Los Alamos Scientific Laboratory report LA-5627 Rev. (in press), to be issued as a Regulatory Guide by the Nuclear Regulatory Commission.

\section{TO ORDER ENGINEERING DRAWINGS}

To obtain a complete set of the 28 full-size engineering drawings for the mechanical and electronic portions of the automated spectrophotometer, write to the U.S. ERDA Technical Information Center, P. O. Box 62, Oak Ridge. TN 37830. Specify that the drawings are for Los Alamos Scientific Laboratory report LA-6091. 